\title{
LOW REYNOLDS NUMBER SCALING EFFECTS FOR SMALL-SCALE ROTORS
}

\author{
by \\ Ammar Jessa \\ Bachelor of Engineering, Ryerson University, 2018 \\ A thesis \\ presented to Ryerson University \\ in partial fulfillment of the \\ requirements for the degree of \\ Master of Applied Science \\ in the program of \\ Aerospace Engineering
}

Toronto, Ontario, Canada, 2020

(C)Ammar Jessa 2020 


\section{AUTHOR'S DECLARATION FOR ELECTRONIC SUBMISSION OF A THESIS}

I hereby declare that I am the sole author of this thesis. This is a true copy of the thesis, including any required final revisions, as accepted by my examiners.

I authorize Ryerson University to lend this thesis to other institutions or individuals for the purpose of scholarly research.

I further authorize Ryerson University to reproduce this thesis by photocopying or by other means, in total or in part, at the request of other institutions or individuals for the purpose of scholarly research.

I understand that my thesis may be made electronically available to the public. 


\title{
LOW REYNOLDS NUMBER SCALING EFFECTS FOR SMALL-SCALE ROTORS
}

\author{
Ammar Jessa \\ Master of Applied Science, Aerospace Engineering, Ryerson University, Toronto (2020)
}

\begin{abstract}
Three T-Motor rotors with different diameters but otherwise identical relative geometries were tested in fully edgewise flow at different advance ratios and Reynolds numbers. The objective was to verify whether the existing scaling relationships between rotor size and the aerodynamic forces are applicable to small scale rotors that operate at relatively low chord-Reynolds numbers. The rotors were mounted onto a test stand housed inside a closed loop wind-tunnel where the air speed of the tunnel was varied to achieve different advance ratios. The chord-Reynolds number at $75 \%$ of the radius of each blade were matched for ranges from 39,000 to 117,000 . The experimental data was also compared to computational results from a blade element momentum theory-based method. The results showed that the existing coefficient based scaling laws can be used to predict the performance parameters for the thrust coefficient, power coefficient, longitudinal force coefficient, side force coefficient and, rolling moment coefficient for the full range of Reynolds numbers tested. Although for the pitching moment coefficient, a coefficient approach became less applicable for chord-Reynolds number of less than 100,000.
\end{abstract}




\section{ACKNOWLEDGEMENTS}

Firstly, I would like to thank Dr. Götz Bramesfeld for his support and guidance throughout this whole project. His questioning pushed me to think critically about problems I was addressing and in the process also helped me to gain a better understanding of the theoretical and applied concepts of aerodynamics.

I would also like to thank the members of the Ryerson Applied Aerodynamics Laboratory of Flight for their help in the experimental testing and data collection for this thesis, in addition to their advice throughout this project.

Lastly, I would like to thank my family for always being there, supporting and encouraging me and always pushing me to work harder. 


\section{TABLE OF CONTENTS}

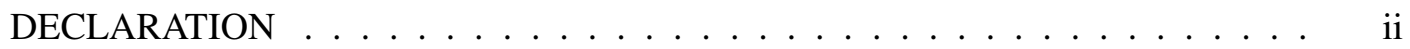

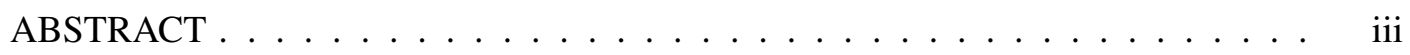

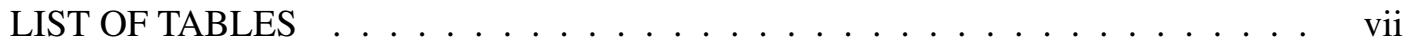

LIST OF FIGURES . . . . . . . . . . . . . . . . . . . . viii

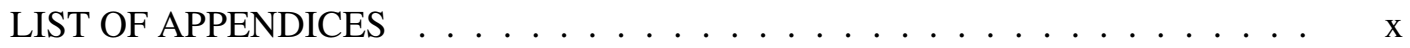

NOMENCLATURE ..................... xi

1 Introduction 1

2 Rotor Aerodynamics 4

2.1 Rotor Coefficients . . . . . . . . . . . . . . . . . . . . 4

2.2 Rotor Reference Frame . . . . . . . . . . . . . . . . . . . . . . 6

2.3 Rotor Loads . . . . . . . . . . . . . . . . . . . . . . . . . . . 7

2.4 Retreating Blade Effects . . . . . . . . . . . . . . . . . . . . 12

3 Experimental Methodology 14

3.1 Description of Experimental Facility . . . . . . . . . . . . . . . . 14

3.1 .1 Wind Tunnel . . . . . . . . . . . . . . . . . . . . . 14

3.1 .2 Test Stand . . . . . . . . . . . . . . . . . . . . . 15

3.2 Data Reductions and Corrections . . . . . . . . . . . . . 17

3.2 .1 Base Loads . . . . . . . . . . . . . . . . . . . . . . . 17

3.2.2 Test Stand Blockage Correction _. . . . . . . . . . . 20 
3.2.3 Uncertainty Analysis . . . . . . . . . . . . . . . . . .

3.3 Comparison with other Experimental Results . . . . . . . . . . . . 21

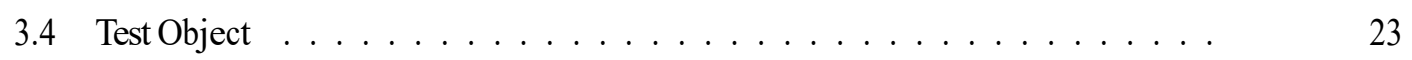

3.5 Test Setup and Plan . . . . . . . . . . . . . . . . . . . 24

4 Experimental Results $\quad 27$

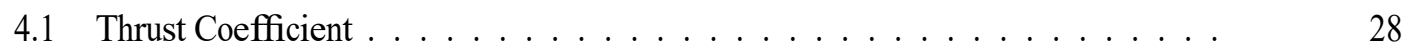

4.2 Power Coefficient . . . . . . . . . . . . . . . . . 30

4.3 Longitudinal Force Coefficient . . . . . . . . . . . . . 32

4.4 Side Force Coefficient . . . . . . . . . . . . . . . . . . 34

4.5 Rolling Moment Coefficient $\ldots \ldots \ldots \ldots \ldots$

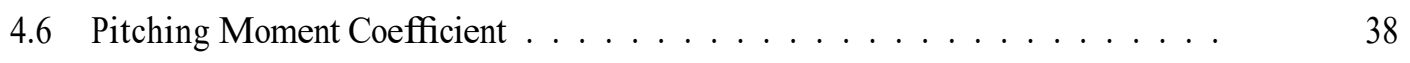

\section{Comparison to Rotor Prediction}

Methods $\quad 40$

5.1 Blade Element Momentum Theory . . . . . . . . . . . . . . . 40

5.2 Blade Element Momentum Theory Results . . . . . . . . . . . . . . . 43

6 Conclusions $\quad 50$

6.1 Conclusions ....................... 50

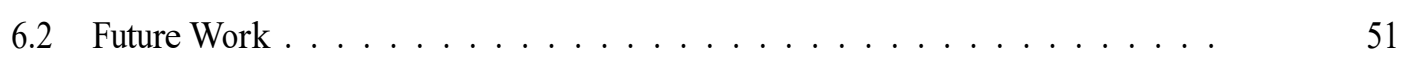

$\begin{array}{ll}\text { Appendices } & 53\end{array}$

$\begin{array}{ll}\text { References } & 76\end{array}$ 


\section{LIST OF TABLES}

3.1 Uncertainty values for the parameters of interest. . . . . . . . . . . . . 21

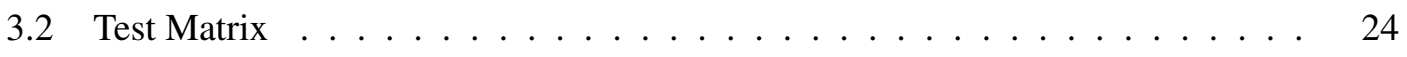




\section{LIST OF FIGURES}

1.1 Examples of different small unmanned aerial vehicles. . . . . . . . . . . 1

2.1 Reference tip path rotor plane coordinate system [7]. . . . . . . . . . . . . . 7

2.2 Advancing and retreating blade cross-sections [7] . . . . . . . . . . . . . 9

2.3 Skewed wake of the rotor disk in forward flight $[6] \ldots \ldots \ldots$

2.4 Leading and trailing edge blade cross-sections[7] . . . . . . . . . . . . . 11

2.5 Variation of reverse flow region with advance ratio [8]. . . . . . . . . . 13

3.1 Ryerson University's subsonic large wind tunnel schematic [10]. . . . . . . . 15

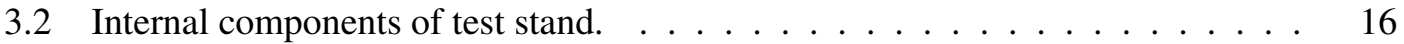

3.3 Test stand mounted on wind tunnel turntable with cowling on. . . . . . . . 17

3.4 Base loads recorded for the test stand at 0-degrees angle of attack. . . . . . . . 19

3.5 Comparison of Ryerson experimental data against published data for the MAE

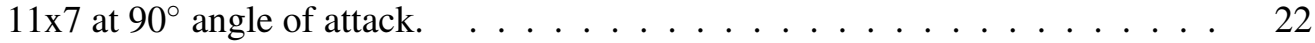

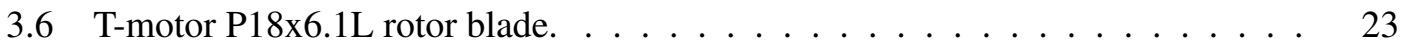

3.7 T-motor rotor normalized chord and twist distributions [14]. . . . . . . . . . . 24

3.8 Chord-Reynolds number variance at the $75 \%$ radial location of the blade with

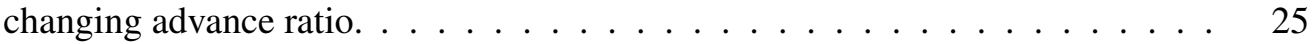

4.1 Experimental thrust coefficient versus advance ratio for several Reynolds numbers. 29

4.2 Experimental power coefficient versus advance ratio for several Reynolds numbers. 31 
4.3 Experimental longitudinal-force coefficient versus advance ratio for several Reynolds

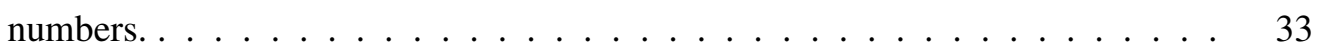

4.4 Experimental side-force coefficient versus advance ratio for several Reynolds

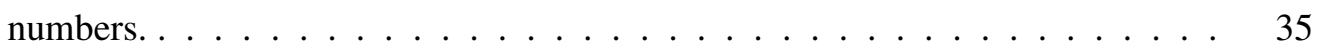

4.5 Experimental rolling moment coefficient versus advance ratio for several Reynolds

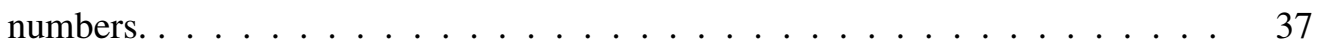

4.6 Experimental pitching moment coefficient versus advance ratio for several Reynolds numbers. . . . . . . . . . . . . . . . . . . . 39

5.1 Linear variation of inflow along longitudinal and lateral axes in forward flight [6]. 41

5.2 Solution methodology for BEMT prediction method [9]. . . . . . . . . . . . . 42

5.3 Predicted and experimental results of $C_{T}$ and $C_{P}$ for $\mathrm{Re}=39,000 \ldots \ldots \ldots$

5.4 Predicted and experimental results of $C_{F_{x}}$ and $C_{F_{y}}$ for $\mathrm{Re}=39,000 \ldots \ldots \ldots \ldots$

5.5 Predicted and experimental results of $C_{M_{x}}$ and $C_{M_{y}}$ for $\mathrm{Re}=39,000 \ldots \ldots$. . . . 49 


\section{LIST OF APPENDICES}

Appendix B: BEMT Results $\quad 56$

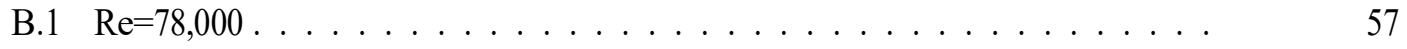

B.2 $\mathrm{Re}=117,000 \ldots \ldots \ldots \ldots \ldots \ldots \ldots \ldots \ldots \ldots$

$\begin{array}{ll}\text { Appendix C: BEMT Manual } & 63\end{array}$ 


\section{NOMENCLATURE}

$\alpha \quad$ Angle of attack, deg

$\mu \quad$ Advance ratio

$v \quad$ Kinematic viscosity of air, $\mathrm{m}^{2} / \mathrm{s}$

$v \quad$ Volume of blockage model in test section, $\mathrm{m}^{3}$

$\Omega \quad$ Rotor rotational speed, $\mathrm{rad} / \mathrm{s}$

$\Psi \quad$ Azimuth angle, deg

$\rho \quad$ Density, $\mathrm{kg} / \mathrm{m}^{3}$

A Rotor disk area, $\mathrm{m}^{2}$

C Cross-sectional area of test section, $\mathrm{m}^{2}$

$C_{P} \quad$ Power coefficient

$C_{Q} \quad$ Torque coefficient

$C_{T} \quad$ Thrust coefficient

$C_{F_{x}} \quad$ Longitudinal force coefficient

$C_{F_{y}} \quad$ Side force coefficient 
$C_{M_{x}} \quad$ Rolling moment coefficient

$C_{M_{y}} \quad$ Pitching moment coefficient

D Propeller diameter, $\mathrm{m}$

$F_{x} \quad$ Longitudinal force along x-axis, $\mathrm{N}$

$F_{y} \quad$ Lateral side force along y-axis, $\mathrm{N}$

$J \quad$ Propeller advance ratio

$K \quad$ Body shape factor for wind tunnel blockage

L Characteristic length, $\mathrm{m}$

$L_{0.75 R}$ Characteristic length at $75 \%$ of rotor blade radius, $\mathrm{m}$

$M_{x} \quad$ Rolling moment about x-axis, N-m

$M_{y} \quad$ Pitching moment about y-axis, N-m

$n \quad$ Propeller rotational speed, rev/sec

$p \quad$ Static pressure, $\mathrm{N} / \mathrm{m}^{2}$

$Q \quad$ Torque, $\mathrm{N}-\mathrm{m}$

$q \quad$ Dynamic pressure, $\mathrm{N} / \mathrm{m}^{2}$

$R \quad$ Rotor radius, $\mathrm{m}$

$R e_{0.75}$ Chord-Reynolds number at $75 \%$ of rotor blade radius

$T \quad$ Thrust force, $\mathrm{N}$

$U_{\mu} \quad$ Advance ratio uncertainty

$U_{\rho} \quad$ Density uncertainty, $\mathrm{kg} / \mathrm{m}^{3}$ 
$U_{V} \quad$ Freestream velocity uncertainty, $\mathrm{m} / \mathrm{s}$

V Velocity, $\mathrm{m} / \mathrm{s}$

$V_{\infty} \quad$ Freestream velocity, $\mathrm{m} / \mathrm{s}$

$v_{i} \quad$ Induced velocity, normal to the rotor disk, $\mathrm{m} / \mathrm{s}$

$V_{R} \quad$ Resultant inflow velocity, $\mathrm{m} / \mathrm{s}$

$V_{T} \quad$ Tangential velocity, $\mathrm{m} / \mathrm{s}$

$V_{T_{0.75 R}}$ Tangential velocity at $75 \%$ of rotor blade radius, $\mathrm{m} / \mathrm{s}$

$U_{\Delta} P \quad$ Differential pressure transducer uncertainty

$U_{\Omega} \quad$ Rotor rotational speed uncertainty, $\mathrm{rad} / \mathrm{s}$

$U_{P} \quad$ Power uncertainty, $\mathrm{W}$

$U_{P} \quad$ Static pressure sensor uncertainty, $\mathrm{N} / \mathrm{m}^{2}$

$U_{T} \quad$ Thermocouple uncertainty, $\mathrm{K}$

$U_{C_{P}} \quad$ Power coefficient uncertainty

$U_{C_{T}} \quad$ Thrust coefficient uncertainty

$U_{F_{x}} \quad$ Longitudinal force uncertainty, $\mathrm{N}$

$U_{F_{y}} \quad$ Lateral side force uncertainty, $\mathrm{N}$

$U_{F_{z}} \quad$ Thrust force uncertainty, $\mathrm{N}$

$U_{T_{x}} \quad$ Rolling moment uncertainty, N-m

$U_{T_{y}} \quad$ Pitching moment uncertainty, N-m

$U_{T_{z}} \quad$ Torque uncertainty, $\mathrm{N}-\mathrm{m}$ 


\section{Chapter 1}

\section{Introduction}

Small Unmanned Aerial Vehicles (sUAVs) have had significant impacts in various industries over the past few years. The versatile abilities of the sUAV have lent themselves to many applications from military operations to recreational photography. According to the Federal Aviation Administration, small UAVs are defined as unmanned aerial vehicles weighing less than $25 \mathrm{~kg}$ [1]. Many different vehicles configurations are encompassed in this definition, from fixed wing vehicles to multi-rotor vehicles that have vertical takeoff and landing (VTOL) capabilities.

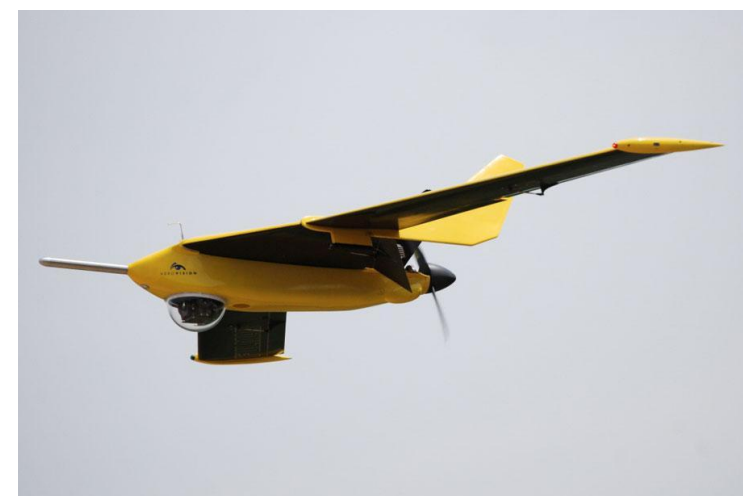

(a) Thales Fulmar fixed wing military sUAV [2].

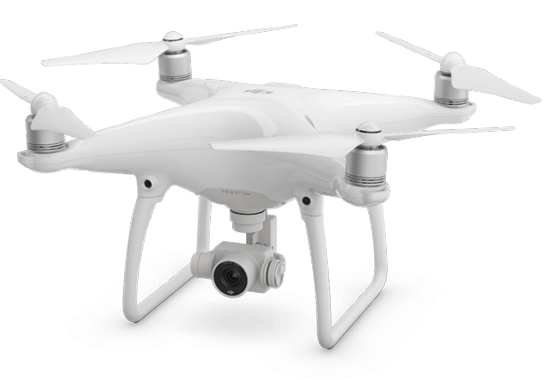

(b) DJI Phantom 4 multi-rotor sUAV [3].

Figure 1.1: Examples of different small unmanned aerial vehicles.

Of the different types of of vehicles, multi-rotor vehicles have advantages over fixed wing 
vehicles such as the ability for VTOL, to hover in a fixed location, and maneuver in confined spaces. This is all due to the multiple rotors that provide the propulsive forces for flight in general, as well as for maneuvering. The forces produced by the rotors are a function of the RPM, which is controlled by the motors. For vehicles with fixed-pitch rotors, the variation of the rotor RPM is used to control and maneuver the vehicle. As the rotor blades are an important aspect for the safe operation of the vehicle, their aerodynamic design and analysis are important considerations during the development of sUAVs.

During the conceptual design phase of an SUAV, design-space explorations are important, especially with respect to the rotor performance. The range of flight speeds, motor RPMs and rotor diameters pose challenges in predicting performance and require substantial resources for testing. An important part of this design space exploration is the selection of the appropriate rotors for the required application. There are many different types and sizes of rotors and testing them all during the conceptual stage can be time and cost intensive. Generally, a rotor of a certain diameter is tested in the wind tunnel to determine the loads developed, such as thrust and torque. Although scaling over different rotational speeds works quite well, if a given rotor needs to be scaled to another diameter, the rotor loads are not easily adjusted using the standard coefficient based approach, thus often requiring more testing.

In addition to the scaling difficulties, small UAVs generally operate at low Reynolds numbers where viscous effects are noticeable, making it harder to accurately predict the loads developed by the rotors. Previous work has been done on the Reynolds number effects on the performance of propellers for sUAVs as reported in reference [4]. In this reference, experimental tests are described that were run on an array of small-scale propellers in static and advancing flow conditions to determine the effect that the Reynolds number had on thrust and power coefficients. It was found that the performance of these small-scale propellers improved as the Reynolds number was increased. The performance metrics used were the thrust coefficient, power coefficient and propeller efficiency, which was shown to increase by approximately $10 \%$ as the Reynolds number was increased. The work done by Deters, Ananda and Selig also serves as a reference 
database for the performance of various off the shelf propellers. However, all the experimental tests run were for propellers where the flow is fully axial, which is not representative of the flight conditions at which multi-rotor vehicles operate. For multi-rotor UAVs in forward flight, the angle of attack between the incoming airflow and the rotor plane is small, a condition known as edgewise flight. The forces and moments developed by the rotors in edgewise flight can differ from the forces and moments produced by propellers with mainly axial flows.

The purpose of this thesis is to introduce scaling relationships between rotor size and their aerodynamic forces at low Reynolds numbers. These relationships were developed using results from wind-tunnel tests of various sized rotors under fully edgewise flow and at different advance ratios and Reynolds numbers based on the rotor-blade chord at the $75 \%$ radial location. During these tests all the forces and moments that act on the rotor were recorded and then compared in order to determine any scaling relationships. Obtaining these data are of value for the conceptual design phase of multi-rotor UAVs, where the results enable a fast and relatively accurate exploration of the design space. A single rotor can be tested after which, the data obtained can be scaled for other rotors that have a similar relative geometry, that is blade sections and normalized planform and twist distributions. The coefficient method generally used for scaling in aerodynamics has been tested and validated for propellers but not for rotors in edgewise flow, which is what this thesis addresses.

Along with experimentally testing rotor blades, the data obtained is also compared to computational methods based on the blade element momentum theory. The experimental results are compared to the computational methods in order to verify whether the computational methods can accurately predict the forces and moments acting on the blade at low Reynolds numbers. Verifying these computational methods is important because it allows an exploration of the conceptual design space without any physical testing, allowing many different designs to be evaluated in a short time. 


\section{Chapter 2}

\section{Rotor Aerodynamics}

In order to understand the effects of scaling rotors that are typically used with small unmanned aerial vehicles, an understanding of the aerodynamic principles that affect the rotor performance is needed. In this chapter the aerodynamics principles are explained that govern rotors and the loads that they develop.

\subsection{Rotor Coefficients}

A rotor generates thrust $T$, torque $Q$, a longitudinal force $F_{x}$, a lateral side force $F_{y}$, a rolling moment $M_{x}$, and a pitching moment $M_{y}$. In order to compare between rotors of different sizes and different operating atmospheric conditions, the forces and moments are used in coefficient form as follows:

$$
\begin{gathered}
C_{T}=\frac{T}{\rho A(\Omega R)^{2}} \\
C_{Q}=\frac{Q}{\rho A \Omega^{2} R^{3}} \\
C_{F_{x}}=\frac{F_{x}}{\rho A(\Omega R)^{2}}
\end{gathered}
$$




$$
\begin{aligned}
& C_{F_{y}}=\frac{F_{y}}{\rho A(\Omega R)^{2}} \\
& C_{M_{x}}=\frac{M_{x}}{\rho A \Omega^{2} R^{3}} \\
& C_{M_{y}}=\frac{M_{y}}{\rho A \Omega^{2} R^{3}}
\end{aligned}
$$

where $\rho$ is the density, $A$ is the rotor disk area, $\Omega$ is the rotor rotational speed in radians per second, and $R$ is the radius of the rotor. The power that is required to turn the rotor is related to torque by the factor of the rotational speed, $\Omega$ :

$$
C_{P}=\frac{P}{\rho A(\Omega R)^{3}}
$$

In the case of rotors, the advance ratio, $\mu$, is defined as the ratio of the tip speed of the blade to the freestream velocity component that is parallel to the rotor tip-path plane:

$$
\mu=\frac{V_{\infty} \cos \alpha}{\Omega R}
$$

As all the test in this thesis were conducted with fully edgewise flow $\left(\alpha=0^{\circ}\right)$, the general advance ratio was used:

$$
\mu=\frac{V_{\infty}}{\Omega R}
$$

The propeller advance ratio, $J$, is defined as the distance advanced by the propeller in a single revolution, non-dimensionalized by the propeller diameter [5]:

$$
J=\frac{V_{\infty}}{n D}
$$


where $V_{\infty}$ is the freestream velocity, $n$ is the propeller speed in rotations per second, and $D$ is the propeller diameter.

The Reynolds number is a non-dimensional number that represents the ratio of the inertial forces in the fluid to the viscous forces in the fluid, and governs whether the flow is laminar or turbulent. In equation form the chord-Reynolds number herein is defined as:

$$
\operatorname{Re}_{0.75}=\frac{V_{T_{0.75 R}} L_{0.75 R}}{v}
$$

where $v$ is the kinematic viscosity of the fluid, and $V_{T_{0.75 R}}$ and $L_{0.75 R}$ are the tangential velocity and characteristic length at $75 \%$ of the rotor blade radius, respectively. For lower chord-Reynolds numbers the viscous forces are more dominant, causing thicker boundary layers and earlier flow separation than what is generally observed for larger chord-Reynolds numbers [6]. The Reynolds number is practically used as a similarity parameter for viscosity to scale objects in a flow. If the chord-Reynolds number of two different sized objects are matched for incompressible conditions then their forces can be directly compared as the effects of the viscous forces relative to the inertial forces are accurately modelled.

\subsection{Rotor Reference Frame}

The local reference frame is depicted as a top down view of the rotor disk and is shown in Fig. 2.1. The tip path plane (TPP) of the rotor blade is the plane created by the tip of the rotor blade as it rotates and can also be referred to as the rotor disk. The angle of the rotor disk relative to the freestream is defined as the angle of attack, $\alpha$, with $\alpha=0^{\circ}$ corresponding to flow fully parallel to the rotor disk, also referred to as fully edgewise flow. All the analysis in this paper was conducted for fully edgewise flow $\left(\alpha=0^{\circ}\right)$. 


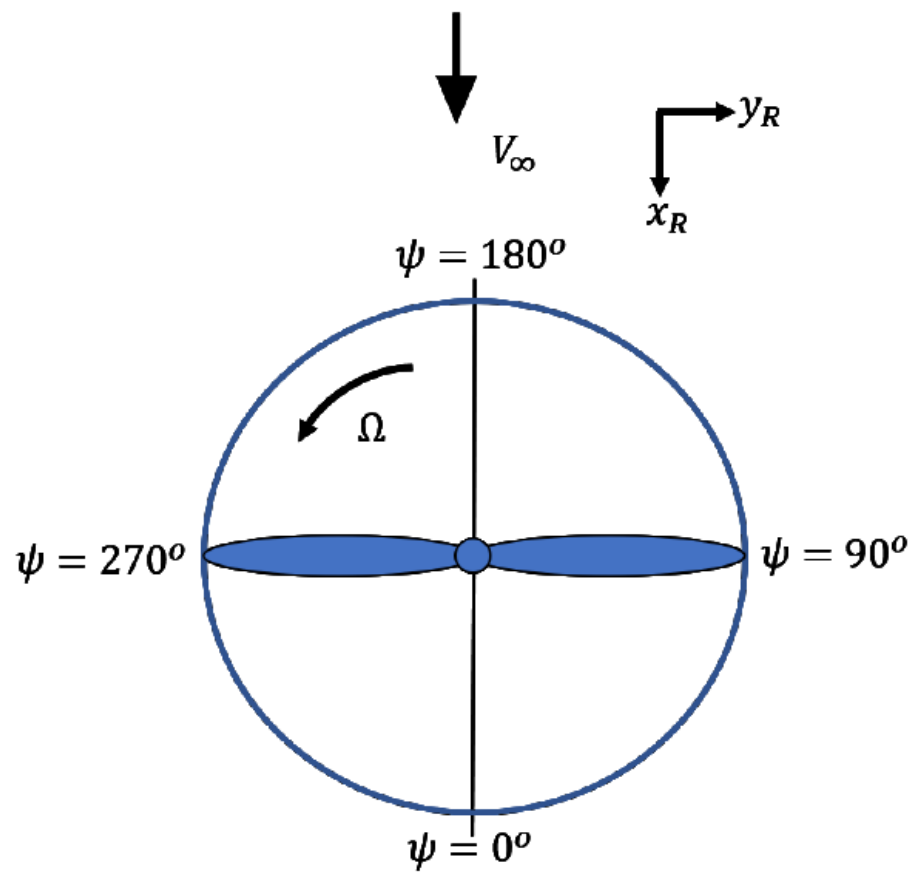

Figure 2.1: Reference tip path rotor plane coordinate system [7].

The position of the blade within the rotor disk is defined by the azimuth angle, $\Psi$. The advancing and retreating blades are located at $\Psi=0^{\circ}-180^{\circ}$ and $\Psi=180^{\circ}-360^{\circ}$, respectively. On the advancing side, the freestream velocity, $V_{\infty}$, is added to the tangential velocity of the blade, while on the retreating side the freestream velocity, $V_{\infty}$, is subtracted from the tangential velocity of the blade.

\subsection{Rotor Loads}

The forces and moments that the rotor produces are a function of the resultant velocity over the blade elements. As the blades rotate, the flow conditions are constantly changing at every azimuth angle, changing the magnitude and direction of resultant force produced by the blades. The variation of the magnitude and direction of the resultant force with azimuth angle is what produces the forces and moments. 
The effect that changing the flow conditions have on the rotor loads can be seen in Fig. 2.2, which shows the blade sections on the advancing and retreating side, that is $\Psi=90^{\circ}$ and $270^{\circ}$, respectively. On the advancing side, the addition of the freestream velocity to the tangential velocity acts to increase the total resultant velocity and effective angle of attack, causing an increase in the resultant force created by the blade section compared to the retreating side. On the retreating side, the subtraction of the freestream velocity from the tangential velocity acts to decrease the total resultant velocity and effective angle of attack, causing a reduction in the resultant force created by the blade section. Due to this velocity differential, more lift is produced on the advancing side as compared to the retreating side and the consequence of this imbalance is a rolling moment to the left about the longitudinal x-axis, $M_{x}$. The blade profile drag on the advancing side is also greater than the blade profile drag on the retreating side due to the velocity differential, resulting in a net drag force on the rotor disk acting rearwards, $F_{x}$. 


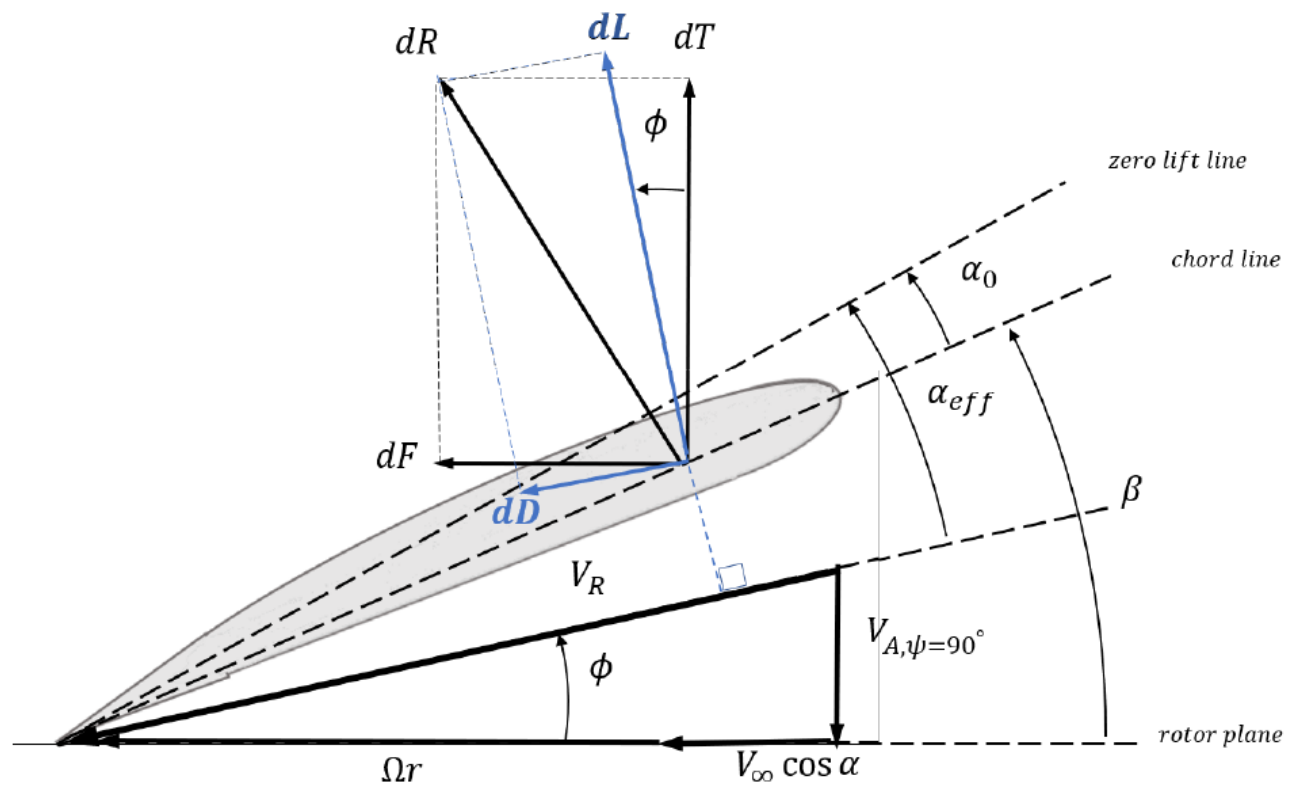

(a) Advancing Blade, $\Psi=90^{\circ}$

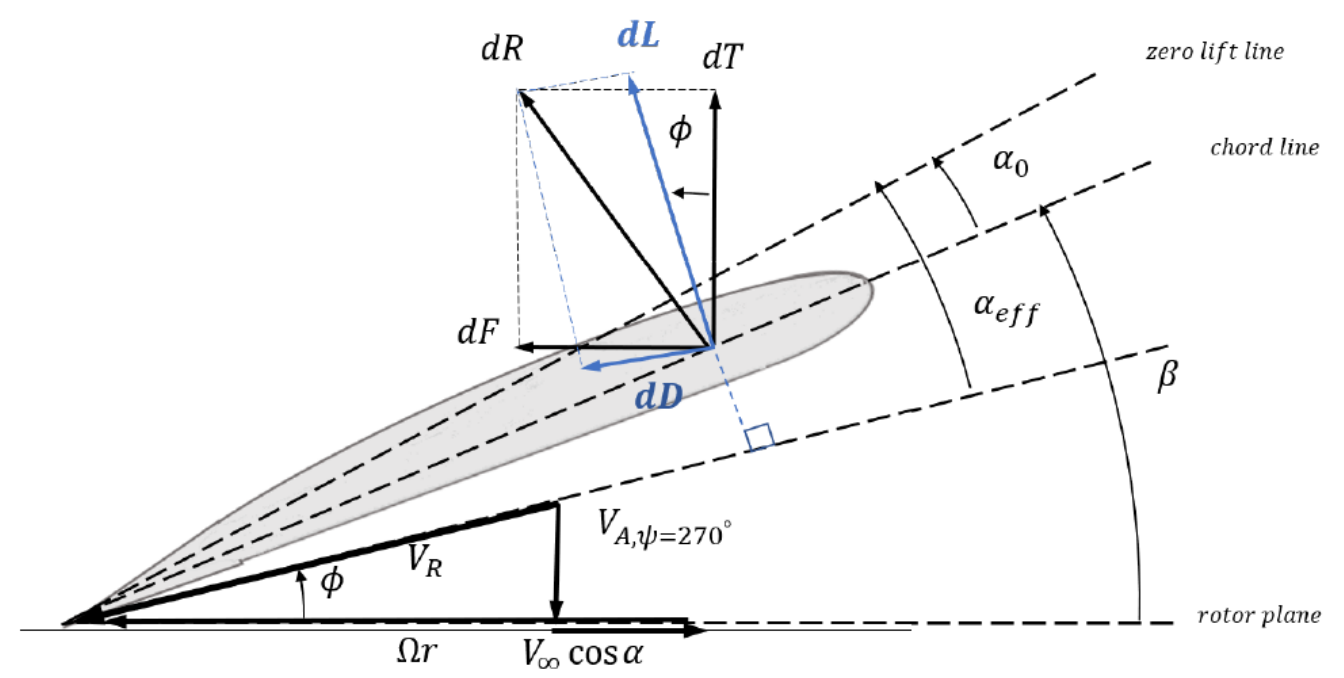

(b) Retreating Blade, $\Psi=270^{\circ}$

Figure 2.2: Advancing and retreating blade cross-sections [7]. 
Figure 2.3 shows a side-view of the skewed wake created by the rotor in forward flight. The skew angle, $X$, is the angle between the vertical and the leading edge of the wake, with the skew angle increasing as advance ratio is increased. This skewed wake alters the inflow conditions and results in a large downwash at the trailing edge and a slight upwash at leading edge of the rotor disk, causing a pitching moment about the lateral y-axis, $M_{y}$.

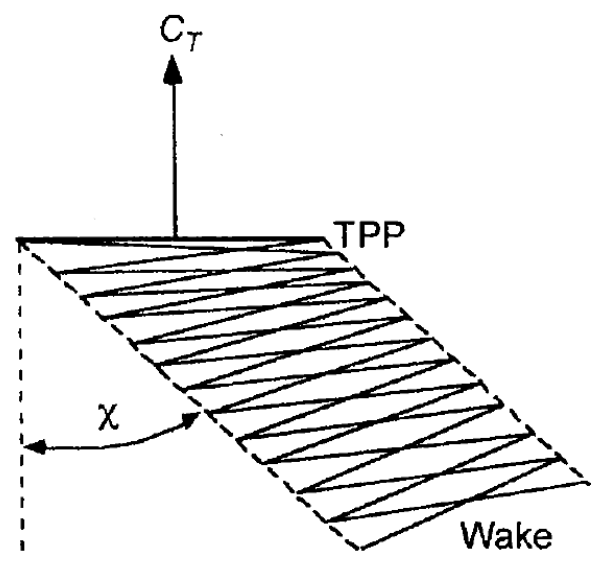

Figure 2.3: Skewed wake of the rotor disk in forward flight [6].

The effect that the skewed inflow conditions have on the rotor loads can be seen in Fig. 2.4, which shows the blade sections at the leading and trailing edges, that is $\Psi=180^{\circ}$ and $0^{\circ}$, respectively. The increased axial component of the flow at the trailing edge causes a reduction in the effective angle of attack, reducing the lift on the trailing edge of the rotor disk. The decreased axial component of the flow at the leading edge causes an increase in the effective angle of attack, increasing the lift on the leading edge of the rotor disk. This difference results in a positive pitch up moment about the y-axis, $M_{y}$. The skewed inflow conditions along the longitudinal axis of the rotor disc also cause the blade drag forces to be different at the leading and trailing edges of the rotor disc, resulting in a positive net side force along the y-axis, $F_{y}$. 


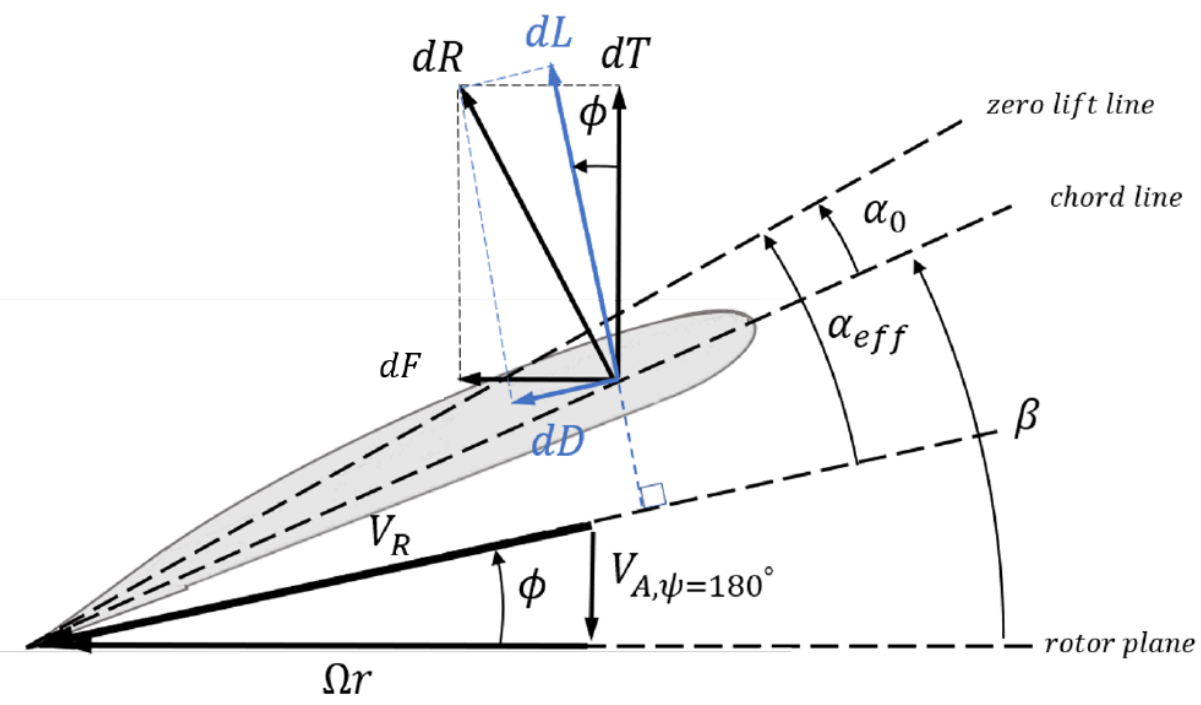

(a) Leading Edge Blade, $\Psi=180^{\circ}$

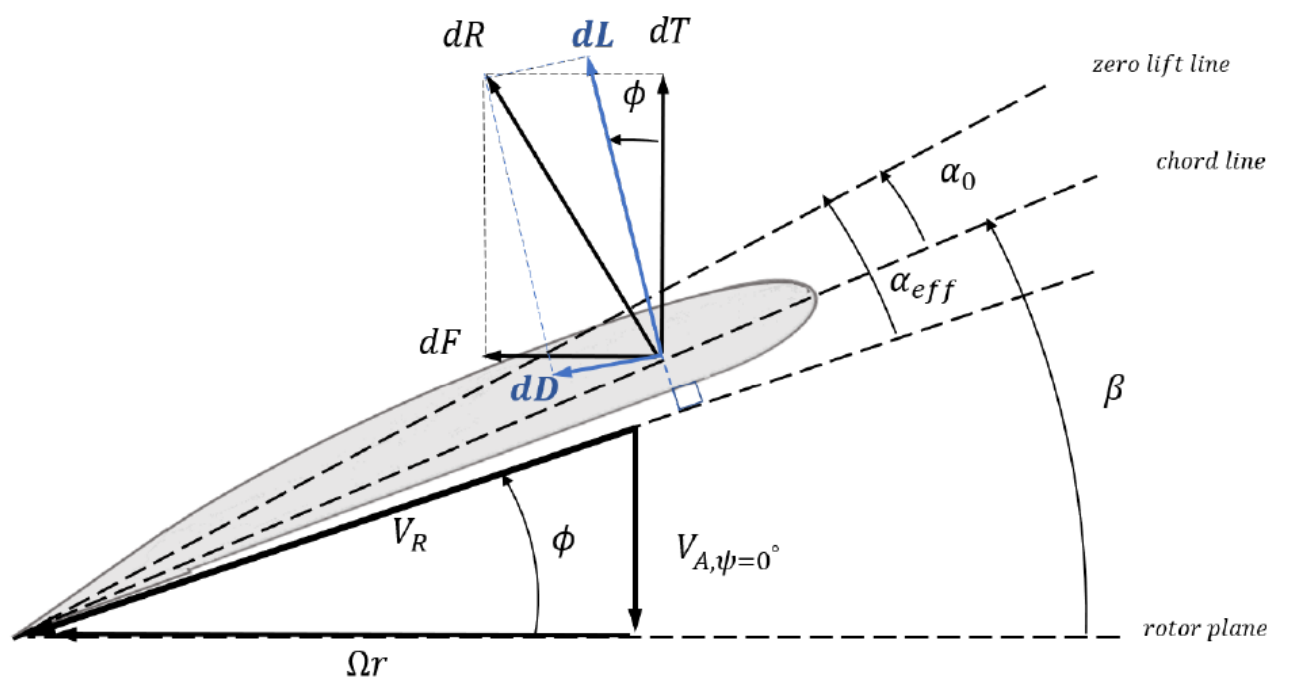

(b) Trailing Edge Blade, $\Psi=0^{\circ}$

Figure 2.4: Leading and trailing edge blade cross-sections[7]. 


\subsection{Retreating Blade Effects}

In addition to the resultant velocity changing with azimuth angle, the resultant velocity over a given rotor blade also changes with radial location. The Reynolds number on a blade section is a function of the tangential velocity and the freestream velocity. The freestream velocity is constant across the full span of the blade. However, the tangential velocity seen by a blade section is:

$$
V_{T}=\Omega\left(\frac{r}{R}\right)
$$

where $r$ is the radial location of the blade section and $R$ is the radius of the full rotor blade. Therefore, for a given rotational speed and blade radius, the chord Reynolds number varies with radial location. This has implications on the flow structure on the advancing and retreating blades in forward flight. Figure 2.5 shows how the reverse flow region grows and moves radially outboard on the retreating blade, as advance ratio is increased. This reverse flow region is a result of the relative airflow moving from the trailing edge to the leading edge on the inboard section of the retreating blade, due to the freestream velocity exceeding the tangential velocity. 


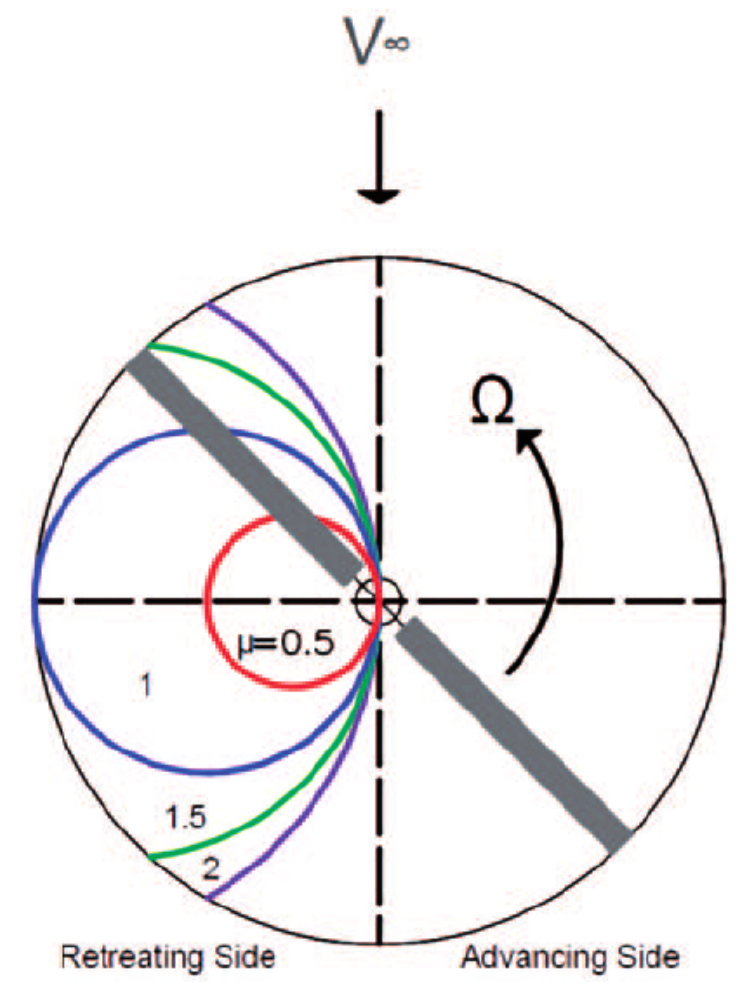

Figure 2.5: Variation of reverse flow region with advance ratio [8].

The onset of reverse flow has various effects on the aerodynamics of the rotor. On the retreating blade, the reverse flow is generally separated, leading to a higher drag force [6]. This drag force opposes the rotation of the motor and therefore increases the power required by the motor. Additionally, the portion of the retreating blade in reverse flow has an angle of attack of about $180^{\circ}$ relative to the flow direction causing the sectional lift coefficient to be approximately zero [9]. On the advancing side, lift is produced along the full span of the blade, which causes a difference in the lift between the advancing and retreating side also known as "dissymmetry of lift". This dissymetry of lift causes a rolling moment about the longitudinal axis, $M_{x}$, which increases as the reverse flow region grows outboard. 


\section{Chapter 3}

\section{Experimental Methodology}

In this chapter the experimental setups and experiments are explained along with the equipment that was used for these tests. Furthermore, the various corrections needed to obtain accurate results are discussed. Propeller-performance data obtained from the Ryerson facility is compared to other facilities in order to verify the experimental setup before any rotor tests were conducted. T-motor rotors of different diameters are then tested at various RPMs in edgewise flow to see the effects that they have on the forces and moments.

\subsection{Description of Experimental Facility}

\subsubsection{Wind Tunnel}

All rotor tests discussed on this thesis were conducted using the Ryerson University subsonic wind tunnel. A top-view sketch of this wind tunnel is shown in Fig. 3.1. The wind tunnel is a closed-loop system and has a contraction ratio of 3.2:1. The rectangular test section has a cross section of $0.914 \mathrm{~m} \times 0.914 \mathrm{~m}$ with a length of $1.5 \mathrm{~m}$. To keep turbulence levels in the test section low, three anti-turbulence screens are located in the settling chamber before the test section. Additionally, each of the four corners contain turning vanes to keep the flow straight and minimize turbulence levels throughout the tunnel. A nacelle for the fan and a streamline device for the belt shaft are located downstream of the fan segment to further reduce turbulence levels. 
The turbulence intensity level in the wind tunnel test section was calculated using a Dantec Mini-CTA constant temperature hotwire anemometer by Barcelos [10]. The average turbulence intensity for the configuration in Fig. 3.1 with the nacelle and streamline device was found to be $0.286 \%$ between tunnel velocities of $12.5 \mathrm{~m} / \mathrm{s}$ and $42.5 \mathrm{~m} / \mathrm{s}[10]$.

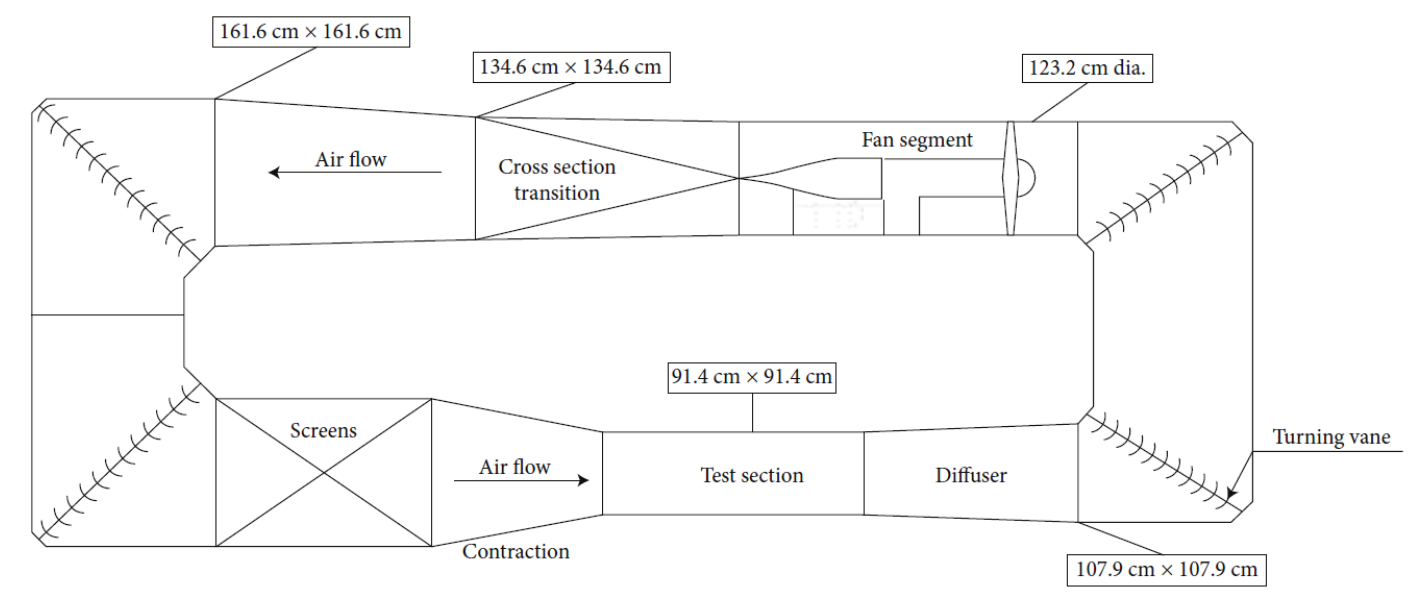

Figure 3.1: Ryerson University's subsonic large wind tunnel schematic [10].

The tunnel airspeed was controlled using a 200hp electric motor that drove a fan with a diameter of $1.23 \mathrm{~m}$ capable of producing a maximum test section airspeed in excess of $60 \mathrm{~m} / \mathrm{s}$ in an empty test section. For these tests however the maximum airspeed reached was $30 \mathrm{~m} / \mathrm{s}$. The airspeed in the test section was measured using an Omega PX277 differential pressure transducer that measured the pressure drop between the settling chamber and the entrance of the test section. The air temperature was measured using a LabJack EI-1034 temperature probe that was located at the end of the test section, and the ambient air pressure was measured using a Validyne P55A pressure transducer.

\subsubsection{Test Stand}

The test stand, shown in Fig. 3.2, consisted of a Scorpion SII-4020-420KV motor that was controlled by an electronic speed controller (ESC) attached to the power supply and the LabJack module. A RM22 rotary magnetic encoder was used to measure the RPM of the Scorpion motor 
shaft. The motor RPM was held constant by using a PID controller that took the RPM input from the encoder and adjusted the RPM output through the ESC to the motor. An ATI Mini 45 F/T transducer measured all the forces and moments developed by the blades. The cowling enclosed the inner electronics and streamlined the test stand to reduce unwanted aerodynamic effects. As shown in Fig. 3.3, the test stand was mounted on a turn table that allowed the angle of attack to be adjusted. The tests for the herein presented study were, however, all run at a 0 degree angle of attack.

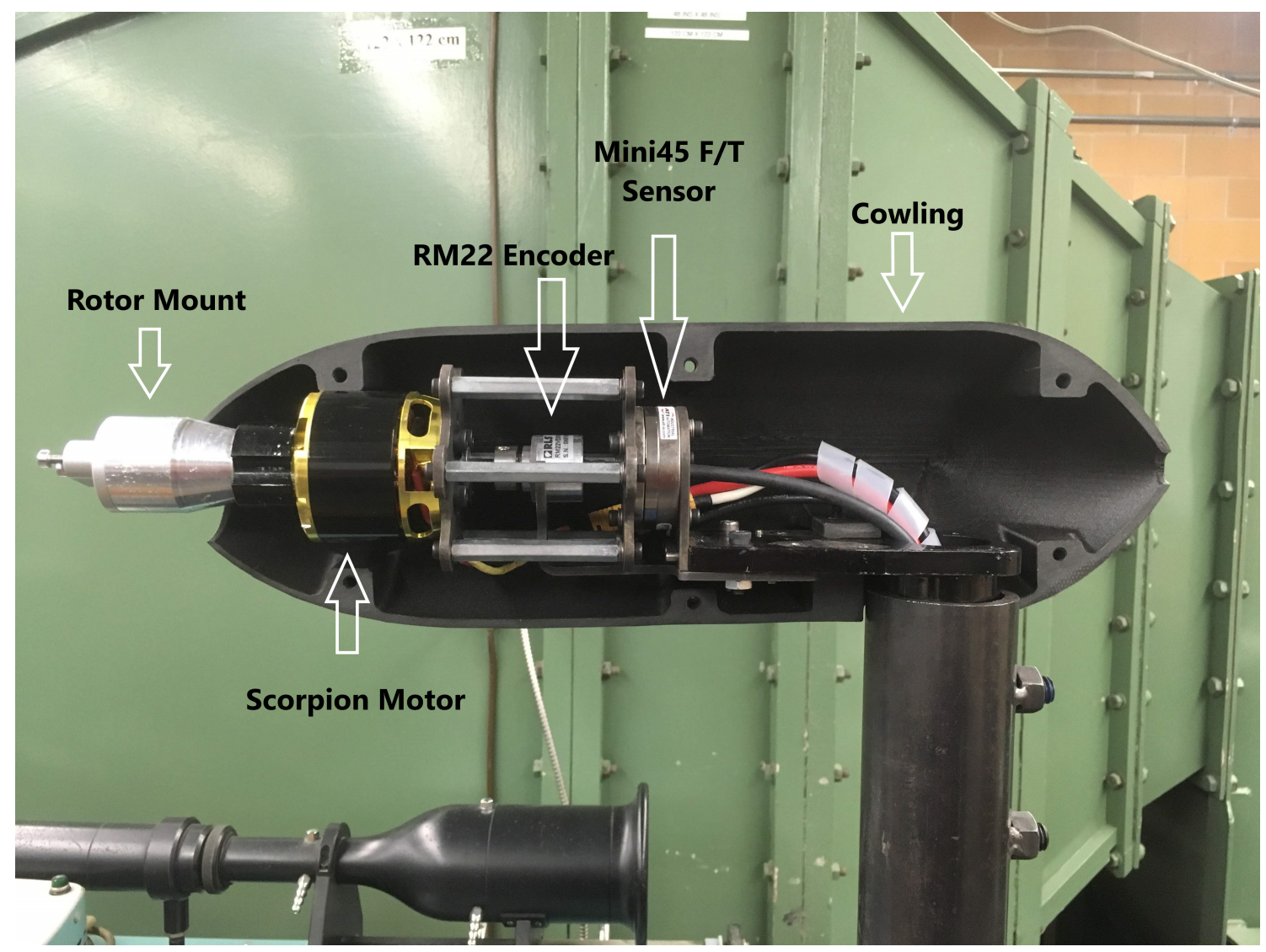

Figure 3.2: Internal components of test stand. 


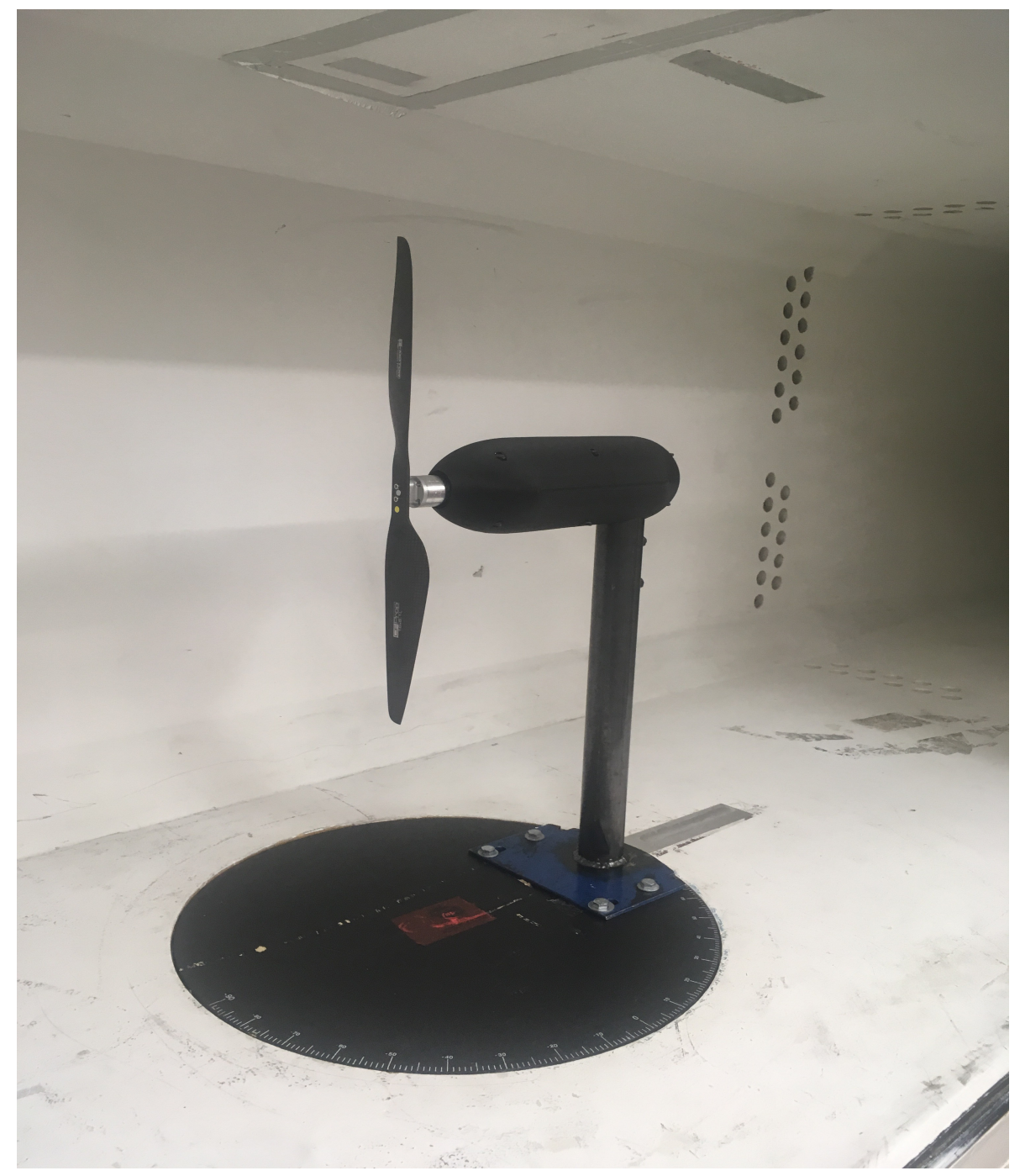

Figure 3.3: Test stand mounted on wind tunnel turntable with cowling on.

\subsection{Data Reductions and Corrections}

\subsubsection{Base Loads}

When running rotor tests, interference effects due to the presence of the rotor-test stand and rotor mount can alter the measured data compared to free-flight results. Therefore the experimental data was corrected in order to account for those interference effects. For example, the 
base loads are the forces and moments registered by the test stand itself without a rotor. The base loads were used to correct the forces and moments from the rotor tests. Other corrections are related to blockage effects.

Figure 3.4 shows the forces and moments recorded by the DAQ for the test stand without an installed rotor. These force and moments are the base loads and were used as correction factors for the test data in order to adjust for the influence of the test stand. Observing Fig. 3.4a, it is seen that the value for $F_{x}$ increases as velocity increases, while the values for $T$ and $F_{y}$ are of a smaller magnitude and show no strong trend. The magnitude of the $F_{x}$ base load is significant, being approximately $40 \%$ of the $F_{x}$ values recorded during the rotor tests. The origin of this base load is primarily the form drag of the rotor mount extending out of the cowling. The base load values for $T$ and $F_{y}$, should theoretically be zero. However, due to errors such as the test stand not being at exactly 0 degrees and air entering minor gaps in the cowling, small values were recorded for the $T$ and $F_{y}$ base loads. These base loads are less than $5 \%$ of their respective values recorded during the rotor tests, and are insignificant. Observing Fig. 3.4b, it is seen that the base loads for all three moments increase as velocity increases. The magnitudes of these base load moments are also less than $5 \%$ of their smallest respective values recorded during the rotor tests. Much like the forces, these moments are caused by the small errors mentioned earlier and not due to any certain physical phenomena. 


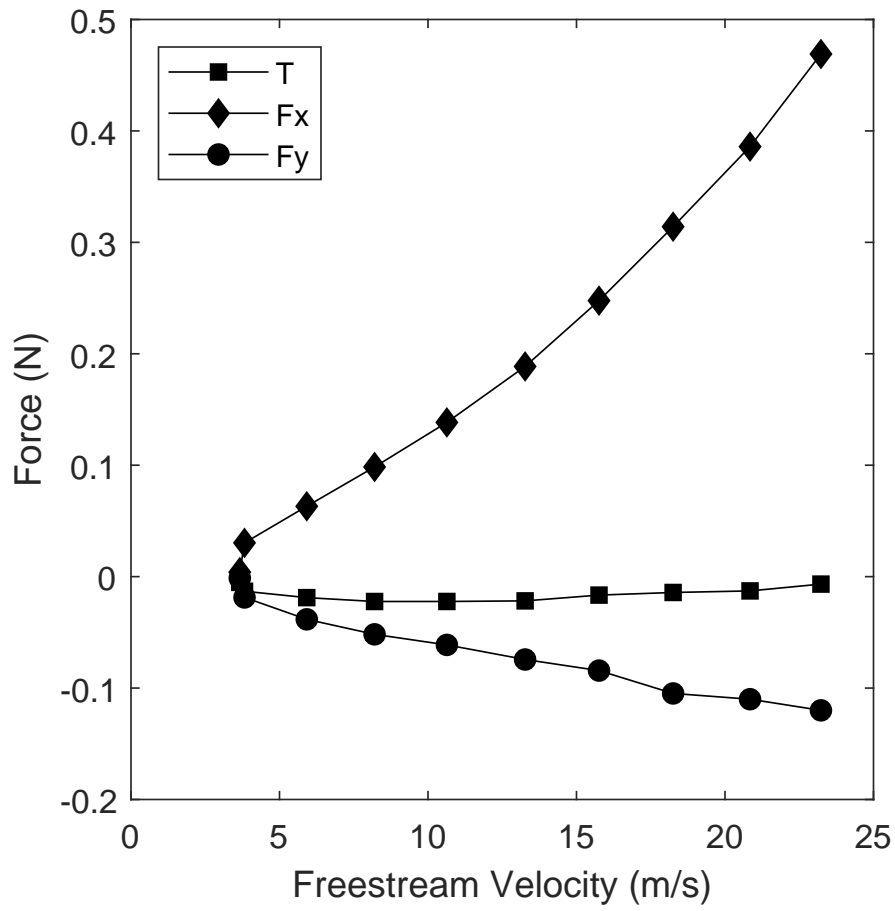

(a) Base Load Forces

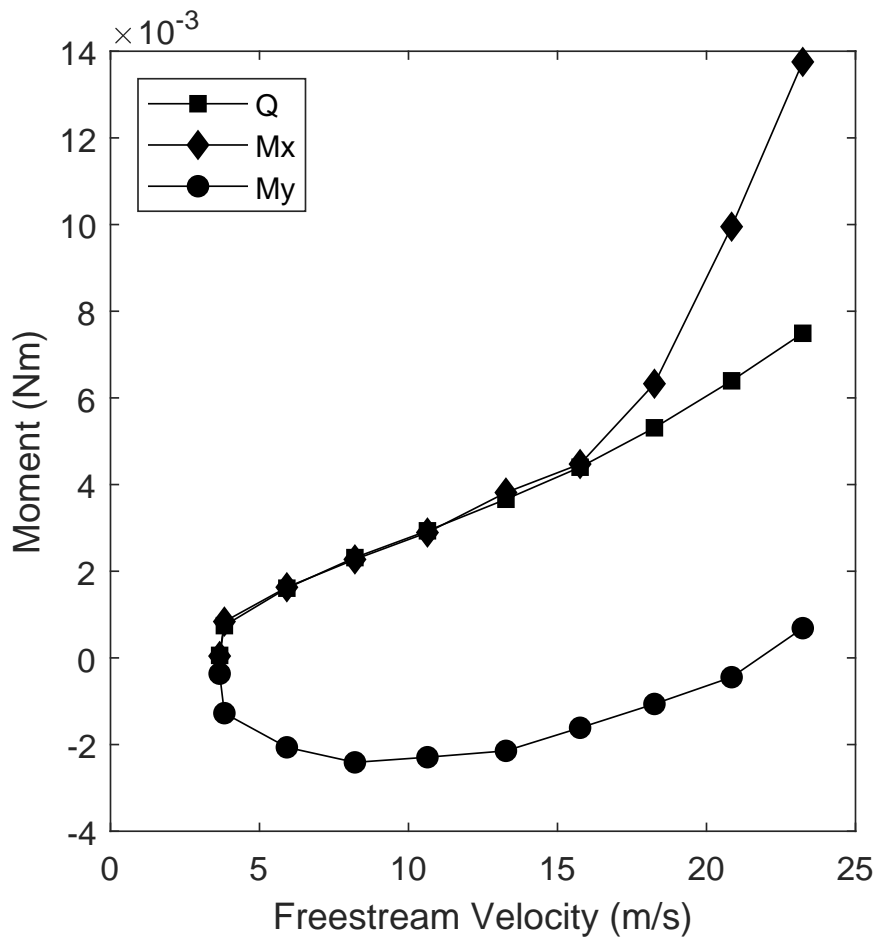

(b) Base Load Moments

Figure 3.4: Base loads recorded for the test stand at 0-degrees angle of attack. 


\subsubsection{Test Stand Blockage Correction}

Another correction accounts for the blockage that is caused by the presence of the test stand in the test section. As mentioned in Section 3.1.1, the wind tunnel velocity was measured using the pressure drop across the contraction section ahead of the test section. However, this was calibrated in an empty test section and the presence of a blockage increases the airspeed in the test section in agreement with the conservation of mass principle. This means that the airspeed in the test section was higher during the tests than what was measured using the pressure drop in the contraction section. To account for a solid blockage in the test section, the method of representing the blockage as a source-sink distribution outlined in Barlow et al. [11] was used. To obtain the increment of change in velocity, the solid-blockage velocity effect for bodies of revolution is estimated using:

$$
\varepsilon_{s b, B}=\frac{\Delta V}{V_{\infty}}=\frac{K v}{C^{3 / 2}}
$$

where $V_{\infty}$ is the freestream velocity and, $K$ is the body shape factor for the blockage, equalling 0.96 for the test stand and cowling. $C$ denotes the cross-sectional area of the test section, while $v$ is the volume of the blockage model. From the aforementioned variables $\varepsilon_{s b, B}$ was calculated to be 0.000366 . The increment of change in velocity, $\Delta V$, was used to correct the recorded freestream velocity from the tunnel for all the tests conducted.

\subsubsection{Uncertainty Analysis}

In an experimental test, all the data acquired has a level of uncertainty due to the accuracy limitations of the instrumentation. To account for this, an uncertainty analysis was done to provide a confidence bound on how far the measured data points might vary from the true values.

The uncertainties in the coefficients presented in Section 2.1 were derived by first calculating the uncertainties in all the observed values and then analyzing the propagation of these uncertainties to the final coefficients as outlined in [12]. For example, the thrust coefficient: 


$$
C_{T}=\frac{T}{\rho A(\Omega R)^{2}}=C_{T}(T, \rho, \Omega)
$$

is a function of the thrust measurement from the load cell, the air density, and the angular velocity measurement from the encoder. For a given data point, each of these parameters will have an associated uncertainty as presented in Table 3.1.

\begin{tabular}{cc}
\hline Parameters & Uncertainty \\
\hline \hline$T$ & $0.0975 \%$ \\
$\Omega$ & $0.4911 \%$ \\
$\rho$ & $1.3198 \%$ \\
\hline
\end{tabular}

Table 3.1: Uncertainty values for the parameters of interest.

The final uncertainties in the coefficients were found from combining the individual uncertainties according to [12], yielding a final uncertainty percentage for each data point that was recorded. These percentages were applied to each of the data points in the form of error bars. The detailed calculations and results for the uncertainties are shown in Appendix A.

\subsection{Comparison with other Experimental Results}

Experimental results for a Master Airscrew Electric, MAE 11x7 were compared to published test data for the same propeller [13]. Figure 3.5 shows the thrust and power coefficients of the Ryerson data against the published data at rotational speeds of 4000 and 5000 RPM for the MAE $11 \times 7$ at $90^{\circ}$. 


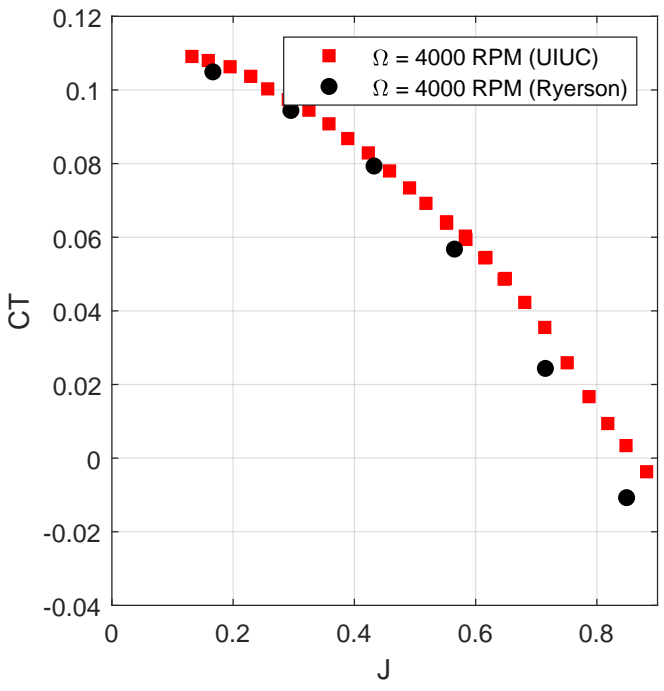

(a) $C_{T}$ (4000 RPM)

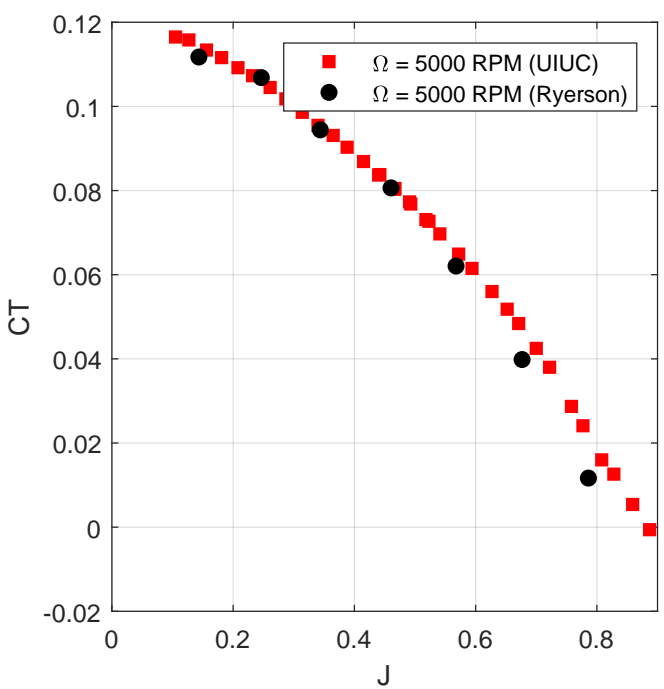

(c) $C_{T}(5000 \mathrm{RPM})$

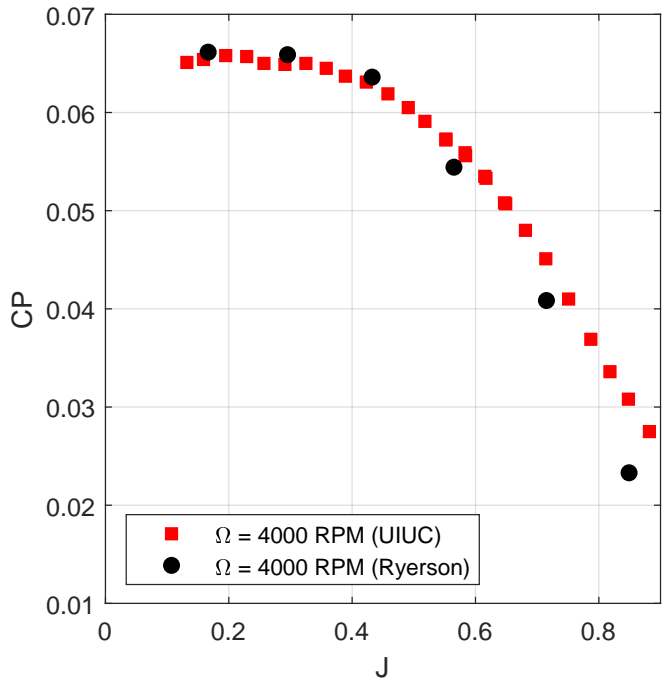

(b) $C_{P}(4000 \mathrm{RPM})$

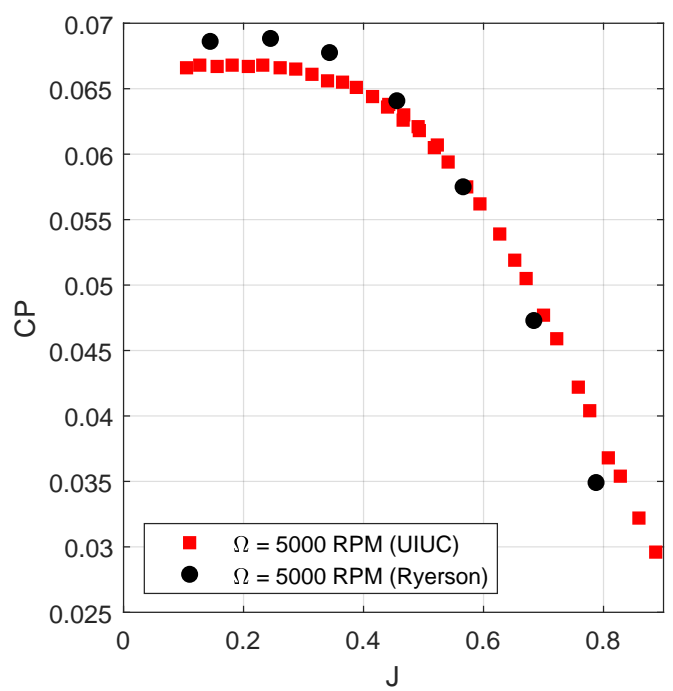

(d) $C_{P}(5000 \mathrm{RPM})$

Figure 3.5: Comparison of Ryerson experimental data against published data for the MAE 11x7 at $90^{\circ}$ angle of attack.

As can be seen in Fig. 3.5, there was very minimal variation between the Ryerson data and the published data for the power coefficient for both RPMs, although there was a slight variation of about $3 \%$ at the lower advance ratios for 5000RPM. For the thrust coefficient, similar trends 
are seen between the Ryerson data and the published data for both RPMs. There are some slight differences at higher advance ratios where the propeller begins to windmill and the values for $C_{T}$ become negative. These discrepancies could be the result of the differences in the tunnel setup and instrumentation at both facilities. These could be the test section area, turbulence intensity, data acquisition apparatus and test stand geometry.

\subsection{Test Object}

Three rotors with different radii were used for the tests that are outlined in this thesis: TMotor $\mathrm{P} 12 \times 4$ rotor, $\mathrm{P} 15 \times 5$ rotor, and $\mathrm{P} 18 \times 6.1$ rotor. All three of these rotors were clockwise spinning and had the same chord and pitch distributions, allowing them to be directly scaled.

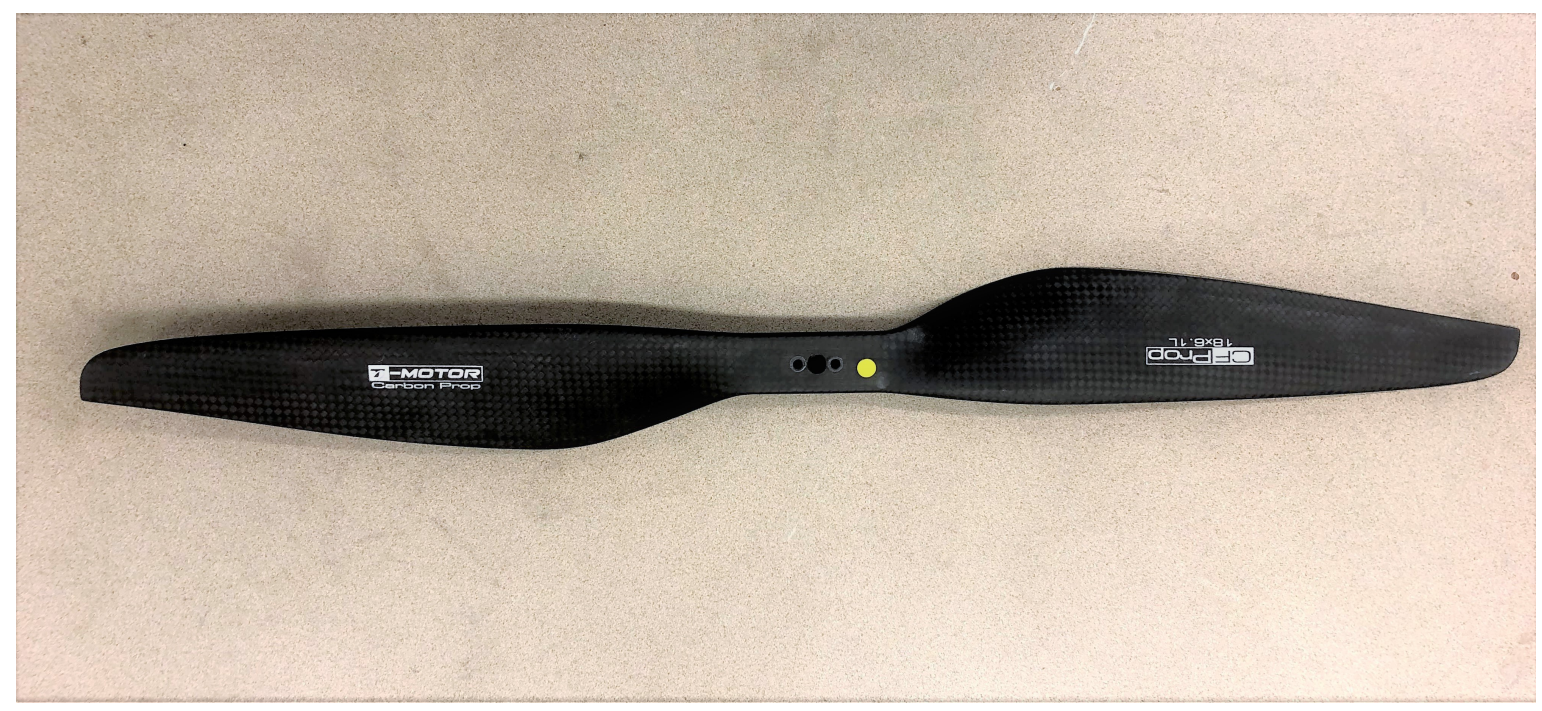

Figure 3.6: T-motor P18x6.1L rotor blade.

The chord and twist distribution for a normalized T-Motor rotor is shown in Fig. 3.7. The chord and pitch distributions were found from a 3D scan of the whole rotor and 2D scans of cut sections of the blade along various radial locations [14]. As can be seen the results from the 2D and 3D scans were very similar, with small differences in the twist distributions. 


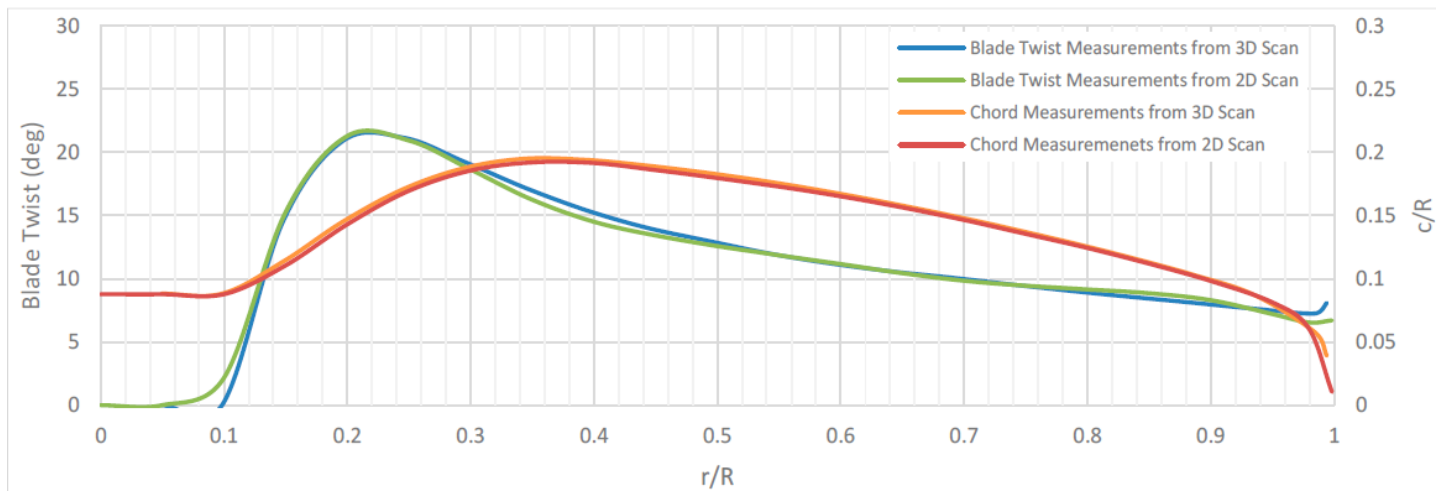

Figure 3.7: T-motor rotor normalized chord and twist distributions [14].

\subsection{Test Setup and Plan}

The test matrix of the experiments herein discussed is shown in Table 3.2. Rotor tests were run on three different T-Motor rotors with diameters of 12in, 15in and 18in in fully edgewise flow at different advance ratios and chord-Reynolds numbers.

\begin{tabular}{cccc}
\hline Test Number & Diameter(in) & Chord-Reynolds Number & RPM \\
\hline \hline 1 & & 39,000 & 1000 \\
2 & \multirow{2}{*}{18} & 78,000 & 2000 \\
3 & & 117,000 & 3000 \\
\hline 4 & \multirow{2}{*}{15} & 39,000 & 1436 \\
5 & & 78,000 & 2873 \\
6 & \multirow{2}{*}{12} & 117,000 & 4320 \\
\hline 7 & & 39,000 & 2256 \\
8 & & 78,000 & 4511 \\
9 & & 117,000 & 6750 \\
\hline
\end{tabular}

Table 3.2: Test Matrix

Each of these rotors was tested at three different chord-Reynolds numbers $(117000,78000,39000)$ that was based on the chord length and tangential speed at $75 \%$ of the radial location of the respective blades. To compare between the different sized rotors, the chord Reynolds number at $75 \%$ of the radius was kept constant by changing the rotor RPM, as rotor diameter was changed. 
For each test, the advance ratio, $\mu$, was varied by changing the tunnel velocity, while keeping the rotor RPM constant.

The three Reynolds numbers mentioned in Table 3.2 are based on the conditions at $75 \%$ of the radius for the rotor under static conditions. Thus, as advance ratio was increased, the chordReynolds number at $75 \%$ of the radius varied due to the addition of the freestream velocity. However, as shown in Fig. 3.8 the different sized rotors were still similar since the variance in the Reynolds number due to the freestream component was equal for all three rotors with increasing advance ratio.

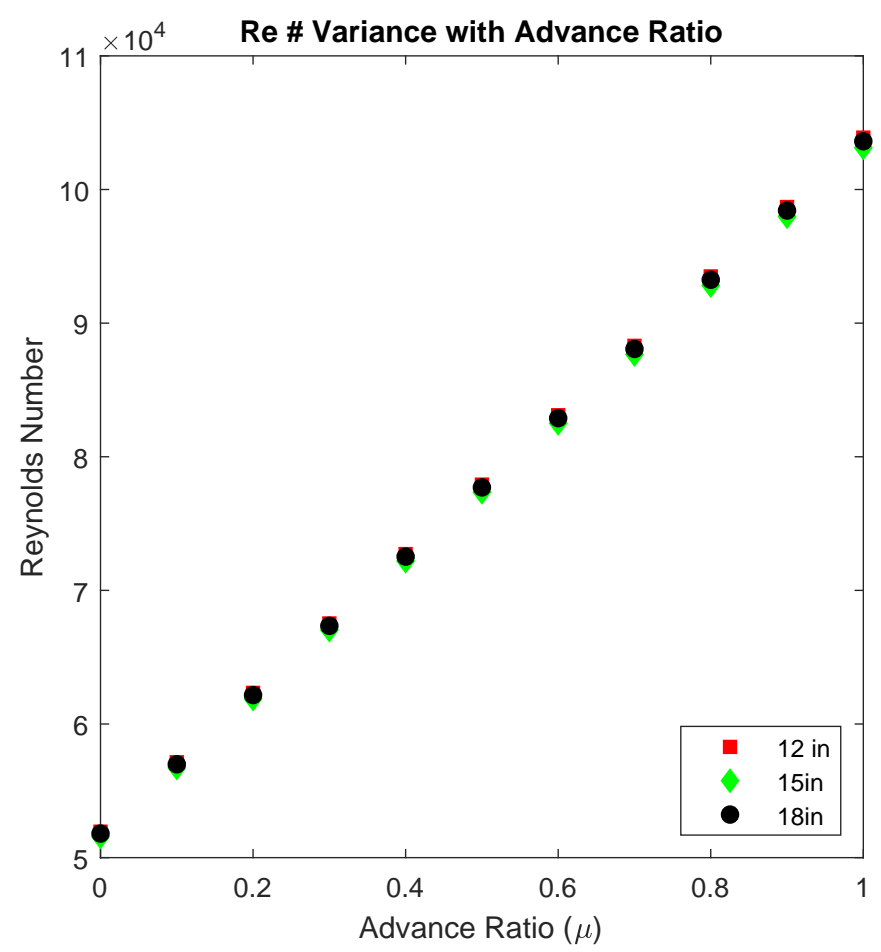

Figure 3.8: Chord-Reynolds number variance at the $75 \%$ radial location of the blade with changing advance ratio.

The procedure for each test point is outlined as follows. For each test, a static case was run before the wind tunnel was started in order to get the static forces and moments of the rotor. This data allowed a direct comparison of the forces and moments for the different sized rotor 
blades at different Reynolds numbers under static conditions. For the advancing flow portion of the tests, the wind tunnel was started and the target motor RPM was set and held with a PID controller for 30 seconds during which the forces and moments were recorded at a rate of $8 \mathrm{kHz}$. The mean of all the data points collected for a given force or moment was used for the results shown in Chapter 4. The freestream velocity was changed by increasing the tunnel motor RPM by 100RPM increments, with the rotor forces and moments being recorded at each increment, up until a tunnel motor RPM of 1000. 


\section{Chapter 4}

\section{Experimental Results}

Rotor test were conducted for the three different diameter rotors at varying Reynolds numbers and advance ratios. The non-dimensionalized results are presented and analyzed in this section. The results for the 12 in rotor at the Reynolds number of 117,000 are not included in the results as there were vibratory effects observed while maintaining a rotor RPM corresponding to this Reynolds number. Additionally, as rotor RPM and therefore chord Reynolds number were increased, higher advance ratios were not achievable due to wind tunnel speed limitations. Therefore, the tunnel velocities for all the tests were varied from $0 \mathrm{~m} / \mathrm{s}$ to approximately $30 \mathrm{~m} / \mathrm{s}$, resulting in tests with lower rotor RPMs reaching higher advance ratios.

All the data points presented in this chapter contain associated error bars. These error bars are based off the uncertainty calculations done in Section 3.2.3 and provide a range of accuracy for the data points. 


\subsection{Thrust Coefficient}

The thrust coefficient is plotted in Fig. 4.1 against the advance ratio for three Reynolds numbers. The thrust coefficient increases as advance ratio increases, which corresponds to an increase in wind-tunnel speed. This trend is consistent for all chord-Reynolds numbers, although slight differences in the magnitude of the thrust coefficient are observed between the different rotor diameters at the lowest chord Reynolds number. For this Reynolds number, and at the lower advance ratios the thrust coefficient is highest for the 12-in rotor and decreases as rotor diameter increases. As the chord Reynolds number increases, less of a discrepancy is seen in the magnitude of the thrust coefficient between the different rotor diameters. In regards to the magnitude, all three Reynolds numbers have the same magnitude for the thrust coefficient at a given advance ratio. The data presented in Fig. 4.1, supports that the traditional coefficientbased scaling laws can be used for the thrust coefficient for the full range of Reynolds numbers presented with a high degree of confidence. 

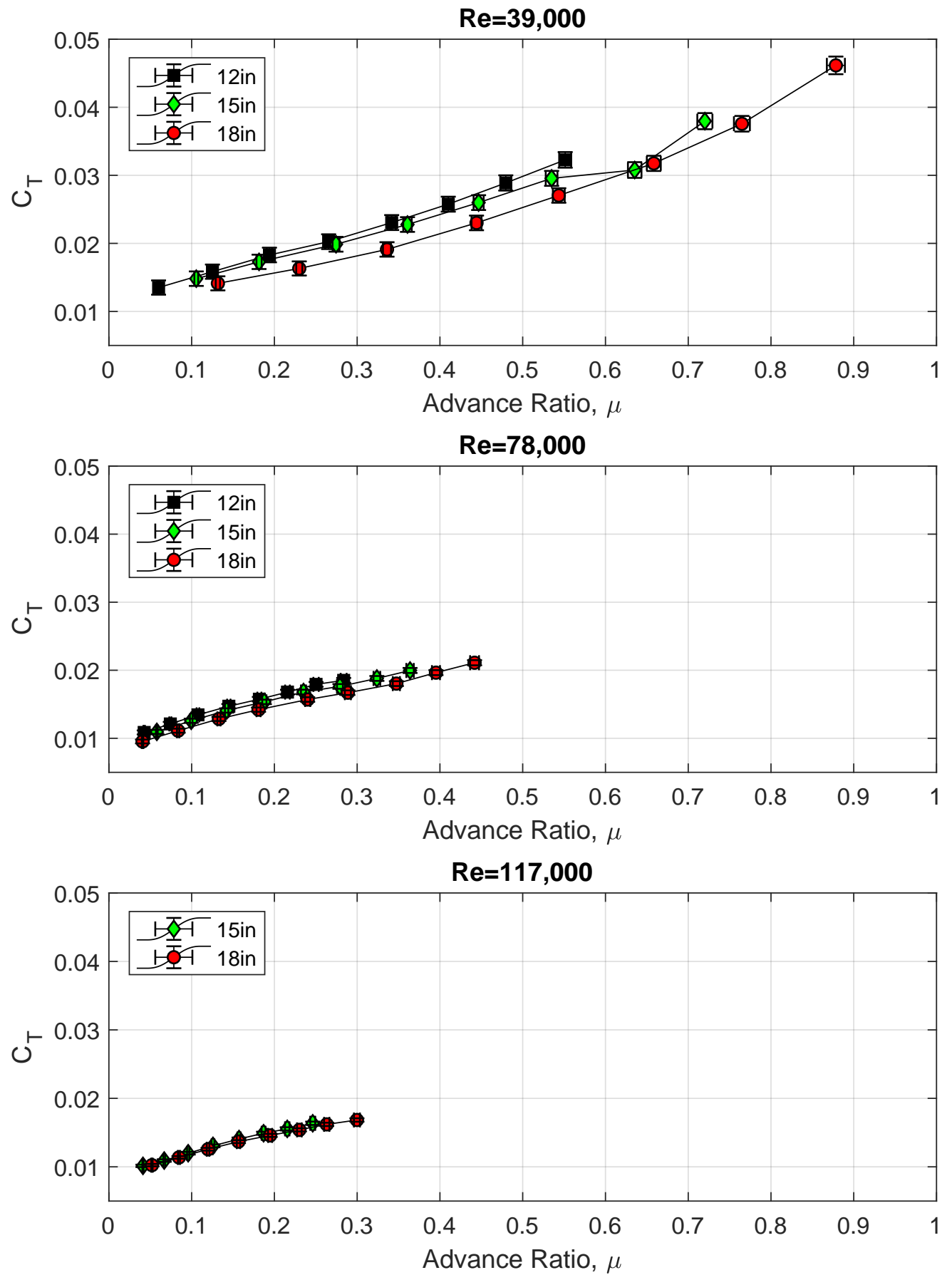

Figure 4.1: Experimental thrust coefficient versus advance ratio for several Reynolds numbers. 


\subsection{Power Coefficient}

Figure 4.2 shows the power coefficient as it changes with advance ratio for the three Reynolds numbers. The power coefficient increases as advance ratio increases, which corresponds to an increase in wind-tunnel speed. The upward trend is a result of the retreating blade experiencing reverse flow which comes with an increase in drag that acts against the direction of rotation, requiring an increase in power that is provided to the rotor. Comparing the three plots in Fig. 4.2 , it is seen that the power coefficient remains relatively constant and is not very dependant on Reynolds number. From the data presented in Fig. 4.2, the traditional coefficient-based scaling laws can be used for the power coefficient for the full range of Reynolds numbers presented with a high degree of confidence. 

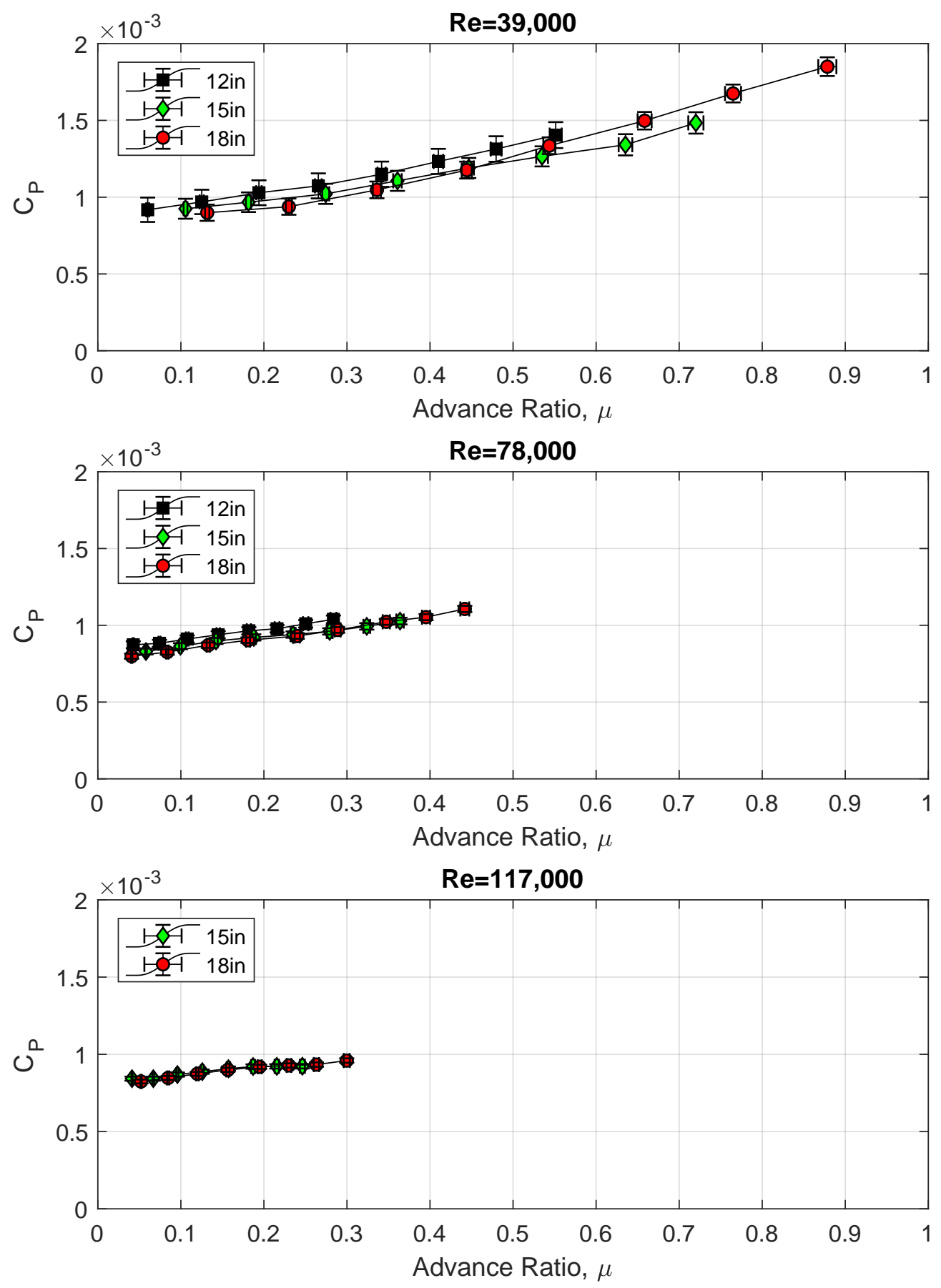

Figure 4.2: Experimental power coefficient versus advance ratio for several Reynolds numbers. 


\subsection{Longitudinal Force Coefficient}

Figure 4.3 shows the longitudinal force coefficient as it changes with advance ratio for the three Reynolds numbers that were investigated. The longitudinal force coefficient corresponds to the drag force of the rotor disk. This drag force coefficient increases in magnitude with an increase in advance ratio, which corresponds to an increase in wind-tunnel speed. At a Reynolds number of 39,000 the data points exhibit some scatter, however the general upward trend for all rotor diameters is seen. This upward trend is a result of the additional freestream velocity on the advancing side, causing an increase in the net drag of the rotor disk with increasing advance ratio. As the Reynolds number increases the variation between the different rotor diameters decreases with the general upward trend still maintained. Overall it can be concluded from the data presented in Fig. 4.3 that the traditional coefficient based scaling laws can be used for the longitudinal force coefficient for the full range of Reynolds numbers tested. 

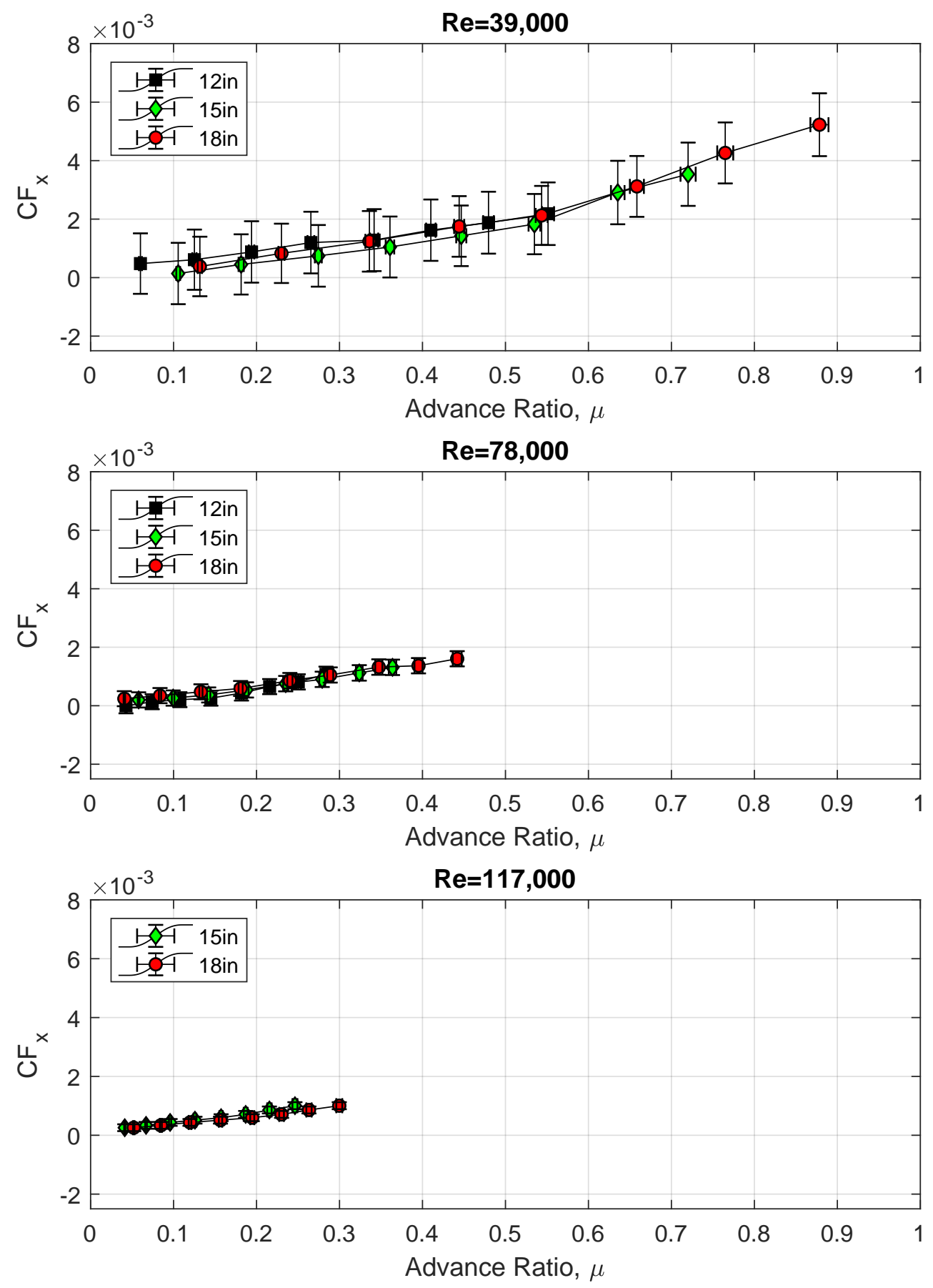

Figure 4.3: Experimental longitudinal-force coefficient versus advance ratio for several Reynolds numbers. 


\subsection{Side Force Coefficient}

Figure 4.4 shows the side force coefficient with respect to advance ratio for the three Reynolds numbers. The side force is a result of different blade drags along the leading and trailing edges of the rotor disc due to skewed inflow conditions along the longitudinal axis of the disc. This force acts in the plane of the rotor disc towards the advancing side. The side force coefficient increases as advance ratio increases, which corresponds to an increase in wind-tunnel speed. At a Reynolds number of 39,000 there is slight variation between the data points of different rotor diameters, however they all match up taking into account the ranges of the error bars. As the Reynolds number is increased, the variations decrease and the data points for all the different rotor diameters line up with each other. The side force is also within the same magnitude as the longitudinal force. From the data presented in Fig. 4.4, the traditional coefficient based scaling laws can be used for the side force coefficient for the full range of Reynolds numbers presented with a high degree of confidence. 

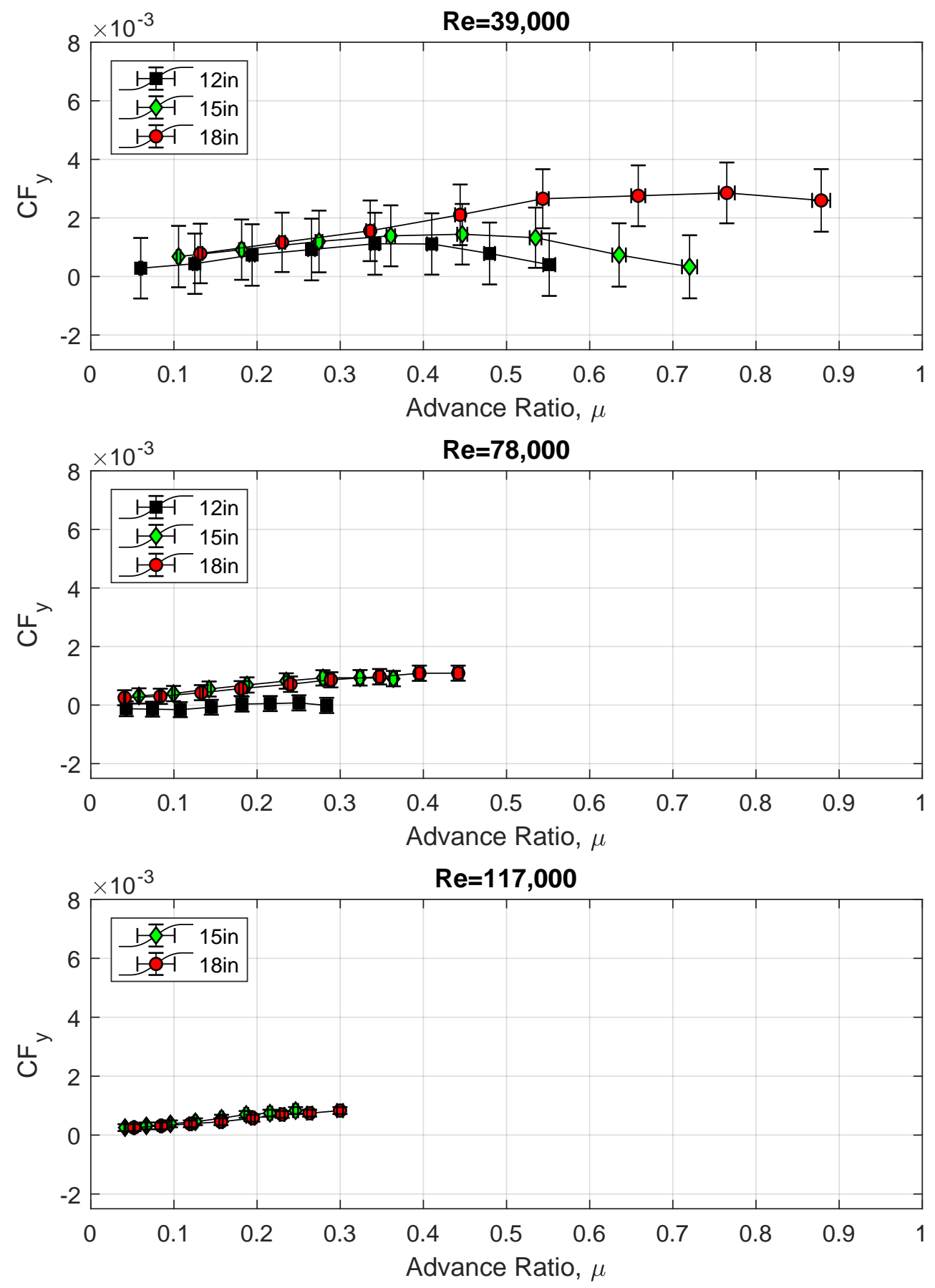

Figure 4.4: Experimental side-force coefficient versus advance ratio for several Reynolds numbers. 


\subsection{Rolling Moment Coefficient}

Figure 4.5 shows the rolling moment coefficient as it changes with advance ratio for the three Reynolds numbers. The magnitude of the rolling moment coefficient increases as advance ratio increases, which corresponds to an increase in wind-tunnel speed. The rolling moment corresponds to the rotor tending to roll towards the side with the retreating blade as the advance ratio increases. This roll moment is a result of the retreating blade producing less thrust than the advancing blade, as discussed in Section 2.3.

At a Reynolds number of 39,000 , it is seen that the data points for the different rotor diameters deviate above an advance ratio of 0.5. However, at lower advance ratios the data points for the different rotor diameters align with each other, as is also seen at the higher Reynolds numbers. Additionally, the magnitude of the rolling moment coefficient is not impacted by the Reynolds number and can be seen by comparing the three plots in Fig.4.5. It can also be concluded that the traditional coefficient based scaling laws can be used for the rolling moment coefficient for the full range of Reynolds numbers presented with a high degree of confidence. 

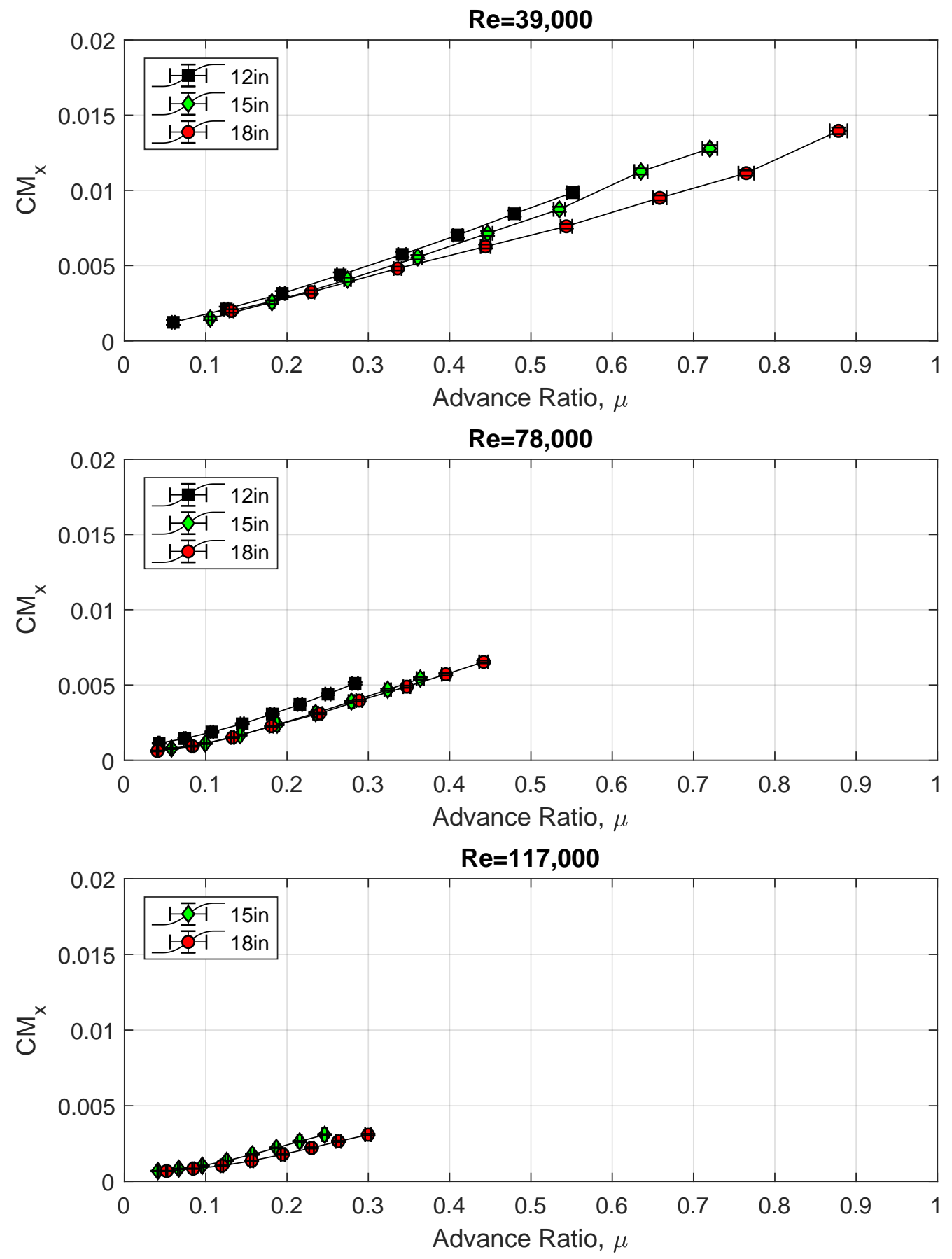

Figure 4.5: Experimental rolling moment coefficient versus advance ratio for several Reynolds numbers. 


\subsection{Pitching Moment Coefficient}

Figure 4.6 shows the pitching moment coefficient as it changes with the advance ratio for the three Reynolds numbers analyzed. The pitching moment is a result of skewed inflow conditions, with more axial inflow near the trailing edge of the rotor disc compared to the leading edge of the rotor, causing more thrust to be produced near the leading edge of the rotor disc. This causes a moment that pitches up the rotor disk about the lateral axis. Observing the three plots in Fig. 4.6, it is seen that the data points at Reynolds numbers of 39,000 and 78,000 are unsteady and show large variations in the data between the different rotor diameters. At the Reynolds number of 117,000 the variation between the different rotor diameters decreases and an initial spike followed by a gradual decrease in $C_{M_{y}}$ is seen.

From the results, it is evident that at lower Reynolds number the pitching moment is unsteady for all rotor diameters and can cause issues for flight control systems trying to trim multi-rotor vehicles. Comparing the three plots in Fig. 4.6, the traditional coefficient based scaling laws cannot be accurately used to scale the pitching moment between different sized rotor at Reynolds numbers under 100,000. However at Reynolds numbers above 100,000 the coefficient based scaling laws can be used to scale the pitching moment with a higher degree of confidence. 

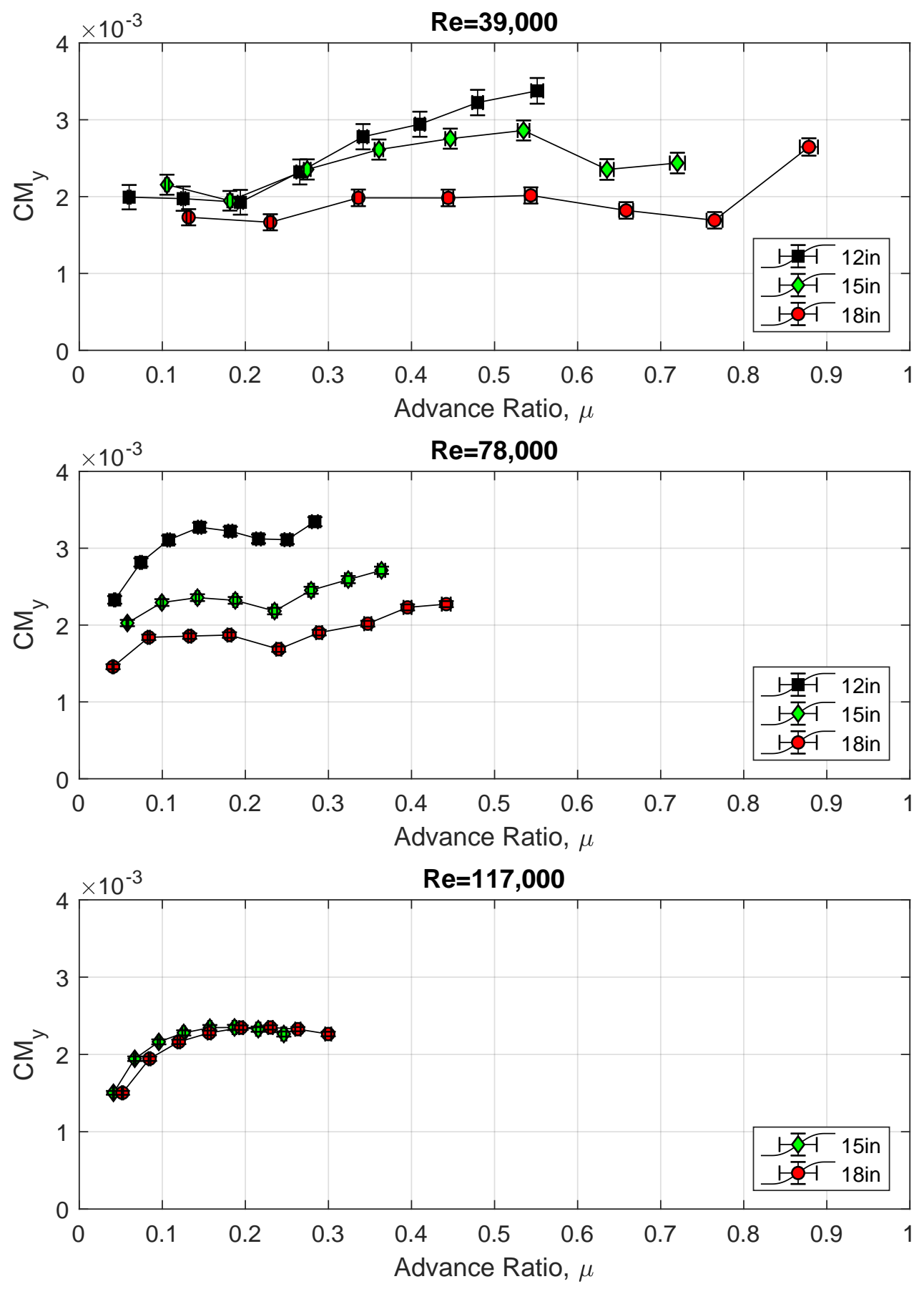

Figure 4.6: Experimental pitching moment coefficient versus advance ratio for several Reynolds numbers. 


\section{Chapter 5}

\section{Comparison to Rotor Prediction}

\section{Methods}

This chapter compares the experimental results obtained to a rotor performance prediction program based off of the blade element momentum theory. The algorithm behind the performance prediction program is discussed followed by a comparison of the experimental results to the predicted results. The results are compared for the coefficients of thrust, power, longitudinal force, side force, rolling moment and pitching moment for all three Reynolds numbers. In order to limit the presented data, only the results for a chord-Reynolds number of 39,000 are presented in this chapter. The comparison plots for Reynolds numbers of 78,000 and 117,000 are included in Appendix B.

\subsection{Blade Element Momentum Theory}

The experimental results are compared to a rotor performance prediction program based off of the blade element momentum theory. This is a code that was developed at Ryerson University by Tim Carroll [9] and was created to predict rotor performance for small quadrotor-like aircraft. In addition to using the general equations from the blade element and momentum theories, this program also incorporates several inflow models from which the linear inflow model was used 
for this thesis.

Experimental research of the inflow over the rotor disk in forward flight has shown that the longitudinal and lateral variations in the inflow are linear and are a result of the rotor wake being swept back [6]. For this reason, the uniform inflow model used for the hover case could not be used to predict the inflow variations in forward flight. The Pitt \& Peters linear inflow model, whose physical depiction is shown in Fig. 5.1, was used in this program to model the inflow in forward flight as it provided the best agreement with experimental observations [9].

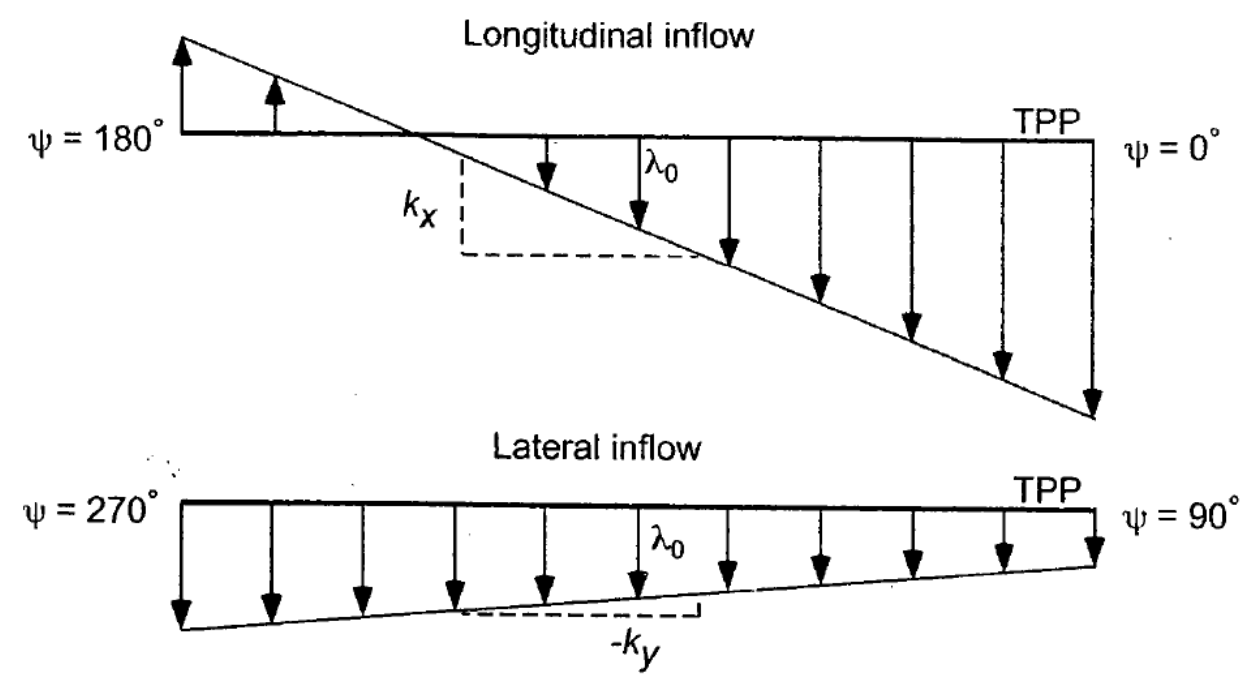

Figure 5.1: Linear variation of inflow along longitudinal and lateral axes in forward flight [6].

The program follows the general methodology shown in Fig. 5.2. First the input parameters were specified, which included defining the rotor geometry and radius along with inputting the operating conditions, which in this case were the rotor RPM and freestream velocity. A uniform momentum with linear inflow method was chosen as this was the model most suited to edgewise flight [9]. With the preceding parameters specified, the program was run and the function on the left side of Fig. 5.2 was executed. The function comprises of an iteration routine to solve for the thrust coefficient with a nested iteration routine to incorporate the linear inflow model. Both of these iteration routines require explicit convergence to solve for their respective param- 
eters. Once solved, the program outputs the blade forces at different radial station and azimuth locations along with performance coefficients for the full rotor.

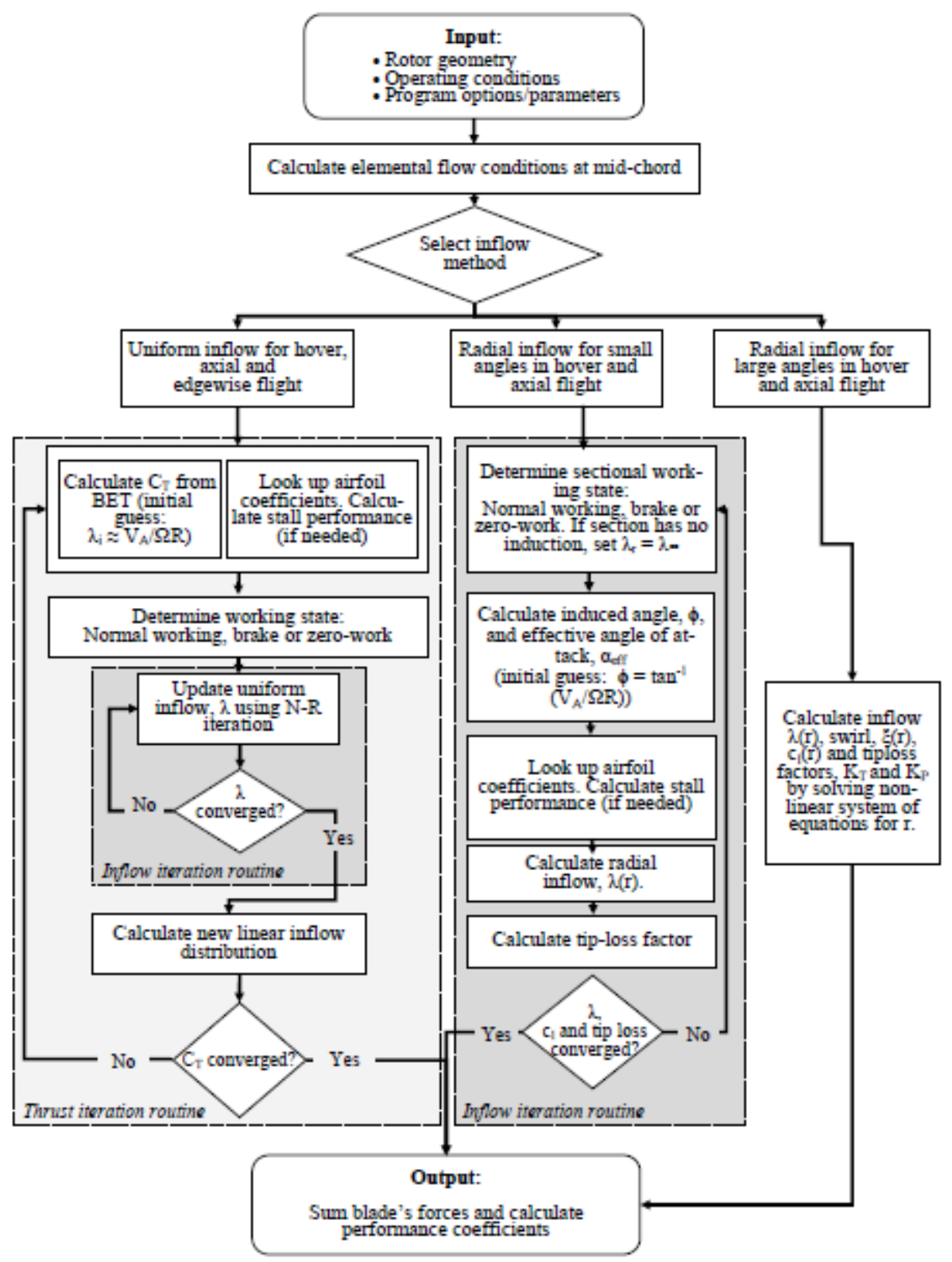

Figure 5.2: Solution methodology for BEMT prediction method [9]. 


\subsection{Blade Element Momentum Theory Results}

Figures 5.3 to 5.5 compare the BEMT predictions with the experimental values for all six coefficients of interest against the advance ratio for a chord-Reynolds number of 39,000 . The comparison plots for the other two chord-Reynolds numbers that were analyzed can be found in Appendix B. In each of these plots there is only a single data set for the predicted BEMT results, while there are three different data sets corresponding to the rotor diameters for the experimental results. According to the conventional scaling laws, if the Reynolds number for two different sized objects are the same for incompressible conditions then the flow physics will be the same and each of the non-dimensionalized forces and moments will be equal. The BEMT results follow the conventional scaling laws, therefore the values for the coefficients should be the same regardless of rotor diameter for a given Reynolds number. However, there are very small differences due to different chord-Reynolds numbers in the section characteristics tablelookup routine of the program. Nonetheless, these difference are very small and not observable at the scale at which the results in this thesis are analyzed and consequently only a single data set is presented for the BEMT results.

In Fig. 5.3 it is seen that the thrust and power predictions follow the same trend as the experimental results with increasing advance ratio. The predicted BEMT data for the thrust coefficient agree within 15 and 30 percent with the measured data for the thrust coefficient for the full range of advance ratios. A lesser difference between the predicted and measured data is seen at lower advance ratios and increases as advance ratio is increased. Similar trends are seen at the higher Reynolds numbers for the thrust coefficient. However, at the higher Reynolds numbers the BEMT data agrees with the measured data well, with a maximum difference of approximately $8 \%$ across the range of advance ratios.

In Fig. 5.3 the predicted values for the power coefficient agree within 5 and 23 percent with the measured values for the power coefficient for all diameters and advance ratios. The predicted and measured sets of data show that the power coefficient increases with advance ratio. At 
Reynolds numbers of 78,000 and 117,000, the same trend is not seen for the power coefficient. At these higher Reynolds numbers, the predicted data shows an initial steep decrease in the power coefficient followed by a more gradual decrease in the power coefficient with increasing advance ratio. The measured data on the other hand shows a gradual increase in the power coefficient with increasing advance ratio. 

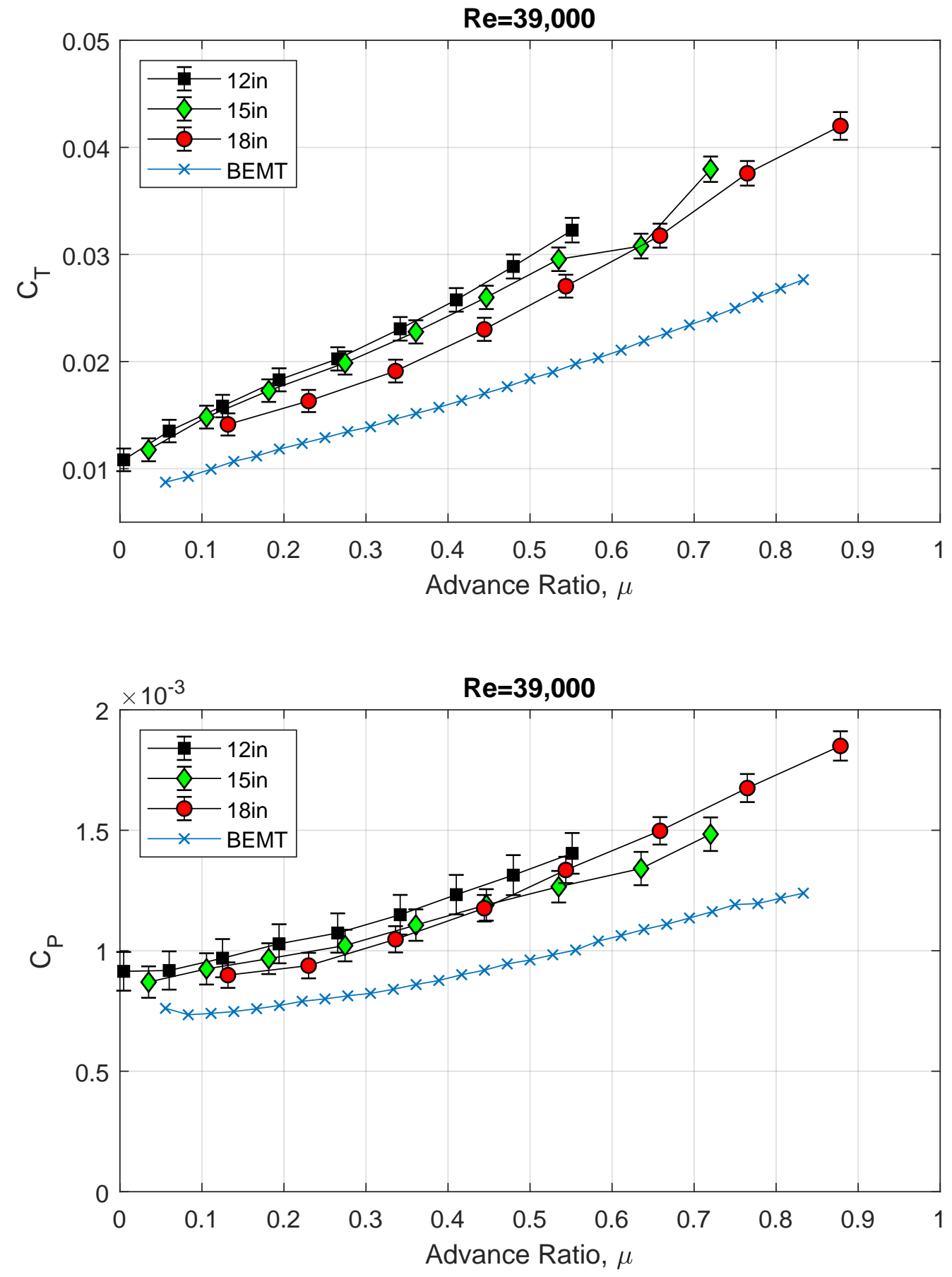

Figure 5.3: Predicted and experimental results of $C_{T}$ and $C_{P}$ for $\operatorname{Re}=39,000$. 
From Fig. 5.4, it is seen that the prediction for the longitudinal force coefficient follows the same trend as the measured data, with $C_{F_{x}}$ increasing as advance ratio increases. Above an advance ratio of 0.6 , the slope of the measured data increase while the slope of the predicted data remains constant. In addition to following the same trend, the predicted data agrees with the measured data points for all the different rotor diameters under an advance ratio of 0.6. At higher advance ratios a maximum difference of $50 \%$ between the measured and predicted data is seen with the error bars accounted for. At the higher Reynolds numbers, the same trend is observed. The scatter in the measured data is also reduced decreasing the difference between the predicted and measured data to maximum of $12 \%$.

Figure 5.4 also shows that there is a discrepancy between the predicted and measured data for the side force coefficient. The measured data shows that $C_{F_{y}}$ increases and then decreases after an advance ratio of 0.4 for all the rotor diameters. However, the predicted data shows that $C_{F_{y}}$ remains constant at a value of around $10^{-5}$ for all advance ratios. This same relationship is also seen at the higher Reynolds numbers. This could be due to limitations in the linear inflow model used by the prediction method; however further work is required to verify this. Another possible explanation for the discrepancies between the predicted and experimental data can be due to unsteady wake effects or the interference of the rotor with the test stand. 

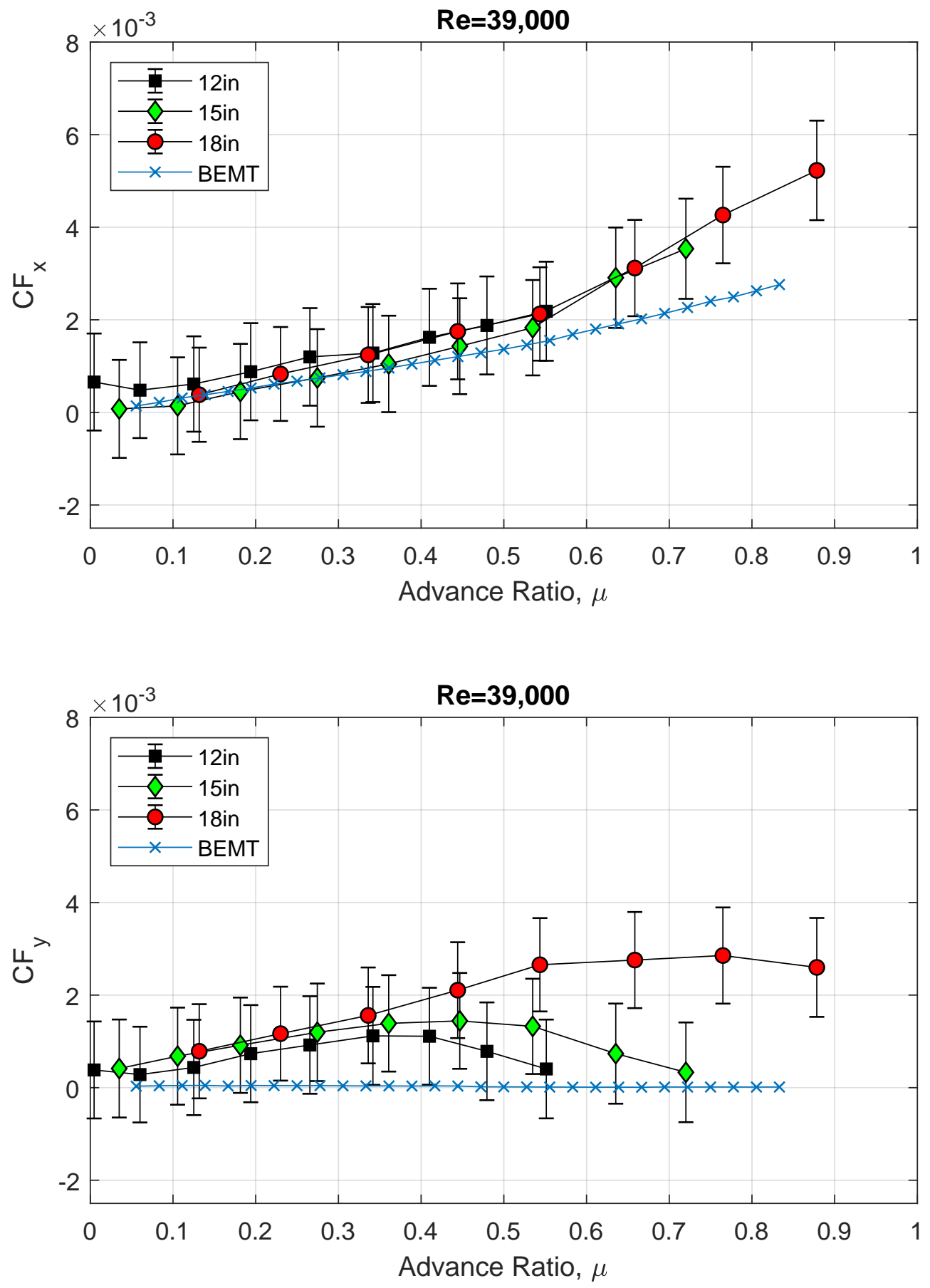

Figure 5.4: Predicted and experimental results of $C_{F_{x}}$ and $C_{F_{y}}$ for $\mathrm{Re}=39,000$. 
From Fig. 5.5, it is seen that the prediction for the rolling moment coefficient follows the same trend as the measured data to within a maximum of $15 \%$, with $C_{M_{x}}$ increasing as advance ratio increases. At the higher Reynolds numbers the predicted data over predicts the measured data up to a maximum of $50 \%$ at the higher advance ratios.

From Fig. 5.5 the predicted data for the pitching moment coefficient shows an initial spike followed by a gradual decrease as advance ratio is increased. As advance ratio increases, the wake is swept back further thereby reducing the inflow differential between the leading and trailing edges of the rotor disk, causing a reduction in the pitching moment. The initial spike however is a result of the nonuniform inflow between the advance ratio range of 0 to 0.1 , where the transition from hover to level forward flight takes place [6]. The measured data on the other hand does not show a concrete trend with increasing advance ratio for any of the rotor diameters. At a Reynolds number of 78,000 the measured data does start to show a trend similar to the predicted data, showing the initial spike and slight decrease in the pitching moment coefficient, however the measured values then start to increase again after an advance ratio of 0.2. At the Reynolds number of 117,00 , there is an initial increase in the measured data followed by a gradual decrease, although the slope of the decrease is a lot shallower than the slope of the decrease for the predicted data. This leads to a $75 \%$ difference between the predicted and measured values for $C_{M_{y}}$ at the maximum advance ratio of 0.3. Possible explanations for the discrepancies between the predicted and experimental data can be due to unsteady wake effects or the interference of the rotor with the test stand. 

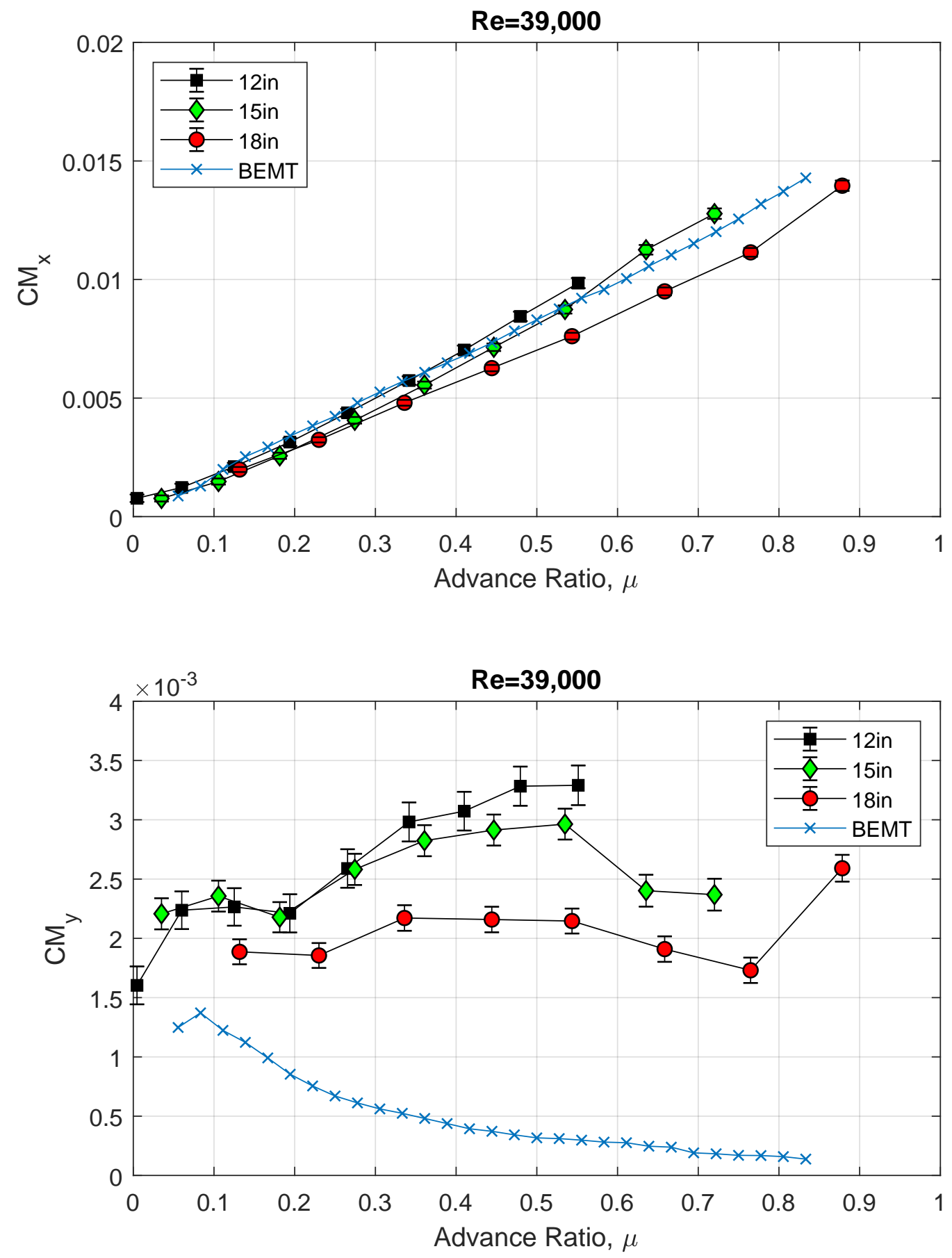

Figure 5.5: Predicted and experimental results of $C_{M_{x}}$ and $C_{M_{y}}$ for $\operatorname{Re}=39,000$. 


\section{Chapter 6}

\section{Conclusions}

\subsection{Conclusions}

Three T-Motor rotors with different diameters but otherwise identical relative geometries were tested in fully edgewise flow at different advance ratios and chord-Reynolds numbers. The objective was to verify whether the existing scaling relationships between rotor size and the aerodynamic forces was applicable to small-scale rotors at relatively low chord-Reynolds numbers. For the experiments, a rotor-test stand was used that was capable of measuring the forces and moments produced by the rotor blades at several angles of attack, however all test conducted in this thesis were at an angle of attack of 0 degrees. The test stand was mounted in a closed loop wind tunnel that allowed the variation of air speed, to test the rotors at a range of advance ratios indicative of forward flight. The chord-Reynolds number at $75 \%$ of the radius of each blade ranged from 39,000 to 117,000 . This represents a relatively low Reynolds-number range that is characteristic for the flight of multi-rotor sUAVs at low forward speeds. The experimental data was also compared to computational results from a code that was based on blade element momentum theory.

The experimental data shows that the conventional coefficient based scaling laws can accurately be used to scale between different rotor diameter in edgewise flight for all the forces and moments at the higher range of the Reynolds numbers tested. At the lowest Reynolds number 
of 39,000 there was variation in the data between the different rotor diameters, especially for the pitching moment coefficient where the variation between the different rotors was approximately $200 \%$. This variation in the data at low Reynolds numbers is presumed to be due to the dominance of viscous forces in this flow regime.

The experimental data is presented alongside data generated from a computational code used as a tool for performance prediction of rotors. The prediction method showed agreement between $5 \%$ and $75 \%$ with the measured data for all the forces and moments for all the Reynolds numbers tested. As Reynolds number was increased, the predicted and measured data showed agreement in the trends, however the magnitude of the predicted data slightly varied from the experimental data. For the side force coefficient, $C_{M_{y}}$, the prediction method did not agree with the trends found in the experimental results for all the Reynolds numbers tested, possibly due to limitations in the prediction inflow model. Despite this, the computational code can be used get approximate performance data for rotors in the initial conceptual design stage.

Overall, the conventional coefficient based scaling laws can be used to accurately scale between rotors of different sizes during the conceptual design stage, given that the rotors being compared are the same in terms of geometry. Additionally, the computational BEMT prediction method can be used during the early conceptual design stage to obtain performance data for rotors of different sizes and geometries, allowing the design space to be explored in a short amount of time.

\subsection{Future Work}

There are many areas that can be improved upon to obtain more accurate and concrete data regarding performance parameters for rotors operating in edgewise flow. This future work includes:

1. Reducing turbulence levels in the wind tunnel test section.

2. Testing rotors of different geometries and sizes outside of the range tested in this thesis. 
3. Testing rotors at different angles of attack to more accurately model the flight conditions that multi-rotor sUAVs operate at.

4. Reducing the uncertainties associated with the test setup, including sealing the cowling, and adjusting the cowling to also cover the rotor mount.

5. Experimentally testing multi-rotor setups to determine whether wake effects alter the scaling relations.

6. Verifying the BEMT computational model for all the forces and moments tested. 


\section{Appendix A: Uncertainty Calculations}

This section outlines the method and steps used to calculate the uncertainties in the coefficients presented in this thesis. To calculate the uncertainties in the coefficients, the uncertainties of the measurement devices were first obtained from the data and calibration sheets of each respective device.

Rotary Magnetic Encoder:

$$
\left(\frac{U_{\Omega}}{\Omega}\right)=0.4911 \%
$$

Static Pressure Sensor:

$$
\left(\frac{U_{P}}{P}\right)=0.2172 \%
$$

Differential Pressure Transducer:

$$
\left(\frac{U_{\Delta P}}{\Delta P}\right)=1.5031 \%
$$

Thermocouple:

$$
\left(\frac{U_{T}}{T}\right)=1.3018 \%
$$

The uncertainty values for the measurement devices listed above were relative uncertainties. This meant that the accuracy of the measurement device was independent of the recorded value. For the F/T sensor, the uncertainty was given as a numerical value which meant that the uncertainty percentage would vary with the recorded value. 
F/T Sensor:

$$
\begin{aligned}
U_{F_{x}}, U_{F_{y}}, U_{F_{z}} & =0.025 \mathrm{lbf} \\
U_{T_{x}}, U_{T_{y}} & =0.02272 \mathrm{lbf}-\mathrm{in} \\
U_{T_{z}} & =0.01136 \mathrm{lbf}-\mathrm{in}
\end{aligned}
$$

An uncertainty analysis was then performed using the Taylor Series Method (TSM) outlined in [12]. This was done by using the uncertainties in the measurement devices and calculating their combined effects on the coefficients.

Density:

$$
\begin{aligned}
\left(\frac{U_{\rho}}{\rho}\right)^{2}=\left(\frac{U_{P}}{P}\right)^{2}+\left(\frac{U_{T}}{T}\right)^{2} & =(0.2172)^{2}+(1.3018)^{2} \\
\left(\frac{U_{\rho}}{\rho}\right) & =1.3198 \%
\end{aligned}
$$

Temperature:

$$
\left(\frac{U_{T}}{T}\right)=1.3018 \%
$$

Rotational Speed:

$$
\left(\frac{U_{\Omega}}{\Omega}\right)=0.4911 \%
$$

Freestream Velocity:

$$
\begin{aligned}
(2)^{2}\left(\frac{U_{V}}{V}\right)^{2} & =\left(\frac{U_{\Delta P}}{\Delta P}\right)^{2}+\left(\frac{U_{\rho}}{\rho}\right)^{2} \\
(4)\left(\frac{U_{V}}{V}\right)^{2} & =(1.5031)^{2}+(1.3198)^{2} \\
\left(\frac{U_{V}}{V}\right) & =1.0001 \%
\end{aligned}
$$

Advance Ratio:

$$
\begin{aligned}
\left(\frac{U_{\mu}}{\mu}\right)^{2} & =\left(\frac{U_{V}}{V}\right)^{2}+\left(\frac{U_{\Omega}}{\Omega}\right)^{2} \\
\left(\frac{U_{\mu}}{\mu}\right)^{2} & =(1.0001)^{2}+(0.4911)^{2} \\
\left(\frac{U_{\mu}}{\mu}\right) & =1.1142 \%
\end{aligned}
$$

As mentioned before, the uncertainty percentage of the loads from the F/T sensor depended on the recorded value. Accordingly, the process for calculating the uncertainty percentage of 
the coefficients is shown for a single data point of the thrust coefficient. However, this process applies for the data points of the all the coefficients except for the power coefficient.

Example of Thrust Coefficient Uncertainty Calculation:

$$
\begin{aligned}
\left(\frac{U_{C_{T}}}{C_{T}}\right)^{2} & =\left(\frac{U_{F_{z}}}{F_{z}}\right)^{2}+\left(\frac{U_{\rho}}{\rho}\right)^{2}+(2)^{2}\left(\frac{U_{\Omega}}{\Omega}\right)^{2} \\
\left(\frac{U_{C_{T}}}{C_{T}}\right)^{2} & =\left(\frac{0.025}{0.2562}\right)^{2}+(1.3198)^{2}+4(0.4911)^{2} \\
\left(\frac{U_{C_{T}}}{C_{T}}\right) & =1.6481 \%
\end{aligned}
$$

For the power coefficient, the power uncertainty was calculated for a single torque data point. This was followed by calculating the uncertainty in the power coefficient for the same single data point.

Power:

$$
\begin{aligned}
\left(\frac{U_{P}}{P}\right)^{2} & =\left(\frac{U_{\Omega}}{\Omega}\right)^{2}+\left(\frac{U_{T_{z}}}{T_{z}}\right)^{2} \\
\left(\frac{U_{P}}{P}\right)^{2} & =(0.4911)^{2}+\left(\frac{0.01136}{0.0150}\right)^{2} \\
\left(\frac{U_{P}}{P}\right) & =0.9026 \%
\end{aligned}
$$

Example of Power Coefficient Uncertainty Calculation:

$$
\begin{aligned}
\left(\frac{U_{C_{P}}}{C_{P}}\right)^{2} & =\left(\frac{U_{P}}{P}\right)^{2}+\left(\frac{U_{\rho}}{\rho}\right)^{2}+(3)^{2}\left(\frac{U_{\Omega}}{\Omega}\right)^{2} \\
\left(\frac{U_{C_{P}}}{C_{P}}\right)^{2} & =(0.9026)^{2}+(1.3198)^{2}+9(0.4911)^{2} \\
\left(\frac{U_{C_{P}}}{C_{P}}\right) & =2.1742 \%
\end{aligned}
$$




\section{Appendix B: BEMT Results}

This section presents the comparison plots of the experimental results and the rotor performance prediction program for chord-Reynolds numbers of 78,000 and 117,000. For the plots in this section the advance ratio error bars are not included due to the fact that their presence made it hard to distinguish between the data points at the scale presented. However, the magnitude of the advance ratio error at these Reynolds numbers is very low and omitting them does not alter the conclusions that can be made from the plots. 


\section{B.1 $\operatorname{Re}=78,000$}
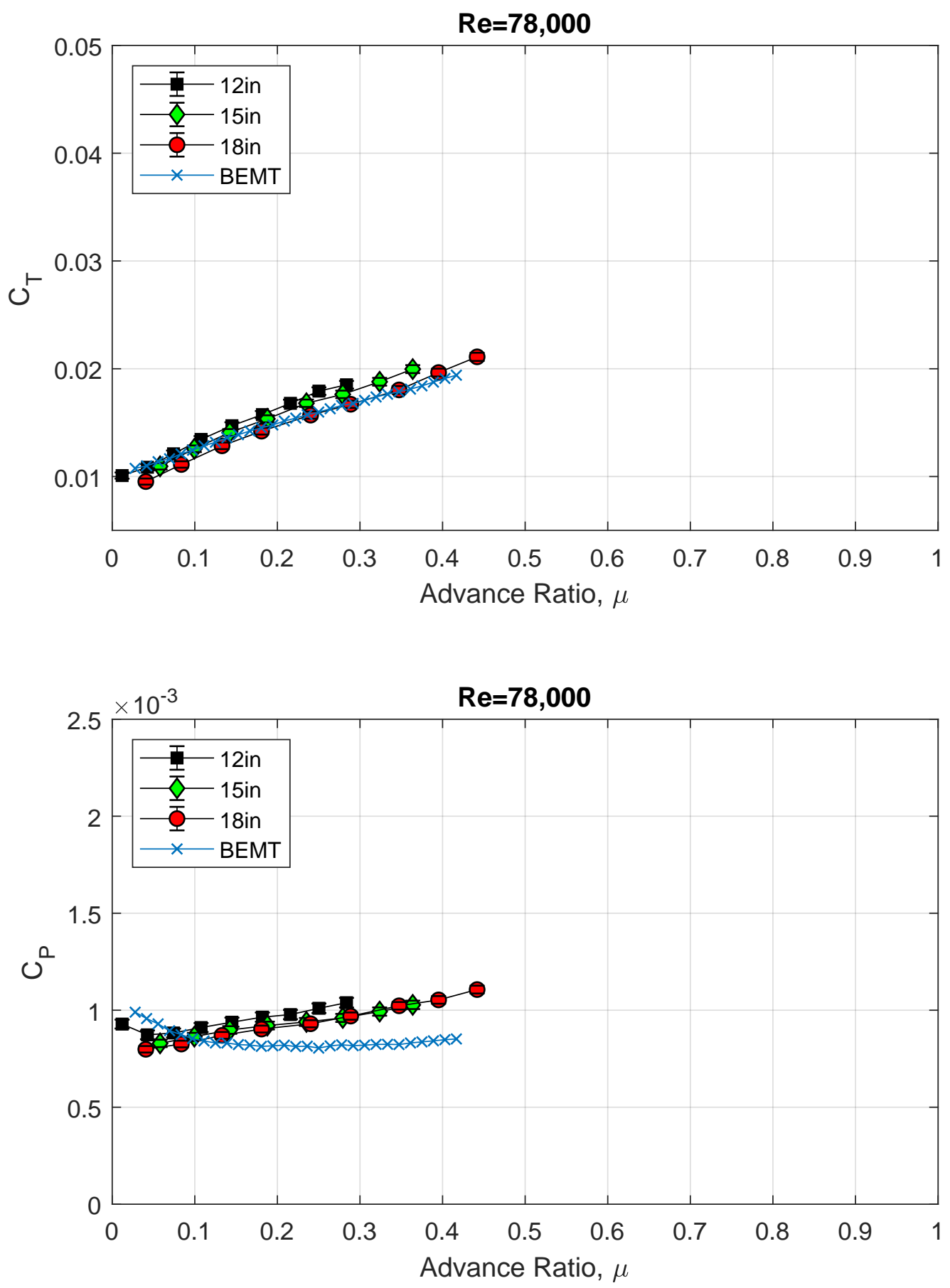

Figure B.1: Predicted and experimental results of $C_{T}$ and $C_{P}$ for $\mathrm{Re}=78,000$. 

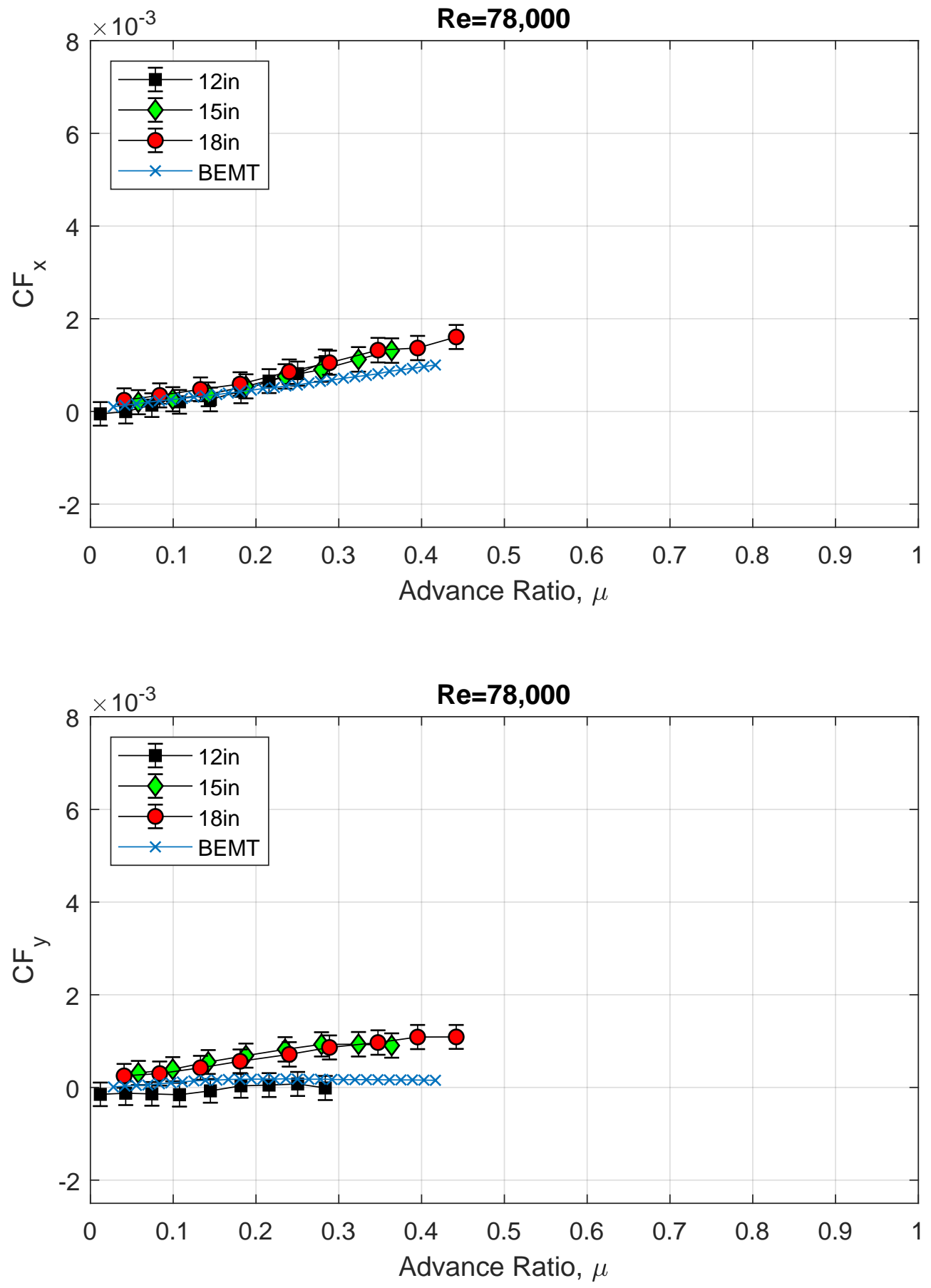

Figure B.2: Predicted and experimental results of $C F_{x}$ and $C F_{y}$ for $\operatorname{Re}=78,000$. 

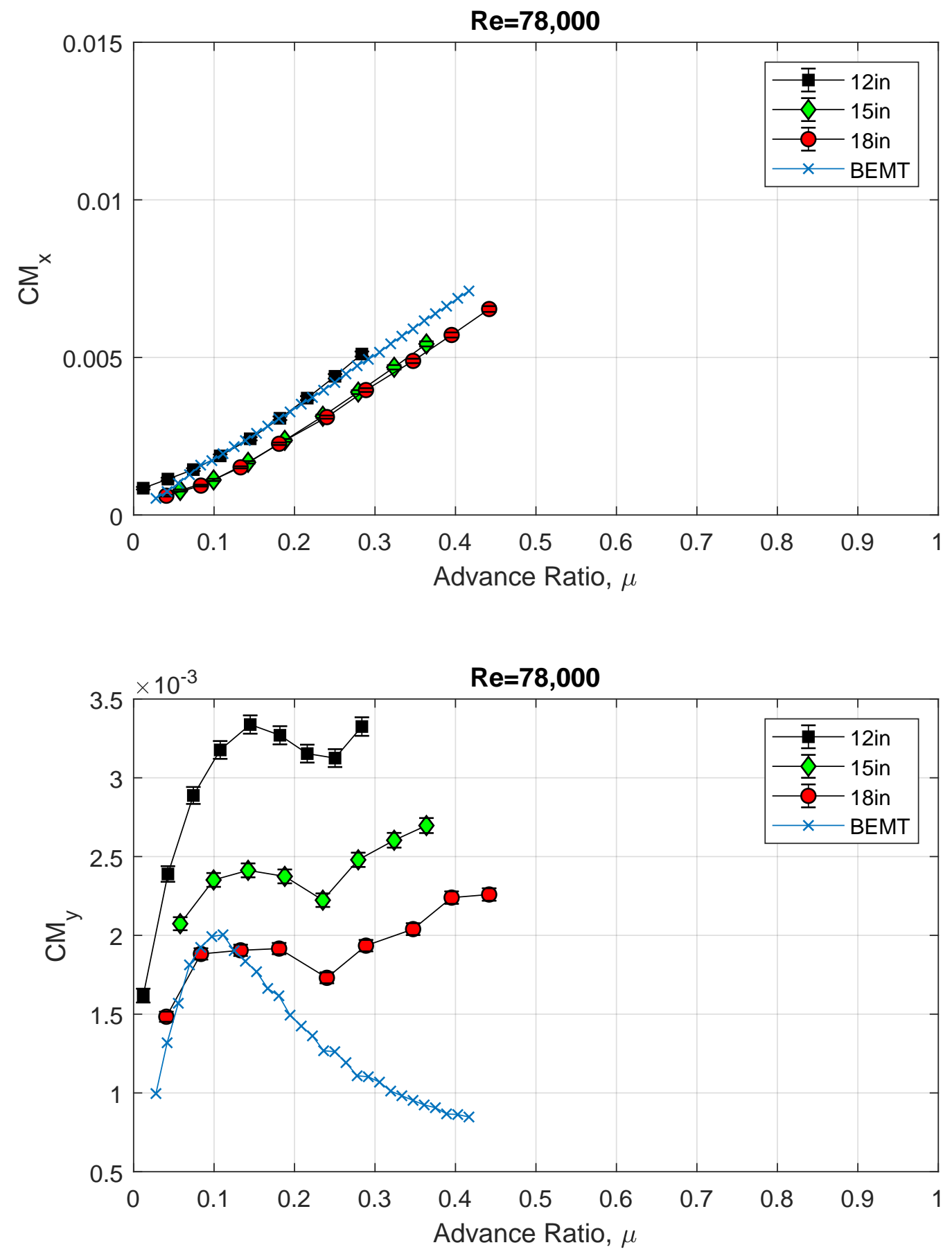

Figure B.3: Predicted and experimental results of $C M_{x}$ and $C M_{y}$ for $\mathrm{Re}=78,000$. 


\section{B.2 $\operatorname{Re}=\mathbf{1 1 7 , 0 0 0}$}
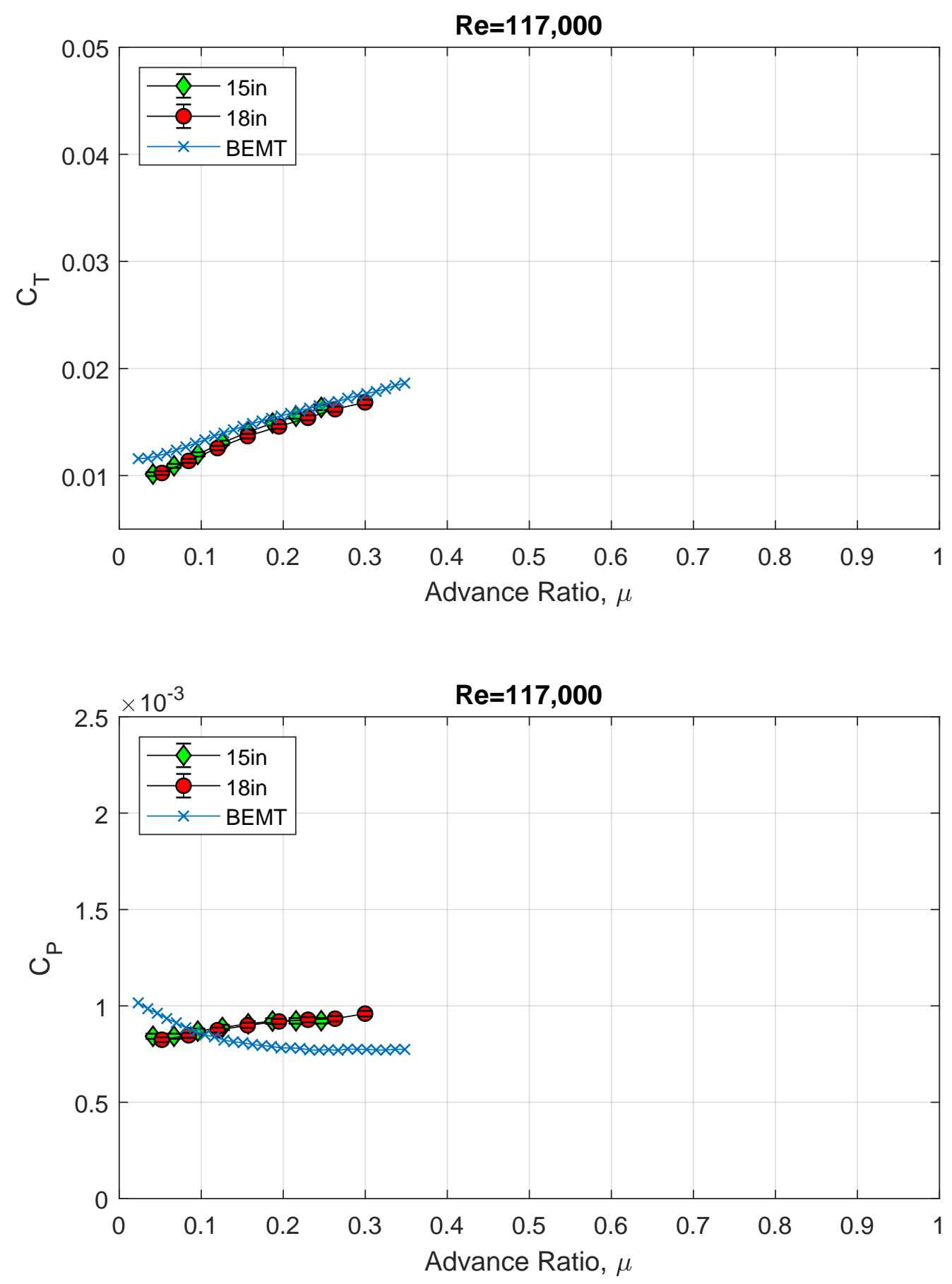

Figure B.4: Predicted and experimental results of $C_{T}$ and $C_{P}$ for $\operatorname{Re}=117,000$. 

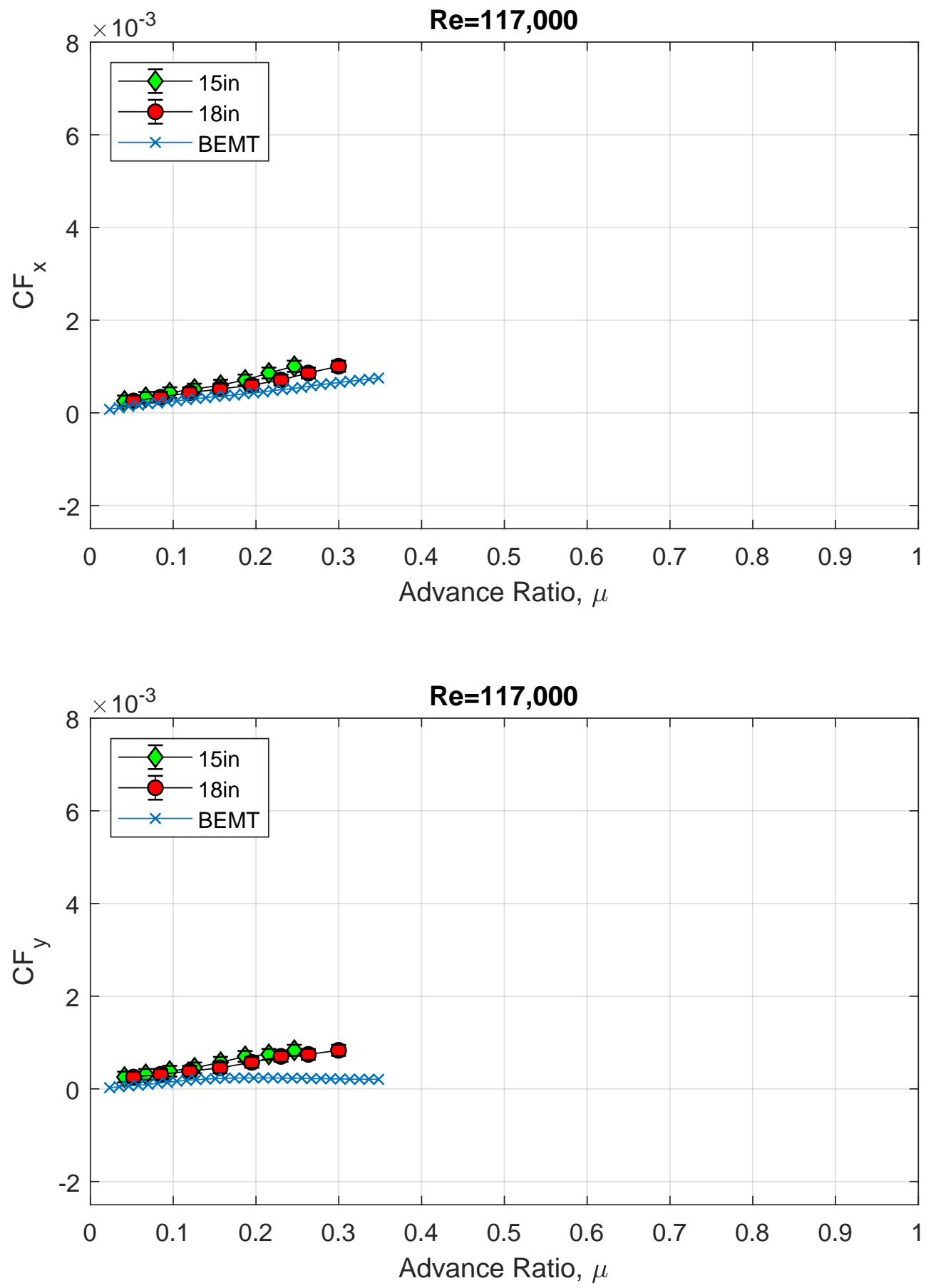

Figure B.5: Predicted and experimental results of $C F_{x}$ and $C F_{y}$ for $\operatorname{Re}=117,000$. 

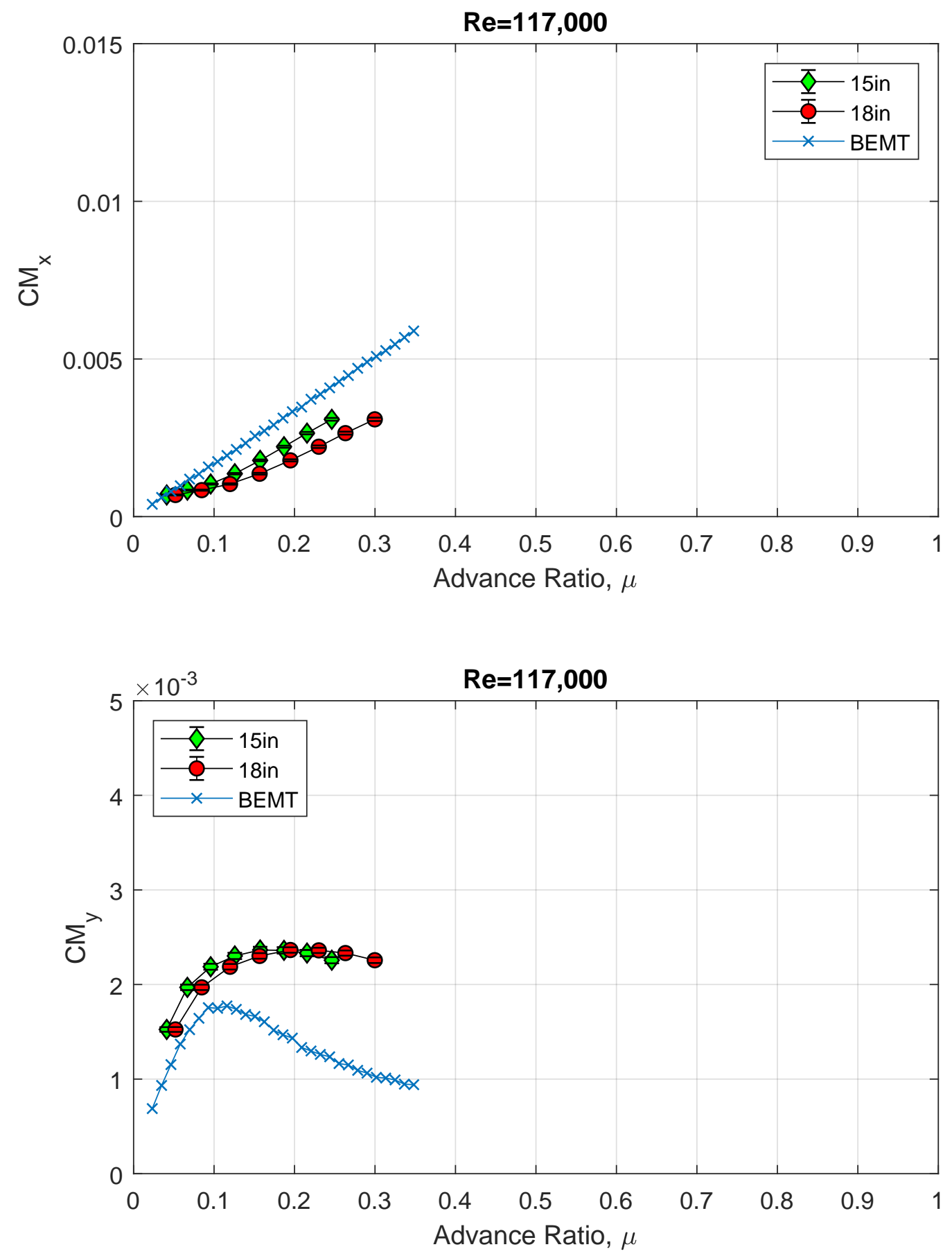

Figure B.6: Predicted and experimental results of $C M_{x}$ and $C M_{y}$ for $\mathrm{Re}=117,000$. 


\section{Appendix C: BEMT Manual}

A manual for the rotor performance prediction program based off of the blade element momentum theory is presented. This is a code that was developed at Ryerson University by Tim Carroll [9] and was created as a way to predict rotor and vehicle performance. The code predicts and outputs the rotor performance parameters for a range of flight conditions and vehicle configurations. This manual includes a breakdown of the code and how to use it, along with sample of outputs and comparison to experimental data. 


\section{BEMT Install and Startup}

To use the program, the BEMT folder must be downloaded from: https://github.com/raalf/BEMT.

The full program is self contained in the single folder. Open the folder In MATLAB and navigate to "BEMT Module" folder by following the path:

\section{BEMT-master $\rightarrow$ BEMT Module}

The "BEMT Module" folder should contain the following folders, scripts and functions:

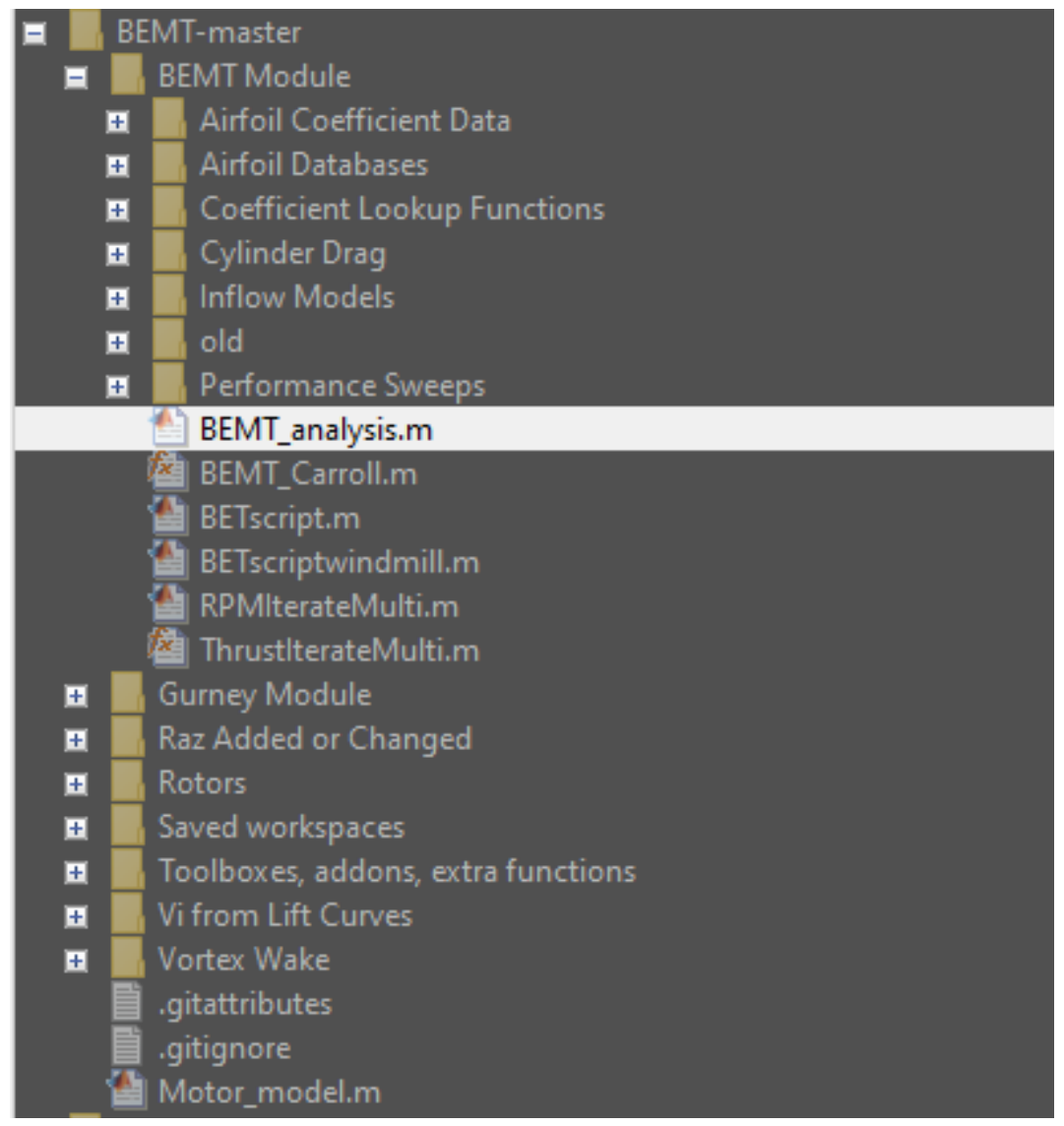

Figure 1: BEMT Folder Tree

To access the analysis code, open "BEMT_analysis.m" from the tree on the left side. 


\section{Breakdown of Code}

The program contains six sections that need to be filled out with the required parameters.

\section{Section 1: Analysis Type and Save Workspace}

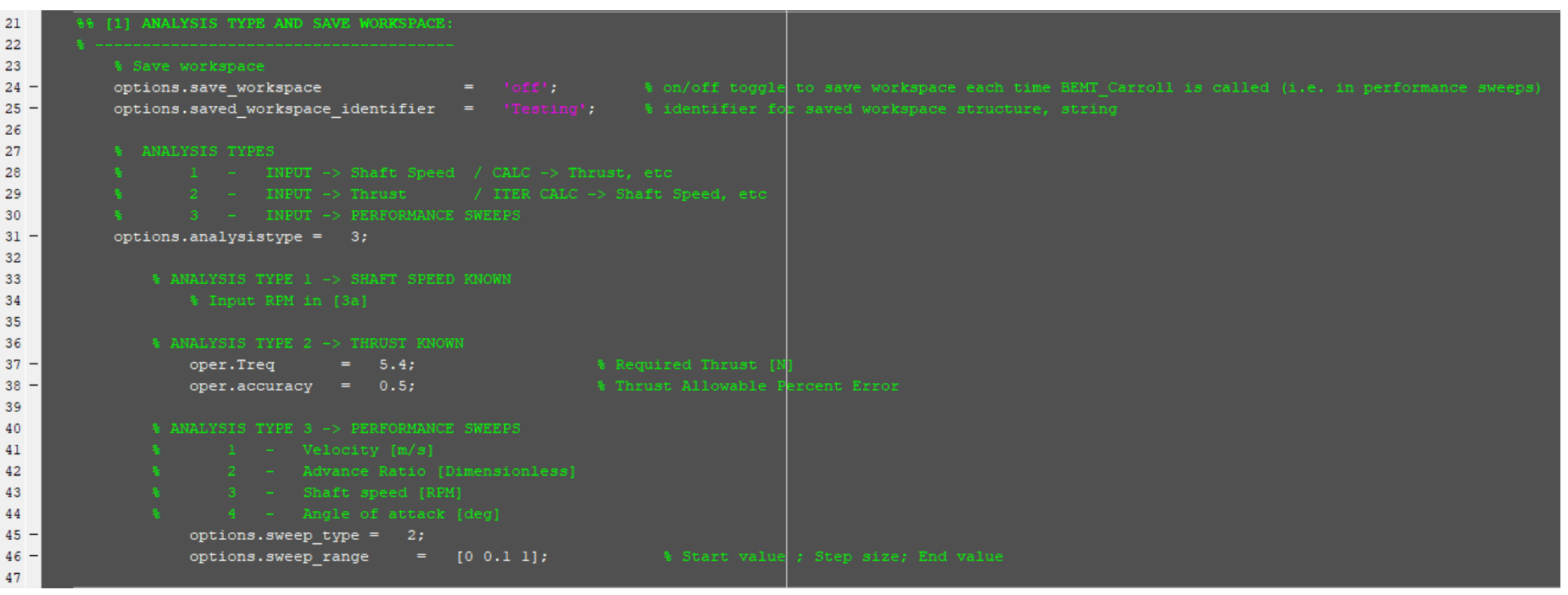

Figure 2: Section 1

\section{Save Workspace}

- Line 24: [string] on/off toggle to save workspace each time BEMT_Carroll is called (i.e. in performance sweeps). BEMT_Carroll is the function that performs the calculations and is called each time the code is run.

- Line 25: [string] Identifier for saved workspace structure (can input any string)

\section{Analysis Types}

- Line 31: [value] Select which analysis type to run from the options given in Lines 28-30.

This program contains three different analysis types:

1. The rotor shaft speed is inputted and the various performance parameters (thrust, power, forces, moments etc.) are calculated and outputted.

2. The required thrust is inputted, and the shaft speed is iteratively calculated and outputted.

3. Performance sweep. One of either velocity, advance ratio, shaft speed, or angle of attack can be swept through while all other parameters are held constant.

\section{Analysis Type $2 \rightarrow$ Thrust Known}

- Line 37: [value] Required thrust in [N]

- Line 38: [value] Thrust allowable percent error in [\%]

\section{Analysis Type $3 \rightarrow$ Performance Sweeps}


- Line 45: [value] Select what parameter is to be swept through from the options given in Lines 41-44.

- Line 46: [value] Specify the start value, step size, and end value for the performance sweep

4 different parameters can be swept through, while keeping all other parameters constant:

1. Velocity $[\mathrm{m} / \mathrm{s}]$

2. Advance Ratio [Dimensionless]

3. Shaft Speed [RPM]

4. Angle of Attack [deg]

\section{Section 2: Flow Field Information}

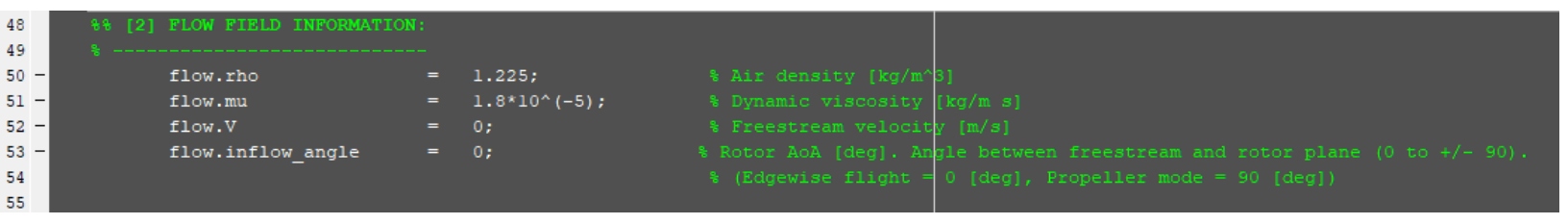

Figure 3: Section 2

- Line 50: [value] Air density in $\left[\mathrm{kg} / \mathrm{m}^{3}\right.$ ]

- Line 51: [value] Dynamic viscosity in $[\mathrm{kg} / \mathrm{m} * \mathrm{~s}]$

- Line 52: [value] Freestream velocity in $[\mathrm{m} / \mathrm{s}$ ]

- Line 53: [value] Inflow angle. The inflow angle is the angle between the freestream and the rotor plane. The inflow angle should be set to 0 degrees for fully edgewise flow and set to 90 degrees for propeller analysis. 


\section{Section 3a: Rotor Geometry, Operating Parameters and Coefficient Options}

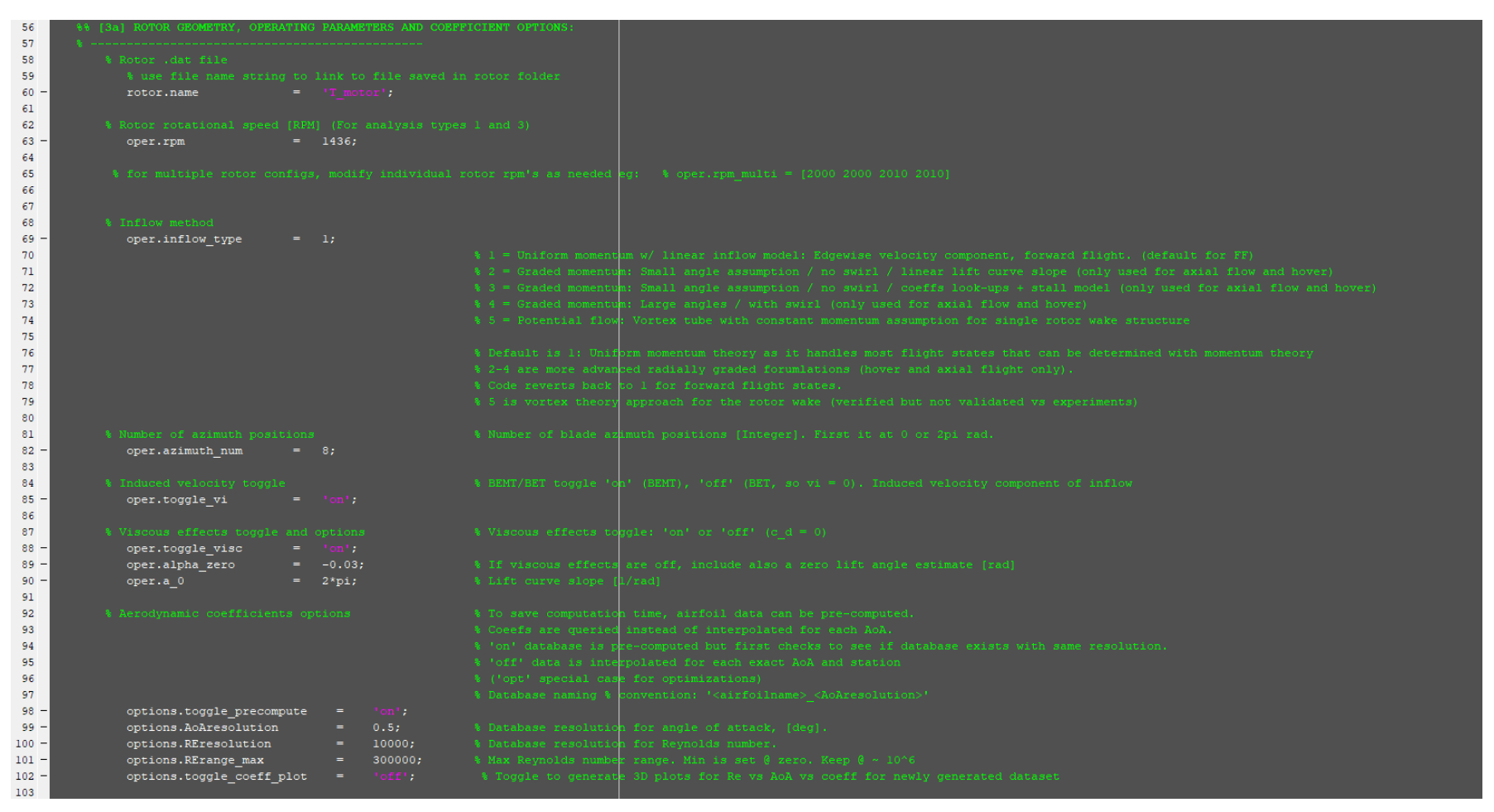

Figure 4: Section 3a

- Line 60: [string] The file name string of the rotor .mat file that specifies the coordinate geometry of the blade element. This .mat file must be located under the "Rotors" folder as shown in Figure 6. 


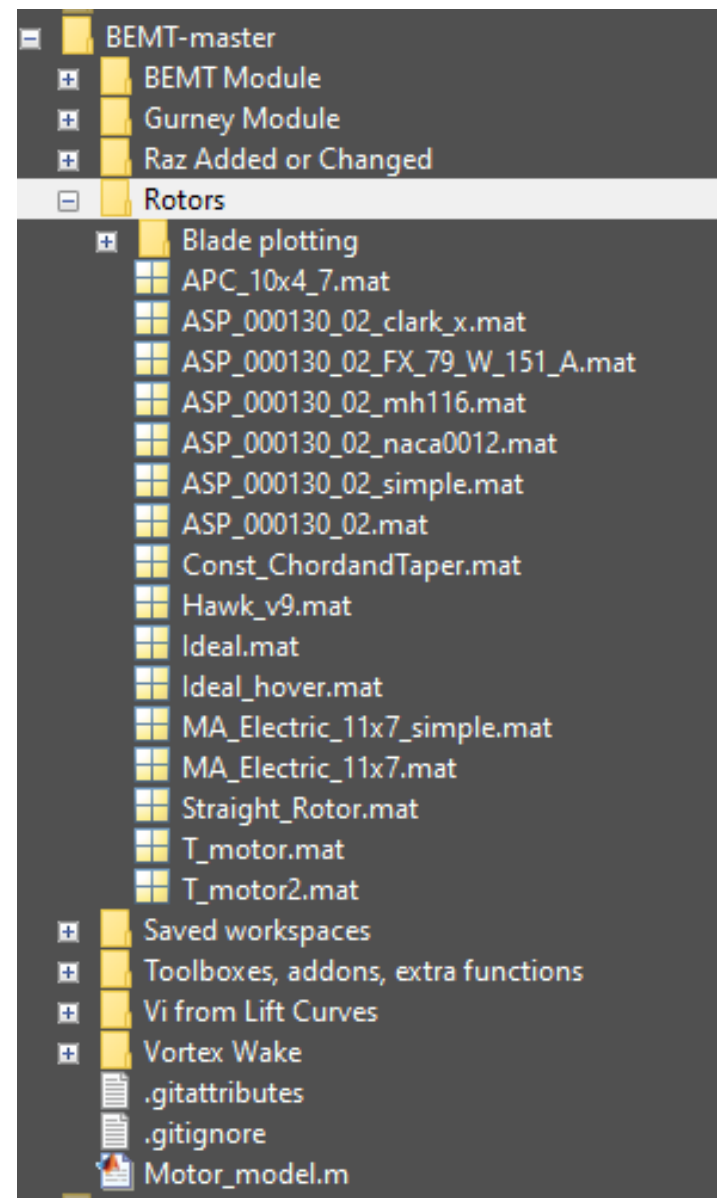

Figure 5: File location of rotor geometry mat file

- Line 63: [value] The rotor rotational speed in [RPM]. For multi-rotor setups refer to note on Line 65.

- Line 69: [value] Select which inflow type from the options given in Lines 70-74. The analysis method (theory) for the inflow is selected here, based on what type of inflow is approaching the rotor plane.

- Line 82: [value] Number of blade azimuth positions iterated through.

- Line 85: [string] Toggle for induced velocity. 'on' for BEMT analysis, 'off' for BET analysis $\left(\mathrm{V}_{\mathrm{i}}=0\right)$

\section{Viscous effects toggle and options}

- Line 88: [string] Toggle for viscous effects, 'on' or 'off'

- Line 89: [value] Zero lift angle estimate in [rad]. This value must be specified if viscous effects in Line 88 are 'off'

- Line 90: [value] Lift curve slope [1/rad]

\section{Aerodynamic coefficients options}

- Line 98: [string] Toggle to allow airfoil data to be pre-computed and placed into a newly generated database 
- Line 99: [value] Database resolution for angle of attack in [deg]

- Line 100: [value] Database resolution for Reynolds number

- Line 101: [value] Max Reynolds number range

- Line 102: [string] Toggle to generate 3D plots for Re vs AoA vs Coeff for newly generated dataset

\section{Section 3b: Rotor Quick Modifiers}

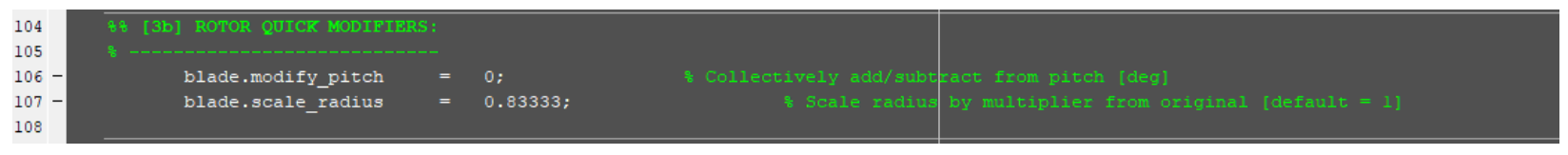

Figure 6: Section 3b

- Line 106: [value] Modify blade pitch in [deg]. Can increase or decrease blade pitch (positive and negative values can be inputted)

- Line 107: [value] Scale blade radius by multiplier from original. Default value is 1.

\section{Section 4: Multirotor Analysis Tool: Vehicle Configuration/ Wake Options}

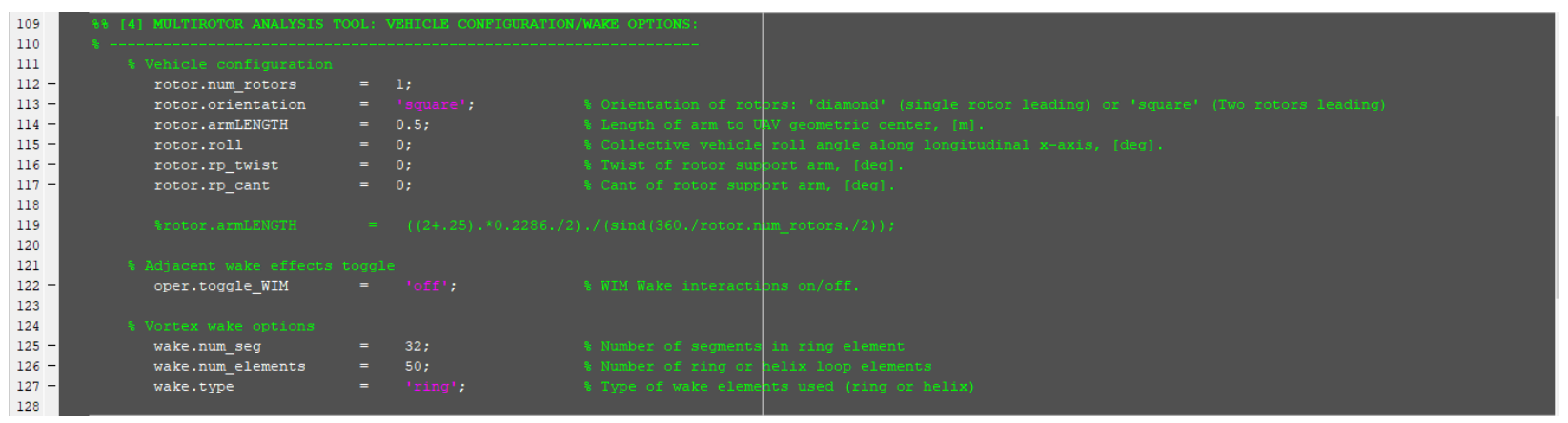

Figure 7: Section 4

\section{Vehicle Configuration}

- Line 112: [value] Specify number of rotors that are to be analyzed. Line 113 to Line 117 need to be specified if number of rotors is greater than 1.

- Line 113: [string] Orientation of rotors, 'diamond' (single rotor leading) or 'square' (Two rotors leading)

- Line 114: [value] Length of arm to UAV geometric center in [m]

- Line 115: [value] Collective vehicle roll angle along longitudinal axis in [deg]

- Line 116: [value] Twist of rotor support arm in [deg]

- Line 117: [value] Cant of rotor support arm, [deg]. Cant is defined as a counter clockwise rotation of the entire rotor disk about an orthogonal axis on the vehicle's xy- plane and passing through vehicle's center point. (i.e pitch of the rotor arm) 


\section{Adjacent Wake Effects Toggle}

- Line 122: [string] Toggle for Wake Impingement Model (WIM) Wake interactions.

\section{Vortex Wake Options}

- Line 125: [value] Number of segments in vortex ring element

- Line 126: [value] Number of ring or helix loop elements

- Line 127: [string] Type of wake elements used ('ring' or 'helix')

\section{Section 5: High Lift Devices}

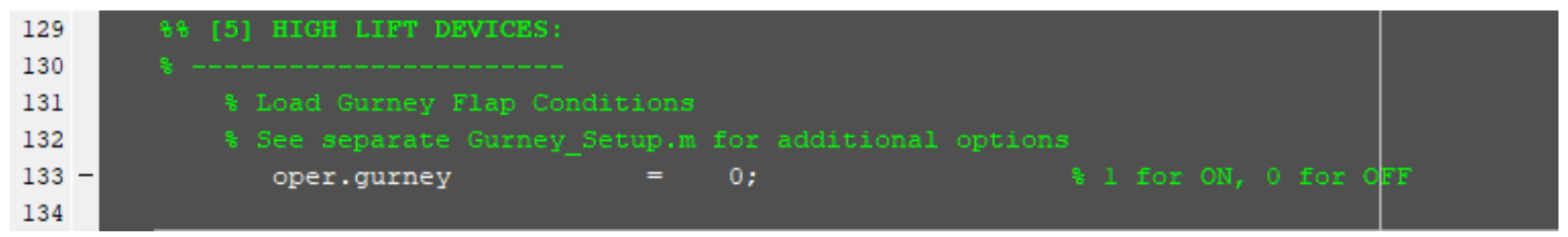

Figure 8: Section 5

Section 5 is where high lift devices such as Gurney flaps can be specified. This section only contains the toggle for including Gurney flaps in the analysis. To specify Gurney flap options, refer to Gurney_Setup.m, located under the Gurney Module folder (Figure 9).

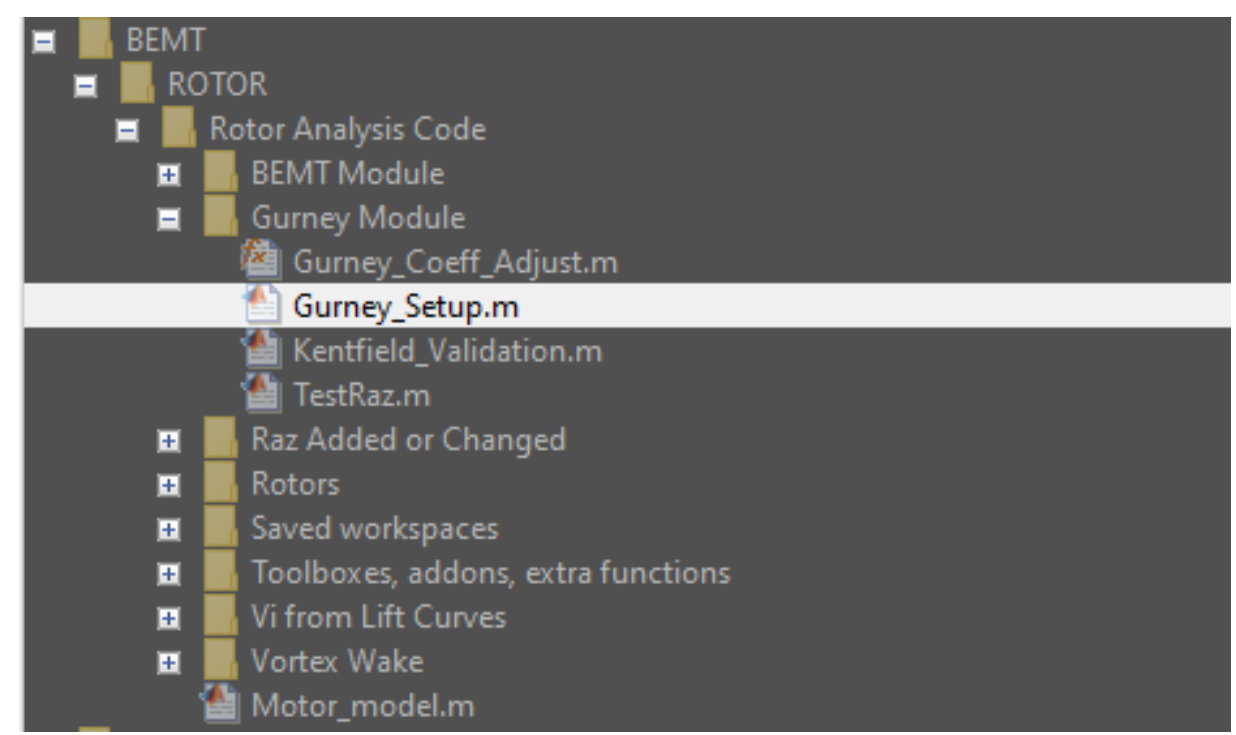

Figure 9: File Location for 'Gurney_Setup.m'

- Line 133: [value] Toggle for loading Gurney Flap conditions (1 for ON, 0 for OFF)

Once the parameters are set in BEMT_analysis.m Sections 1-6, run the program and click "add to path" at prompt. 


\section{Output}

Depending on the type of analysis chosen the program will run anywhere from a few seconds to a few minutes.

The calculations are output in a structure called "perf", that will be located in the 'Workspace' window (Figure 10).

\begin{tabular}{|c|c|}
\hline \multicolumn{2}{|l|}{ Workspace } \\
\hline Name - & Value \\
\hline Ch ADDRESS_OF_ROTOR_FOLDER & 'C:\Users\ammar\OneDrive $\backslash$ Documents $\backslash \mathrm{B}$ \\
\hline -耳 airfoil_coeff_database & $1 \times 3$ struct \\
\hline ch BEMTfunct & 'BEMT_Carroll' \\
\hline - blade & $1 x 1$ struct \\
\hline 宜 flow & $1 \times 1$ struct \\
\hline 亘 oper & $1 \times 1$ struct \\
\hline 目 options & $1 \times 1$ struct \\
\hline EE perf & $1 \times 1$ struct \\
\hline E- rotor & $1 \times 1$ struct \\
\hline 再 T_motor & $20 \times 8$ table \\
\hline 臬 wake & $1 \times 1$ struct \\
\hline
\end{tabular}

Figure 10: Output files

If a performance sweep (Option 3 ) is run then the calculations are output in a structure called "perf_sweep", which will also be located in the 'Workspace' window (Figure 11).

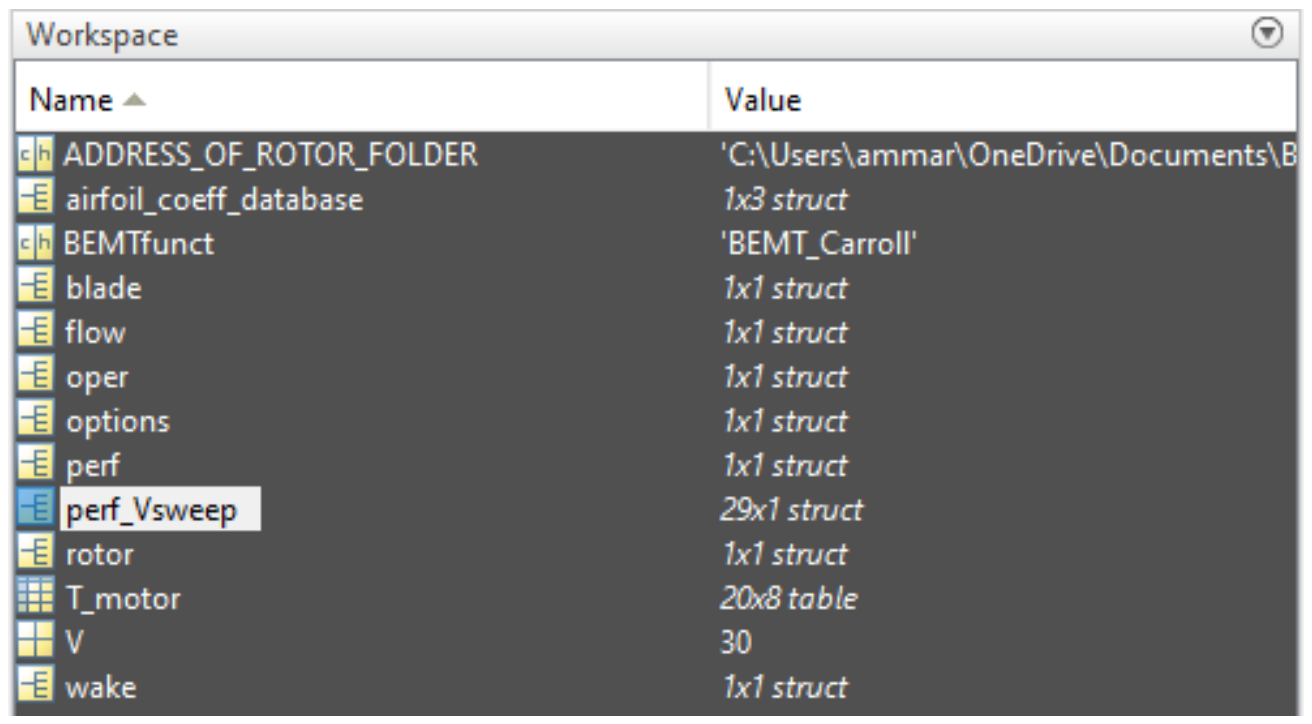

Figure 11: Output files for Performance Sweep 


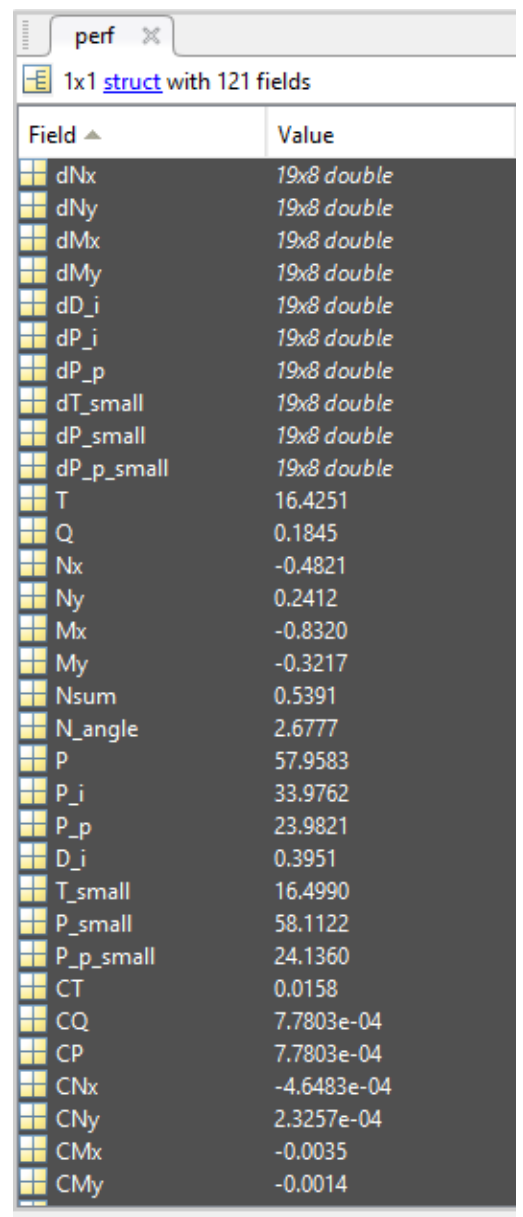

Figure 12: Portion of sample output from the "perf" structure

The output "perf" structure contains a magnitude of data about the analysis. This includes but is not limited to the output forces, moments and coefficients. The "perf" structure also contains the variables inputted in to the analysis in addition to the blade and airfoil data. For every iteration it also contains the incremental forces and moments at the blade stations for every azimuth location. A portion of a sample output "perf" structure is shown in Figure 12. 


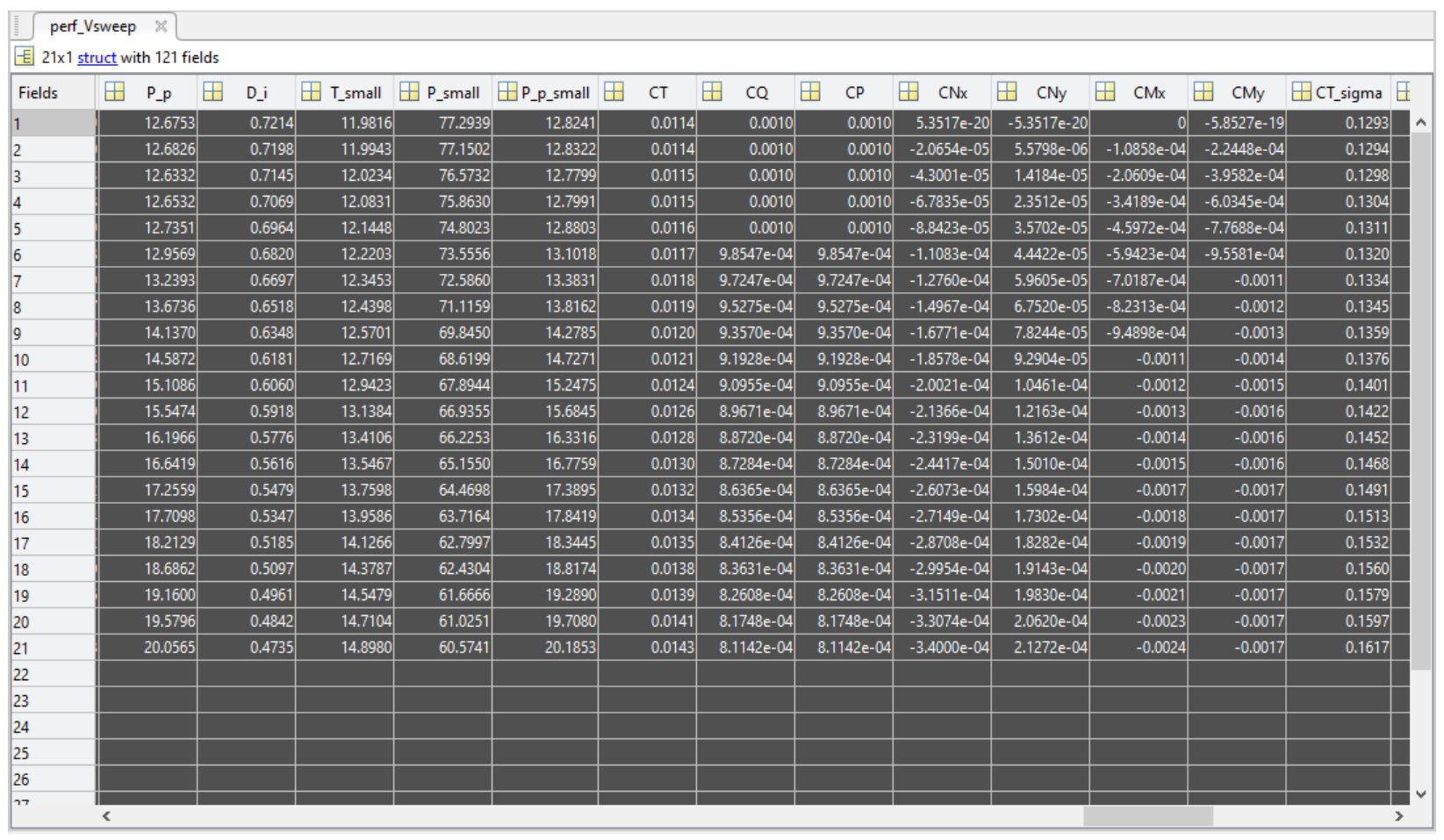

Figure 13: Portion of sample output from the "perf_Vsweep" structure

The output "perf_Vsweep" structure contains the same information as the "perf" structure for every step in the sweep. A portion of a sample output "perf_Vsweep" structure is shown in Figure 13. 


\section{$\underline{\text { Appendix }}$}

\section{Comparison to Experimental Data}

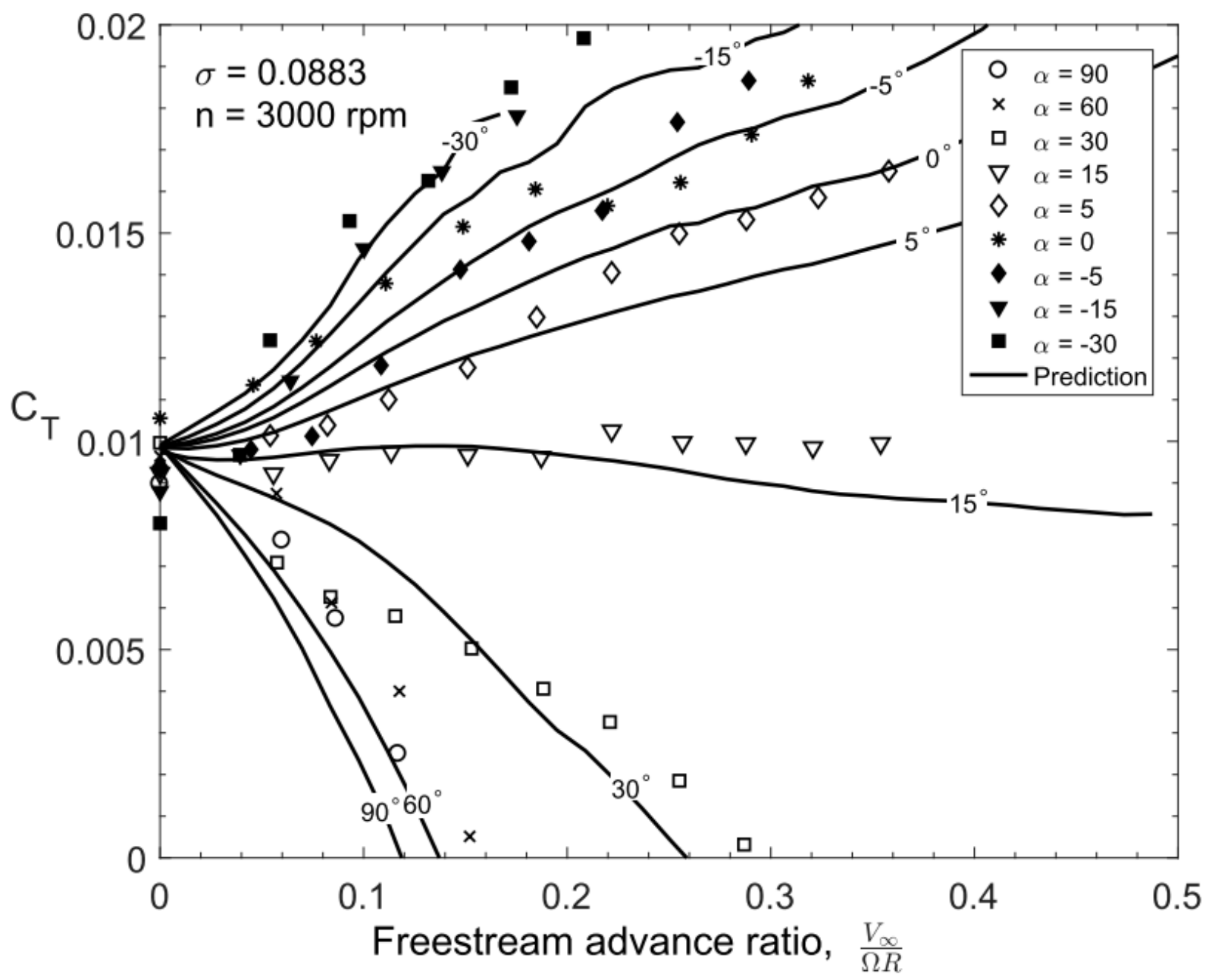

Figure 14: Predicted and Experimental Data for CT vs. Freestream Advance Ratio for a range of inflow angles. 


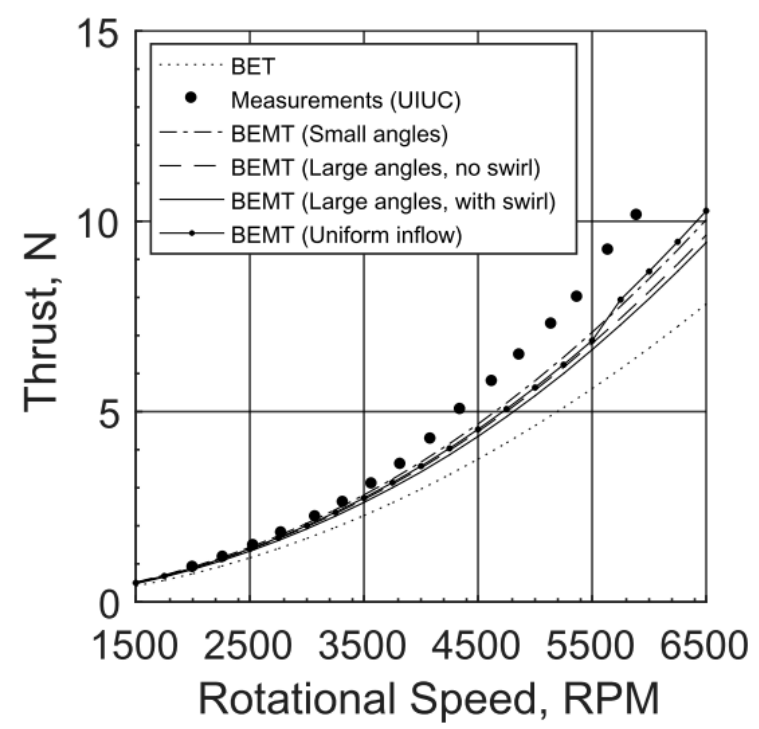

(a) Thrust in static conditions.

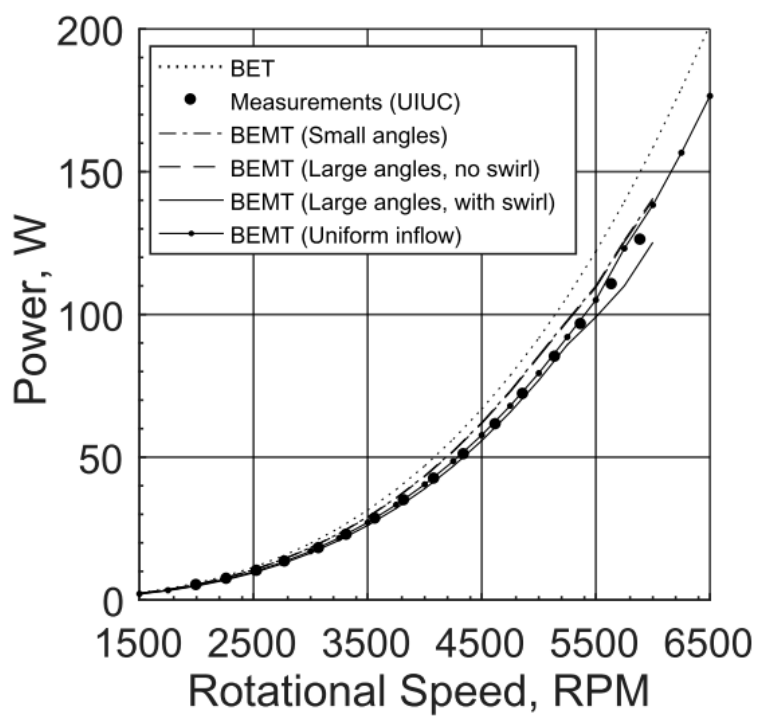

(b) Power in static conditions.

Figure 15: Predicted and Experimental results for thrust and power at static conditions for a range of RPMs. 


\section{References}

[1] FAA, "Fact sheet $\quad-$ small unmanned aircraft regulations (part 107)," accessed 15 December 2019. [Online]. Available: https://www.faa.gov/news/fact_sheets/news_story.cfm?newsId=22615

[2] AINonline, "Thales offers spanish uav for coastal surveillance," accessed 16 December 2019. [Online]. Available: https://www.ainonline.com/aviation-news/defense/2012-0210/thales-offers-spanish-uav-coastal-surveillance

[3] DJI, “DJI Phantom 4,” accessed 8 October 2019. [Online]. Available: https://www.dji.com/ca/phantom-4

[4] R. W. Deters, G. K. Ananda, and M. S. Selig, "Reynolds number effects on the performance of small-scale propellers," 32nd AIAA Applied Aerodynamics Conference, 062014.

[5] MIT, "Thermodynamics and propulsion," accessed 12 September 2019. [Online]. Available: https://web.mit.edu/16.unified/www/FALL/thermodynamics/notes/node86.html

[6] J. G. Leishman, Principles of Helicopter Aerodynamics. New York, NY: Cambridge University Press, 2006.

[7] J. D. Tsaltas, "Trim solutions of multirotor vehicles using a fast performance prediction method," Master's thesis, Ryerson University, 2018. 
[8] V. Raghav, M. Mayo, R. Lozano, and N. Komerath, "Evidence of vortex-induced lift on a yawed wing in reverse flow," Proceedings of the Institution of Mechanical Engineers Part G Journal of Aerospace Engineering, vol. 228, 092014.

[9] T. B. Carroll, "A design methodology for rotors of small multirotor vehicles," Master's thesis, Ryerson University, 2014.

[10] D. Barcelos, "Flow quality testing and improvement of the ryerson university low speed wind tunnel," Undergraduate Thesis, Ryerson University, 2016.

[11] J. B. Barlow, W. H. Rae, and A. Pope, Low-Speed Wind Tunnel Testing. New York, NY: Wiley-Interscience, 1999.

[12] R. W. Fox, P. J. Pritchard, and A. T. McDonald, Introduction to Fluid Mechanics 7th Edition. Hoboken, NJ: Wiley, 2008.

[13] J. B. Brandt and M. S. Selig, "Propeller performance data at low reynolds numbers," 49th AIAA Aerospace Sciences Meeting, 012011.

[14] M. Brazinskas, S. D. Prior, and J. P. Scanlan, "An empirical study of overlapping rotor interference for a small unmanned aircraft propulsion system," Aerospace, vol. 3, p. 6, 10 2016. 